PENNSTATE

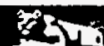

855

THE DEVELOPMENT OF COAL-BASED TECHNOLOGIES

FOR DEPARTMENT OF DEFENSE FACUITIES

Semiannual Technical Progress Report for the Period 03/28/1997 to 09/27/1997

By

Bruce G. Miller, Sharon Falcone Miller, Joel L. Morrison, Sarma V. Pisupati, Alan W. Scaroni, and Ronald T. Wincek,

The Energy Institute;

Andre' Boehman,

Fuel Science Program;

Richard Hogg, Subhash Chander, Heechan Cho, M. Thaddeus Ityokumbul, Mark S. Klima, and Peter T. Luckie,

Mineral Processing Section;

Adam Rose, Ping-Cheng Li, and A. Michael Schaal, Department of Energy, Environmental, and Mineral Economics;

Paul Painter,

Polymer Science Program; and

Norman Chigier and Adel Mansour,

Carnegie Mellon University

January 6,1998

RECEIVED

FFR 131998

OSTI

Work Performed Under Cooperative Agreement No. DE-FC22-92PC92162

For

U.S. Department of Energy

Federal Energy Technology Center

P.O. Box 10940

Pittsburgh, Pennsylvania 15236

DISTREUTION OF THIS DOMIMANT IS INIARTFO

By

The Consortium for Coal-Water Slurry Fuel Technology

The Pennsylvania State University

C211 Coal Utilization Laboratory

University Park, Pennsylvania 16802

W. 


\section{DISCLAIMER}

This report was prepared as an account of work sponsored by an agency of the United States Government. Neither the United States Government nor any agency thereof, nor any of their employees, makes any warranty, express or implied, or assumes any legal liability or responsibility for the accuracy, completeness, or usefulness of any information, apparatus, product, or process disclosed, or represents that its use would not infringe privately owned rights. Reference herein to any specific commercial product, process, or service by trade name, trademark, manufacturer, or otherwise does not necessarily constitute or imply its endorsement, recommendation, or favoring by the United States Government or any agency thereof. The views and opinions of authors expressed herein do not necessarily state or reflect those of the United States Government or any agency thereof. 


\section{DISCLAIMER}

Portions of this document may be illegible electronic image products. Images are produced from the best available original document. 


\section{PENNSTATE}

\section{(x)}

85

THE DEVELOPMENT OF COAL-BASED TECHNOLOGIES

FOR DEPARTMENT OF DEFENSE FACILITIES

Semiannual Technical Progress Report for the Period 03/28/1997 to 09/27/1997

By

Bruce G. Miller, Sharon Falcone Miller, Joel L. Morrison, Sarma V. Pisupati, Alan W. Scaroni, and Ronald T. Wincek,

The Energy Institute;

Andre' Boehman,

Fuel Science Program;

Richard Hogg, Subhash Chander, Heechan Cho, M. Thaddeus Ityokumbul, Mark S. Klima, and Peter T. Luckie,

Mineral Processing Section;

Adam Rose, Ping-Cheng Li, and A. Michael Schaal, Department of Energy, Environmental, and Mineral Economics;

Paul Painter,

Polymer Science Program; and

Norman Chigier and Adel Mansour,

Carnegie Mellon University

January 6, 1998

Work Performed Under Cooperative Agreement No. DE-FC22-92PC92162

For

U.S. Department of Energy

Federal Energy Technology Center

P.O. Box 10940

Pittsburgh, Pennsylvania 15236

By

The Consortium for Coal-Water Slurry Fuel Technology

The Pennsylvania State University

C21 1 Coal Utilization Laboratory

University Park, Pennsylvania 16802 


\title{
THE DEVELOPMENT OF COAL-BASED TECHNOLOGIES FOR DEPARTMENT OF DEFENSE FACILITIES
}

Semiannual Technical Progress Report for the Period 03/28/1997 to 09/27/1997

\section{By}

\author{
Bruce G. Miller, Sharon Falcone Miller, Joel Morrison, Sarma V. Pisupati, Alan W. \\ Scaroni, and Ronald T. Wincek, \\ The Energy Institute; \\ André Boehman, \\ Fuel Science Program; \\ Richard Hogg, Subhash Chander, Heechan Cho, M. Thaddeus Ityokumbul, \\ Mark S. Klima, and Peter T. Luckie, \\ Mineral Processing Section; \\ Adam Rose, Ping-Cheng Li, and A. Michael Schaal, \\ Department of Energy, Environmental, and Mineral Economics; \\ Paul Painter, \\ Polymer Science Program; and \\ Norman Chigier and Adel Mansour, \\ Carnegie Mellon University
}

January 6, 1998

Work Performed Under Cooperative Agreement No. DE-FC22-92PC92162

For

U.S. Department of Energy

Federal Energy Technológy Center

P.O. Box 10940

Pittsburgh, Pennsylvania 15236

By

The Consortium for Coal-Water Slurry Fuel Technology

The Pennsylvania State University

C211 Coal Utilization Laboratory

University Park, Pennsylvania 16802

\footnotetext{
"U.S. DOE Patent Clearance is NOT required for the publication of this document."
} 


\section{DISCLAIMER}

This report was prepared as an account of work sponsored by the United States Government. Neither the United States Government nor the United States Department of Energy, nor any of their employees, nor any of their contractors, subcontractors, or their employees makes any warranty, express or implied, or assumes any legal liability or responsibility for the accuracy, completeness, or usefulness of any information, apparatus, product, or process disclosed, or represents that its use would not infringe privately owned rights. 


\section{EXECUTIVE SUMMARY}

The U.S. Department of Defense (DOD), through an Interagency Agreement with the U.S. Department of Energy (DOE), has initiated a three-phase program with the Consortium for Coal-Water Slurry Fuel Technology, with the aim of developing technologies which can potentially decrease DOD's reliance on imported oil by increasing its use of coal. The program is being conducted as a cooperative agreement between the Consortium and DOE.

Activities this reporting period are summarized by phase.

\section{PHASE I}

Phase I was completed on November 1, 1995.

\section{PHASE II}

Work in Phase II focused on emissions reductions, coal beneficiation/preparation studies, and economic analyses of coal use.

Emissions reductions investigations included performing pilot-scale air toxics (i.e., trace elements and volatile organic compounds) testing and evaluating a ceramic filtering device on the demonstration boiler. Also, a sodium bicarbonate duct injection system was installed on the demonstration boiler.

An economic analysis was conducted which investigated the benefits of decreased dependence on imported oil by using new coal combustion technologies.

Work related to coal preparation and utilization was primarily focused on preparing the final report.

\section{PHASE III}

Work in Phase III focused on coal preparation studies, pilot-scale $\mathrm{NO}_{x}$ reduction studies, economic analyses of coal use, and evaluation of deeply-cleaned coal as boiler fuel.

Coal preparation studies were focused on continuing activities on particle size control, physical separations, and surface-based separation processes.

The evaluation of deeply-cleaned coal as boiler fuel included receiving three cleaned coals from Cyprus-Amax. 


\section{TABLE OF CONTENTS}

\section{Page}

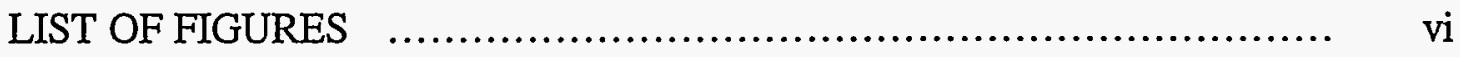

LIST OF TABLES $\quad$......................................................... viii

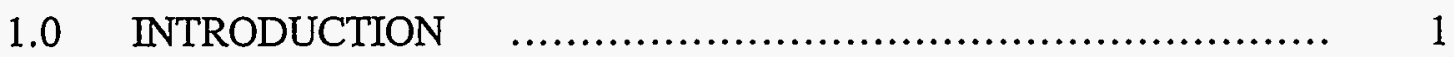

2.0 PHASE I; TASK 5 FINAL REPORT/SUBMISSION OF

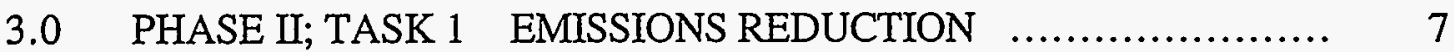

3.1 Subtask 1.1 Evaluation of Emissions Reduction Strategies .... 7

3.2 Subtask 1.2 Install System on the Demonstration Boiler ...... 7

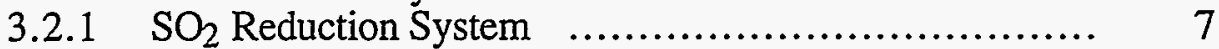

3.2.2 Ceramic Filter ........................................ 23

3.3 Subtask 1.3 Evaluate Emissions Reduction System $\quad$........... 23

3.3.1 Ceramic Filter System Shakedown .................... 23

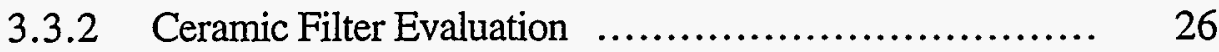

3.4 Subtask 1.4 Conduct $\mathrm{NO}_{\mathrm{x}}$ Emissions Study $\quad \ldots \ldots \ldots \ldots \ldots \ldots . . . . . .42$

3.5 Subtask 1.5 Conduct VOC Study ........................... 42

3.6 Subtask 1.6 Conduct Trace Element Study ................... 48

3.7 Subtask 1.7 Nitrogen Containing Groups in Coal Study ...... 49

3.7.1 Work to be Accomplished ............................. 49

3.7.2 Progress to Date ...................................... 51

3.8 Subtask 1.8 Conduct $\mathrm{NO}_{\mathrm{x}}$ Reduction Study ................. 51

3.8.1 Conduct Cofiring Tests in the DFC ..................... 51

3.8.2 Analysis of the Results ............................... 53

3.9 Subtask 1.9 Evaluate BioLime as a $\mathrm{SO}_{2} / \mathrm{NO}_{\mathrm{x}}$ Reduction

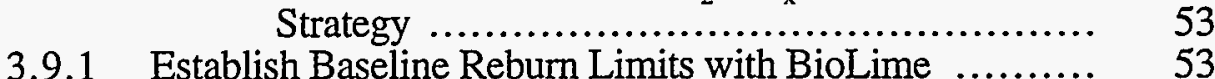

3.9.2 Establish Operating Limits for BioLime .................. 53

3.9.3 Pilot-Scale Testing of Wood Feedstock with High

$\mathrm{NO}_{\mathrm{x}}$ Retention Formula ............................ 53

3.9.4 Fundamental Study of the Predominant Mechanism....... 54

3.9.5 Scale Up of BioLime Injection Technology ….......... 54

4.0 PHASE II; TASK 2 COAL PREPARATION/UTMIZATION $\quad . . . . . . \quad 54$

4.1 Subtask 2.10 Conduct Atomization Study ........................ 54

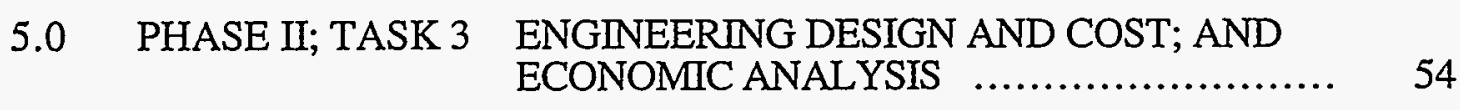

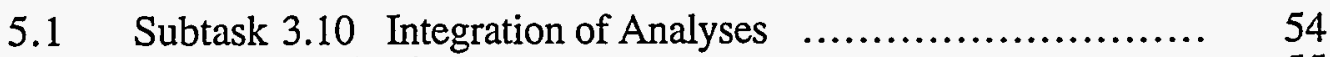

5.1 .1 Introduction ............................................ 55

5.1.2 Market Penetration Model ................................. 56 
TABLE OF CONTENTS (cont.)

Page

5.1.3 The Pennsylvania CGE Model f........................ 60

5.1.4 Application ....................................... 68

6.0 PHASE II; TASK 4 FINAL REPORT/SUBMISSION OF

DESIGN PACKAGE $\ldots \ldots \ldots \ldots \ldots \ldots \ldots \ldots . . . \ldots \ldots$

7.0 PHASE III; TASK 1 COAL PREPARATION/UTILIZATION ........ 72

7.1 Subtask 1.1 Particle Size Control ............................ 72

7.1.1 Evaluation of Dry Grinding/Classifier Circuit f.......... 72

7.2 Subtask 1.2 Physical Separations .......................... 73

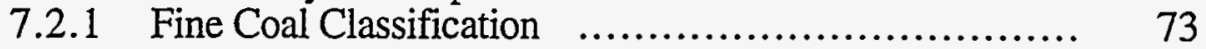

7.3 Subtask 1.3 Surface-Based Separation Processes .............. 77

7.3.1 Evaluation of Flotation System Performance ............. 77

8.0 PHASE III; TASK 2 EMISSIONS REDUCTION ..................... 81

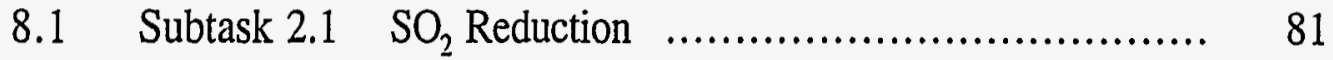

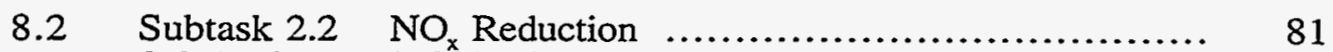

8.2.1 Research Objectives ............................... 81

8.2.2 Current Status of the Bench-Scale Catalyst Tests ........ 81

8.2.3 Current Status of the Pilot-Scale Testing ................ 83

8.3 Subtask 2.3 VOC and Trace Elements …................. 83

9.0 PHASE III; TASK 3 ECONOMIC ANALYSIS ..................... 83

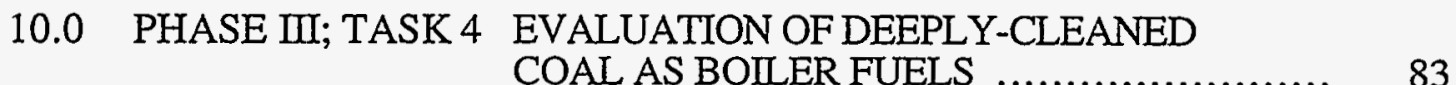

10.1 Subtask 4.1 Modify MCWM Preparation Circuit .............. 83

10.2 Subtask 4.2 Fuels Characterization ......................... 83

11.0 PHASE III; TASK 6 FINAL REPORT/SUBMISSION OF DESIGN

PACKAGE ................................ 84

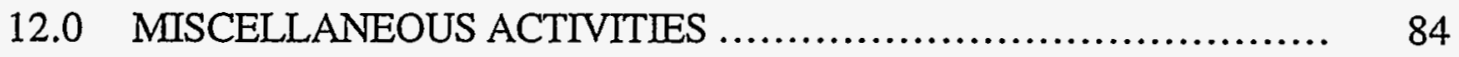

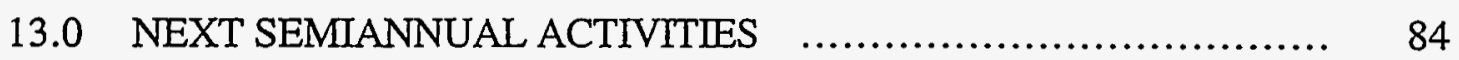

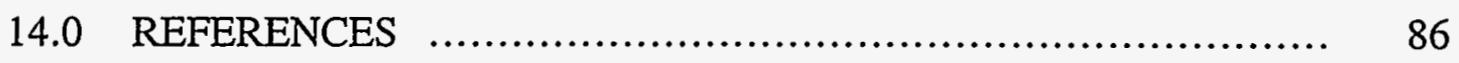

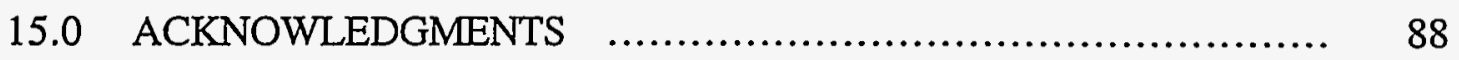




\section{LIST OF FIGURES}

FIGURE 1-1. DOD phase II milestone schedule ...........................

FIGURE 1-2. DOD phase III milestone schedule .......................... 12

FIGURE 3-1. Interior of the ceramic filter chamber showing baffles and ceramic filters ...................................... 24

FIGURE 3-2. Side view of one row of ceramic filters with venturis, blowtube, and nozzles ..................................... 25

FIGURE 3-3. Ceramic filter chamber pressure drop as a function of time firing coal from April 28, 1997 through October 2, 1997 ......

FIGURE 3-4. Ceramic filter chamber pressure drop as a function of time

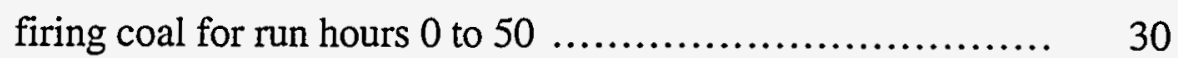

FIGURE 3-5. Ceramic filter chamber pressure drop as a function of time

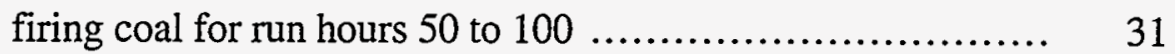

FIGURE 3-6. Ceramic filter chamber pressure drop as a function of time

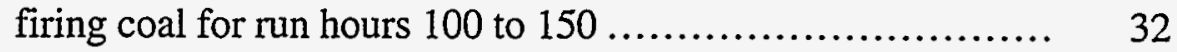

FIGURE 3-7. Ceramic filter chamber pressure drop as a function of time

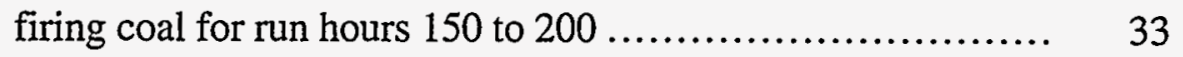

FIGURE 3-8. Ceramic filter chamber pressure drop as a function of time firing coal for run hours 200 to 250 .......................... 34

FIGURE 3-9. Ceramic filter chamber pressure drop as a function of time

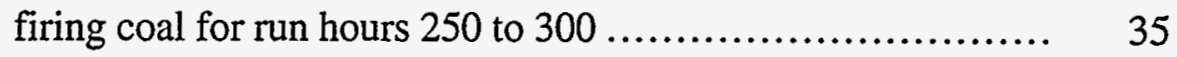

FIGURE 3-10. Ceramic filter chamber pressure drop as a function of time

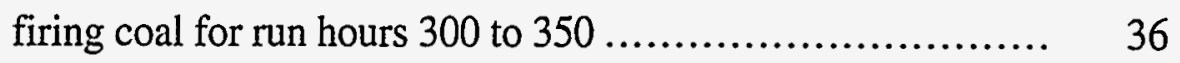

FIGURE 3-11. Ceramic filter chamber pressure drop as a function of time firing coal for run hours 350 to $400 \ldots \ldots \ldots \ldots \ldots \ldots \ldots \ldots \ldots . . . \ldots \ldots$

FIGURE 3-12. FTIR spectra of a styrene/ vinyl pyridine copolymer before

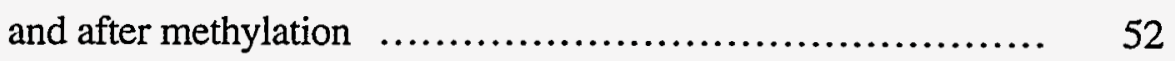

FIGURE 5-1. Pennsylvania water-tube boilers by 3-digit zip code region ..... 59

FIGURE 5-2. Schematic diagram of the Pennsylvania CGE model ........... 65

FIGURE 7-1. Feed and product size distributions for centrifuge tests 1 and 2 when separating - 100 mesh Upper Freeport seam coal (test 1: filled symbols, test 2: open symbols) ............ 75

FIGURE 7-2. Effect of back drive speed on the size selectivity curves in solid-bowl centrifuge 
FIGURE 7-3. Reduced classification curve for centrifuge tests 1-4

FIGURE 7-4. Comparison of flotation rate constants for the batch, batch with no paddling (batch*), and pilot plant tests at different frother concentrations

FIGURE 7-5. Effect of collector addition on flotation rate constant for the batch, batch with no paddling (batch*), and pilot 


\section{LIST OF TABLES}

Page

TABLE 1-1. Phase II milestone description .......................... 16

TABLE 1-2. Phase III milestone description ............................. 19

TABLE 3-1. Ceramic filter chamber pressure drop and inlet and outlet temperatures when firing natural gas

TABLE 3-2. Preliminary summary of EPA Method 5 testing on the ceramic filter chamber when firing Middle Kittanning seam coal

TABLE 3-3. Comparison of ceramic filter chamber and fabric filter baghouse particulate emissions

TABLE 3-4. Matrix summary for the trace element testing ................ 50

TABLE 5-1. Summary of Pennsylvania boilers by type ................... 58

TABLE 5-2. Pennsylvania market penetration results at varying differential

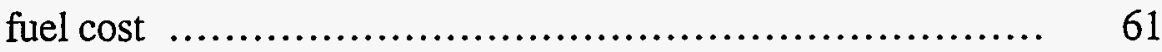

TABLE 5-3. Market penetration estimates for three scenarios .............. 62

TABLE 5-4. Calculation of coal substitution for petroleum in boiler retrofit sectors

TABLE 5-5. Macroeconomic impacts of industrial boiler retrofit using MCWM technology -- all scenarios (percentage change) ........

TABLE 5-6. Microeconomic impacts of industrial boiler retrofit using MCWM technology -- mid-range scenario for key sectors (percentage change)

TABLE 7-1. Summary of the operating conditions and tests results for the solid-bowl centrifuge (feed rate $=11.4 \mathrm{~L} / \mathrm{min}$, weir setting three (second deepest pool), solids concentration $=10 \%$ by weight . 74

TABLE 7-2. Flotation rate constants and froth factors .................. 79

TABLE 7-3. Change in flotation rate constants and froth factors due to the addition of collector for the batch, batch with no paddling (batch*), and pilot plant tests

TABLE 10-1. Summary of Cyprus-Amax Deeply Cleaned Filter Cakes 


\subsection{INTRODUCTION}

The U.S. Department of Defense (DOD), through an Interagency Agreement with the U.S. Department of Energy (DOE), has initiated a three-phase program with the Consortium for Coal-Water Slurry Fuel Technology, with the aim of decreasing DOD's reliance on imported oil by increasing its use of coal. The program is being conducted as a cooperative agreement between the Consortium and DOE. The first phase was completed; work is underway in the other two phases.

To achieve the objectives of the program, a team of researchers was assembled from Penn State (The Energy Institute, Mineral Processing Section, Department of Energy, Environmental, and Mineral Economics, Fuel Science Program, and Polymer Science Program), Energy and Environmental Research Corporation (EER), AMAX Research and Development Center, ABB Combustion Engineering, Inc., CeraMem Separations, Inc., Comprehensive Design Architects and Engineers, and Raytheon Constructors \& Engineers.

Phase I activities were focused on developing clean, coal-based combustion technologies for the utilization of both micronized coal-water mixtures (MCWMs) and dry, micronized coal (DMC) in fuel oil-designed industrial boilers. Phase II research and development continued to focus on industrial boiler retrofit technologies by addressing emissions control strategies for providing ultra-low emissions when firing coal-based fuels in industrial-scale boilers. Phase III activities expands upon emissions reduction strategies through the use of deeply-cleaned coals as a means for reducing air toxics Each phase includes an engineering cost analysis and technology assessment. The activities and status of the phases are described below.

The objective in Phase I was to deliver fully engineered retrofit options for a fuel oil-designed watertube boiler located on a DOD installation to fire either MCWM or DMC. This was achieved through a program consisting of the following five tasks: 1) Coal Beneficiation and Preparation; 2) Combustion Performance Evaluation; 3) Engineering Design; 4) Engineering and Economic Analysis; and 5) Final Report/Submission of Design Package. Following is an outline of the project tasks that comprised Phase I:

Task 1: Coal Beneficiation/Preparation

Subtask 1.1 Identify/Procure Coals

Subtask 1.2 Determine Liberation Potential

Subtask 1.3 Produce Laboratory-Scale Quantities of Micronized CoalWater Mixtures (MCWMs)

Subtask 1.4 Develop Dry Coal Cleaning Technique

Subtask 1.5 Produce MCWMs and Dry, Micronized Coal (DMC) From Dry Clean Coal

Subtask 1.6 Produce MCWM and DMC for the Demonstration Boiler Subtask 1.7 Project Management and Support 
Task 2: Combustion Performance Evaluation

Subtask 2.1 Boiler Retrofit

Subtask 2.2 Fuel Evaluation in the Research Boiler

Subtask 2.3 Performance Evaluation of the MCWM and DMC in the Demonstration Boiler

Subtask 2.4 Evaluate Emissions Reductions Strategies

Subtask 2.5 Project Management and Support

Task 3: Engineering Design

Subtask 3.1 MCWM/DMC Preparation Facilities

Subtask 3.2 Fuel Handling

Subtask 3.3 Burner System

Subtask 3.4 Ash Removal, Handling, and Disposal

Subtask 3.5 Air Pollution Control

Subtask 3.6 Integrate Engineering Design

Subtask 3.7 Project Management and Support

Task 4: Engineering and Economic Analysis

Subtask 4.1 Survey Boiler Population/Identify Boilers for Conversion

Subtask 4.2 Identify Appropriate Cost-Estimating Methodologies

Subtask 4.3 Estimate Basic Costs of New Technologies

Subtask 4.4 Process Analysis of MCWM and DMC

Subtask 4.5 Analyze/Identify Transportation Cost of Commercial Sources

of MCWM and Cleaned Coal for DMC Production

Subtask 4.6 Determine Community Spillovers

Subtask 4.7 Regional Market Considerations and Impacts

Subtask 4.8 Integrate the Analysis

Subtask 4.9 Project Management and Support

Task 5: Final Report/Submission of Design Package

The Phase I activities included:

Task 1: The coal beneficiation and preparation effort was conducted by Penn State's Mineral Processing Section with assistance from Penn State's Polymer Science Program and AMAX Research and Development Center. This task involved identifying and procuring six coals that could be cleaned to $<1.0 \mathrm{wt}$. \% sulfur and $<5.0 \mathrm{wt}$. \% ash which have been, or possess the characteristics to enable them to be, made into MCWMs. The coals were subjected to detailed characterization and used to produce laboratory-scale quantities of MCWM. A fundamental study of MCWM stabilization was conducted. Additional activities included developing a dry coal cleaning technique and producing MCWMs and DMC from the resulting cleaned coal.

Task 2: Penn State's Energy Institute conducted the combustion performance evaluation with assistance from EER and Penn State's Fuel Science Program. The technical aspects of converting a fuel oil-designed boiler at a DOD facility were identified in this task. All appropriate components were evaluated, including the fuel, the fuel storage, handling and delivery equipment, the burner, the boiler, the ash handling and disposal equipment, the emissions control system, and the boiler control system. Combustion 
performance as indicated by flame stability, completeness of combustion, and related issues such as system derating, changes in system maintenance, the occurrence of slagging, fouling, corrosion and erosion, and air pollutant emissions were determined. As part of this task, MCWM and DMC were evaluated in The Energy Institute's 15,000 lb steam/h watertube boiler. EER provided a coal-designed burner for retrofitting Penn State's boiler. In addition, EER designed the burner for the DOD boiler identified for retrofitting.

Task 3: An engineering study was performed for a complete retrofit of a DOD boiler facility to fire either MCWM or DMC. The designs were performed by EER with input from the other project participants. The designs included the coal preparation, the fuel handling, the burner, the ash removal, handling, and disposal, and the air pollution control systems. The two designs were for the DOD boiler identified in Task 4. The retrofits were designed for community/societal acceptability. The deliverables for this task were a detailed design that could be used for soliciting bids from engineering/construction firms to retrofit the candidate DOD boiler.

Task 4: An engineering cost analysis and a technology assessment of MCWM and DMC combustion were performed by Penn State's Department of Energy, Environmental, and Mineral Economics and Energy Institute with assistance from the industrial participants. The effort involved surveying the DOD boiler population, identifying boilers for conversion, identifying appropriate cost-estimating methodologies, estimating basic costs for new technologies, developing a process model, analyzing and identifying transportation costs for commercial sources of MCWM and cleaned coal, determining community spillovers, and determining regional market considerations and impacts.

Task 5: The results from each of the tasks were summarized in a final report. In addition, the design packages for the boiler retrofits were submitted. These included the engineering design and economic analysis.

The original objectives of Phase II were to: (a) extend the Phase I boiler retrofit options by including designs to achieve further reductions in gaseous and particulate emissions, (b) prepare and characterize fuels compatible with coal precombustors, and (c) investigate precombustion as a means of using high ash, high sulfur coals. Upon investigating precombustion options for installing a system on either the demonstration boiler $(15,000 \mathrm{lb} \mathrm{steam} / \mathrm{h})$ or research boiler $(1,000 \mathrm{lb} \mathrm{steam} / \mathrm{h})$, it became apparent that there were limited viable options and that the complexity of the systems would likely preclude their use on small-scale, industrial boilers. A similar conclusion was presented by the U.S. Corps of Engineers regarding the use of slagging combustors in the Army (Davidson et al., 1991). Consequently, the Phase II work was revised by eliminating the 
precombustion fundamental, pilot-scale, and demonstration-scale studies and focusing on fundamental, pilot-scale, and demonstration-scale emissions reduction strategies. An economic analysis of precombustion strategies was conducted, as originally planned, in order to compare precombustion strategies with (low ash) MCWM and DMC combustion retrofits. The revised Phase $\Pi$ consists of four tasks as outlined below:

Task 1. Emissions Reduction

Subtask 1.1 Evaluation of Emissions Reduction Strategies

Subtask 1.2 Installation of an Emissions Reduction System on the Demonstration Boiler

Subtask 1.3 Evaluation of an Emissions Reduction System

Subtask 1.4 Conduct NO Emissions Study

Subtask 1.5 Conduct VOC Study

Subtask 1.6 Conduct Trace Element Study

Subtask 1.7 Conduct Nitrogen Occurrence Study

Subtask 1.8 Conduct $\mathrm{NO}_{\mathrm{x}}$ Reduction Study

Subtask 1.9 Evaluate BioLime as a $\mathrm{SO}_{2} / \mathrm{NO}_{x}$ Reduction Strategy

Task 2. Coal Preparation/Utilization

Subtask 2.1 Optimization of Particle Size Consist for CWM

Formulation

Subtask 2.2 Fine Grinding/Classification/Liberation

Subtask 2.3 Fine Gravity Concentration

Subtask 2.4 Agglomeration/Flotation Studies

Subtask 2.5 Fundamental Studies of Surface-Based Processes

Subtask 2.6 Column Flotation

Subtask 2.7 Dry Cleaning of Fine Coal

Subtask 2.8 CWM Density Control

Subtask 2.9 Stabilization of CWM

Subtask 2.10 Atomization Study

Task 3. Engineering Design and Cost; and Economic Analysis

Subtask 3.1 Determination of Basic Cost Estimation of Boiler Retrofits

Subtask 3.2 Determination of Process Analysis

Subtask 3.3 Determination of Environmental and Regulatory Impacts

Subtask 3.4 Determination of Transportation Cost Analysis

Subtask 3.5 Determination of Technology Adoption

Subtask 3.6 Determination of Regional Economic Impacts

Subtask 3.7 Determination of Public Perception of Benefits and Costs

Subtask 3.8 Determination of Social Benefits

Subtask 3.9 Determination of Coal Market Analysis

Subtask 3.10 Engineering Design

Subtask 3.11 Integration of Analyses

Task 4. Final Report/Submission of Design Package

Portions of Phase II have been completed. The Phase II activities include:

Task 1: Task 1 activities are ongoing. In Task 1, strategies are being developed to provide for ultra-low emissions when firing coal-based fuels in industrial-scale boilers. Emissions being addressed are $\mathrm{SO}_{2}, \mathrm{NO}_{\mathrm{x}}$, fine particulate matter $(<10 \mu \mathrm{m})$, and air toxics (volatile organic compounds and trace metals). Post-combustion and during-combustion 
technologies to reduce $\mathrm{SO}_{2}$ and $\mathrm{NO}_{\mathrm{x}}$ emissions from coal-fired industrial boilers were surveyed. Novel technologies that are under development but are not commercially available were also surveyed as well as proven technologies such as limestone/lime injection, selective catalytic reduction, and nonselective catalytic reduction. Options for removing the submicron particulate were investigated. In addition, methods to remove air toxics from the flue gas, such as scrubbing, were investigated.

Task 2: Task 2 activities have been completed except for Subtask 2.10, which is an atomization study being conducted by Carnegie Mellon University, which was recently added to the program. Emphasis in Task 2 was on the refinement and optimization of coal grinding and CWM preparation procedures, and on the development of advanced processes for beneficiating high ash, high sulfur coals. CWM formulation is still an art and there was a clear need for scientifically-based guidelines for slurry design. This involved determining the optimum particle size distribution, how and why the optimum particle size distribution varies from coal to coal, and the specific roles of chemical dispersing and stabilizing agents. Extensive, physical pre-cleaning of coal is especially important in small-boiler applications. The research effort built on work conducted in Phase I.

Task 3: Task 3 economic analysis activities are nearly complete and focus on determining the basic cost estimation of boiler retrofits, evaluating environmental, regulatory, and regional economic impacts, and analyzing the coal market.

Task 4: The results from each of the tasks will be summarized in a final report.

The original objectives of Phase III were to: (a) develop coal-based fuel/waste cofiring technologies, and (b) assist DOD in improving the combustion performance and reducing emissions from existing stoker-fired boilers. Since the initial development of the program's statements of work (Phases I through III), there has been a change in military boiler plant operating philosophy. This, coupled with recent developments in cofiring technologies and DOE coal preparation programs, necessitates the revision of the Phase III statement of work. Consequently, the Phase III work has been revised by eliminating coalbased fuel/waste cofiring and stoker combustion performance analysis and evaluation, and focusing these efforts toward evaluating deeply-cleaned coals as industrial boiler fuels, and investigating fundamental, pilot-scale, and demonstration-scale emissions reduction strategies. The revised Phase III consists of five tasks as outlined below:

Task 1. Coal Preparation/Utilization

Subtask 1.1 Particle Size Control

Subtask 1.2 Physical Separations

Subtask 1.3 Surface-Based Separation Process

Subtask 1.4 Dry Processing 
Subtask 1.5 Stabilization of Coal-Water Mixtures

Task 2. Emissions Reduction

Subtask $2.1 \quad \mathrm{SO}_{2}$ Reduction

Subtask 2.2 $\mathrm{NO}_{\mathrm{x}}$ Reduction

Subtask 2.3 Study of VOC and Trace Element Production, Reduction, and Capture

Task 3. Economic Evaluation

Subtask 3.1 Cost and Market Penetration of Coal-Based Fuel

Technologies

Subtask 3.2 Selection of Incentives for Commercialization of the Coal-

Subtask 3.3 Community Sensitivity to Coal Fuel Usage

Subtask 3.4 Regional Economic Impacts of New Coal Utilization

Technologies

Subtask 3.5 Economic Analysis of the Defense Department's Fuel Mix

Subtask 3.6 Constructing a National Energy Portfolio which Minimizes

Subtask 3.7 Proposed Research on the Coal Markets and their Impact

Subtask 3.8 Integrate the Analysis

Task 4. Evaluation of Deeply-Cleaned Coal as Boiler Fuels

Subtask 4.1 Modify MCWM Preparation Circuit

Subtask 4.2 Fuels Characterization

Subtask 4.3 Pilot-Scale Combustion Tests

Subtask 4.4 Demonstration-Scale Combustion Tests

Task 5. Final Report

The Phase III activities include:

Task 1: Research conducted under Phase I and Phase II of this project has revealed a number of specific areas where continued and/or more focused effort is required in order to develop more effective and more reliable coal processing systems. Specific objectives of Task 1 are centered around:

- focused investigations into specific coal-cleaning options and their associated ancillary operations; and

- integration of processing/cleaning operations for overall system optimization.

As in the previous phases, emphasis is on fine-coal processing for the production of highquality, micronized coal for dry coal and coal-water mixture (CWM) applications.

Task 2: Task 2 is a continuation of the emissions reduction work started in Phase II, and involves fundamental studies, pilot-scale investigations, and full-scale demonstrations. The low-temperature $\mathrm{NO}_{\mathrm{x}}$ reduction catalyst identified in Phase $I$ will be tested at the pilot and demonstration scale. The effect of coal cleaning, particulate removal devices, and boiler operating conditions on air toxics emissions from coal-fired industrial boilers will also be investigated. 
Task 3: The activities in Task 3 focus on determining cost and market penetration, selection of incentives, and regional economic impacts of coal-based fuel technologies. In addition, DOD's fuel mix is being determined and a national energy portfolio constructed.

Task 4: The results from each of the tasks will be summarized in a final report.

The status of Phase $I$ is presented in Section 2.0. The accomplishments and status of Phase II, Tasks 1, 2, 3, and 4 are presented in Sections 3.0, 4.0, 5.0, and 6.0, respectively. The accomplishments and status of Phase III, Tasks 1, 2, 3,4, and 5 are presented in Sections 7.0, 8.0, 9.0, 10.0, and 11.0, respectively. Section 12.0 discusses miscellaneous activities that were conducted. Activities planned for the next semiannual period are listed in Section 13.0. References and acknowledgments are contained in Sections 14.0 and 15.0, respectively. The project schedule for Phases $I$ and $I I$ is given in Figures 1-1 and 1-2, respectively, with a description of the milestones contained in Tables $1-1$ and $1-2$, respectively.

\subsection{PHASE I}

Phase I has been completed and the final report was submitted on January 31, 1997.

\subsection{PHASE II, TASK 1: EMISSIONS REDUCTION}

The objective of this task is to develop strategies to provide for ultra-low emissions when firing coal-based fuels in industrial-scale boilers. Emissions being addressed are $\mathrm{SO}_{2}, \mathrm{NO}_{\mathrm{x}}$, fine particulate matter $(<10 \mu \mathrm{m}$ ), and air toxics (volatile organic compounds and trace metals).

\subsection{Subtask 1.1 Evaluation of Emissions Reduction Strategies} Subtask 1.1 was previously completed.

\subsection{Subtask 1.2 Install System on the Demonstration Boiler}

Subtask 1.2 was completed during this reporting period. An $\mathrm{SO}_{2}$ reduction system and a ceramic filter chamber were installed on the demonstration boiler to reduce $\mathrm{SO}_{2}$ emissions, and remove ultrafine particulate and increase the particulate collection efficiency, respectively. The $\mathrm{SO}_{2}$ reduction system and a ceramic filter chamber are discussed in Sections 2.2.1 and 2.2.2, respectively. Details of the demonstration boiler system and micronizing coal system have been discussed elsewhere (Miller et al., 1997).

\subsection{1 $\mathrm{SO}_{2}$ Reduction System}

A sodium duct injection system, which consists of a bag (sodium bicarbonate) unloading station, hopper with weigh cells, eductor, and piping to a port located in the ducting upstream of the baghouse and ceramic filter, was installed during this reporting period. A roof and siding were also installed on the system to protect the equipment from 


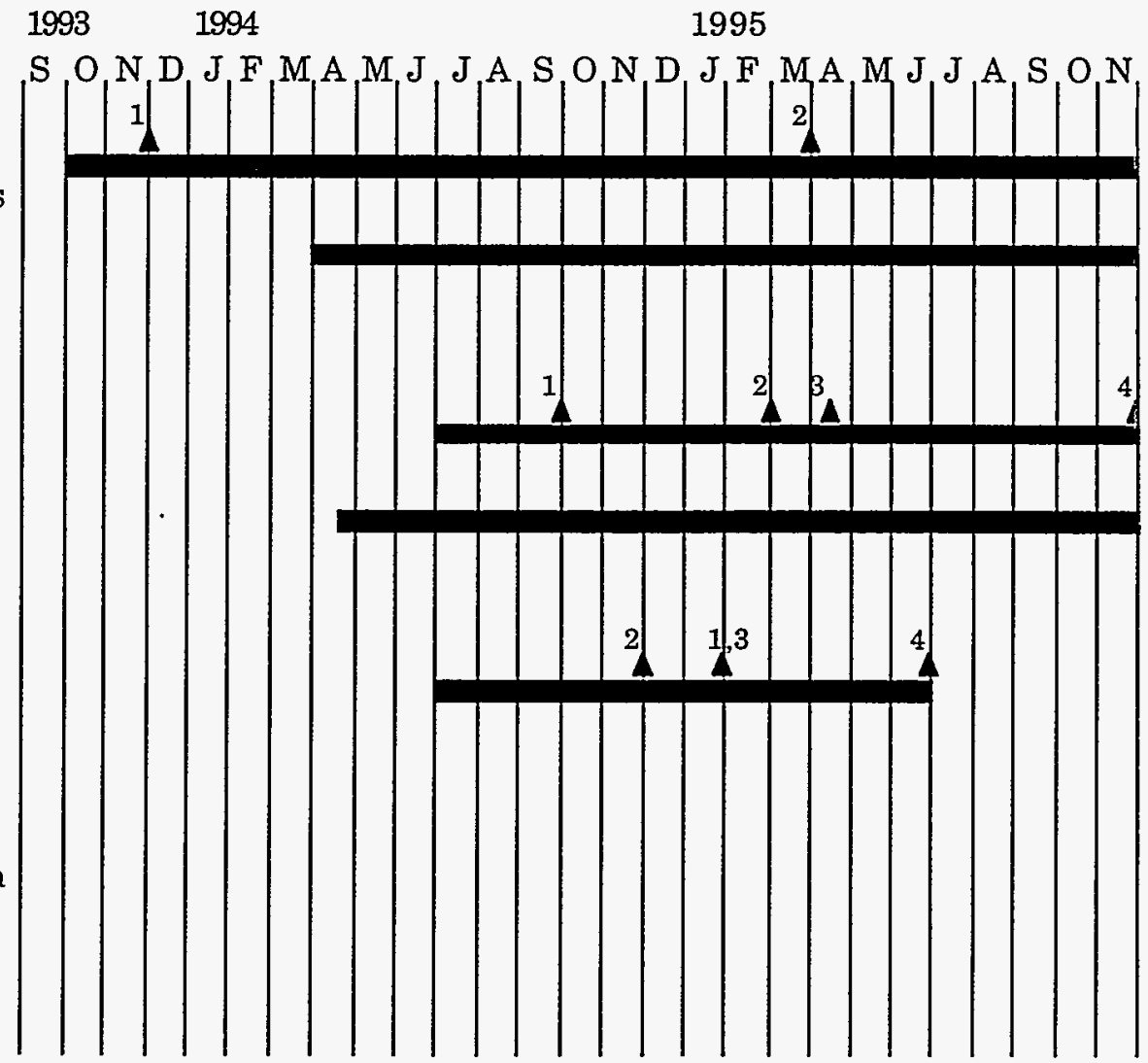

Task 1. Emissions Reductions

Subtask 1.1 - Evaluate Emissions Reductions Strategies

Subtask 1.2 - Install System on Demonstration Boiler

Subtask 1.3 - Evaluate Emissions Reduction System

Subtask 1.4 - Conduct $\mathrm{NO}_{\mathrm{X}}$ Emissions Study

Subtask 1.5 - Conduct VOC Study

Subtask 1.6 - Conduct Trace Element Study

Subtask 1.7 - Conduct Nitrogen Occurrence Study

Subtask 1.8 - Conduct $\mathrm{NO}_{\mathrm{x}}$ Reduction Study

Subtask 1.9 - Evaluate BioLime as a $\mathrm{SO}_{2} / \mathrm{NO}_{\mathrm{x}}$ Reduction Strategy

Figure 1-1. DOD PHASE II MILES 


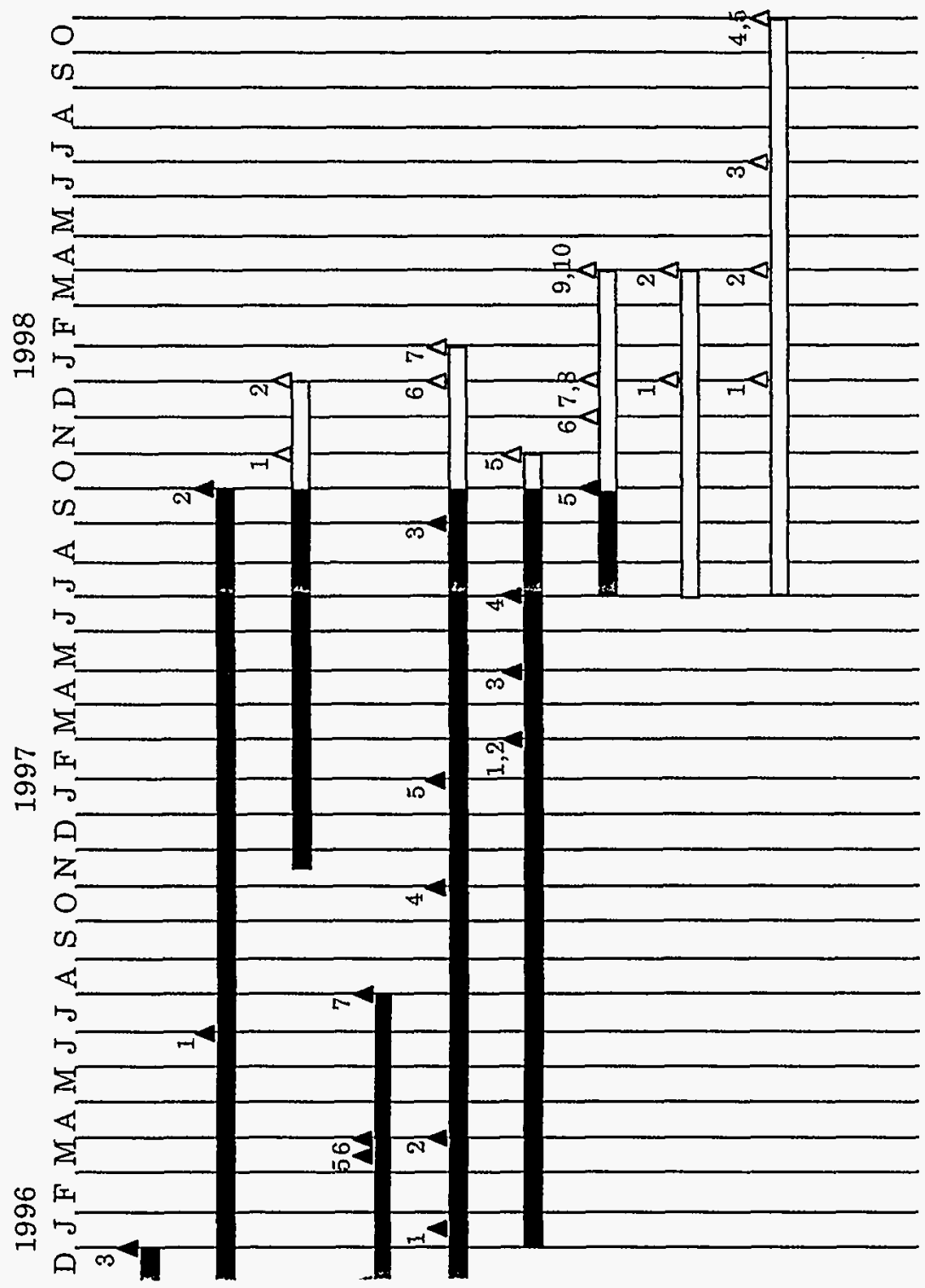


Task 3. Engineering Design and Cost and Economic Analysis

Subtask 3.1 - Basic Cost Estimation of Boiler Retrofits

Subtask 3.2 - Process Analysis

Subtask 3.3 - Environmental and Regulatory Impacts

Subtask 3.4 - Transportation Cost Analysis

Subtask 3.5 - TechnologyAdoption

Subtask 3.6 - Regional Economic Impacts

Subtask 3.7 - Public Perception of Benefits and Costs

Subtask 3.8 - Social Benefits

Subtask 3.9 - Coal Market Analysis

Subtask 3.10 - Integration of Analyses

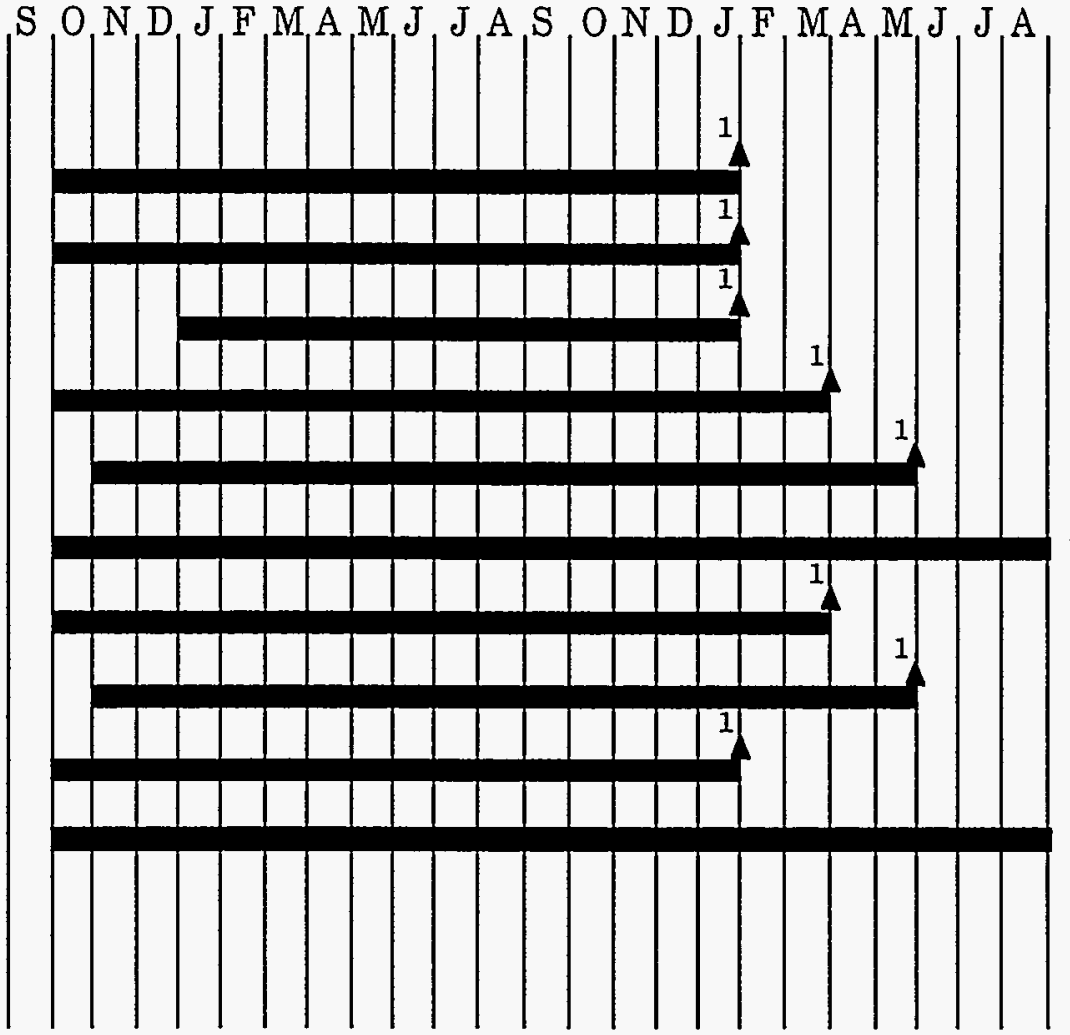




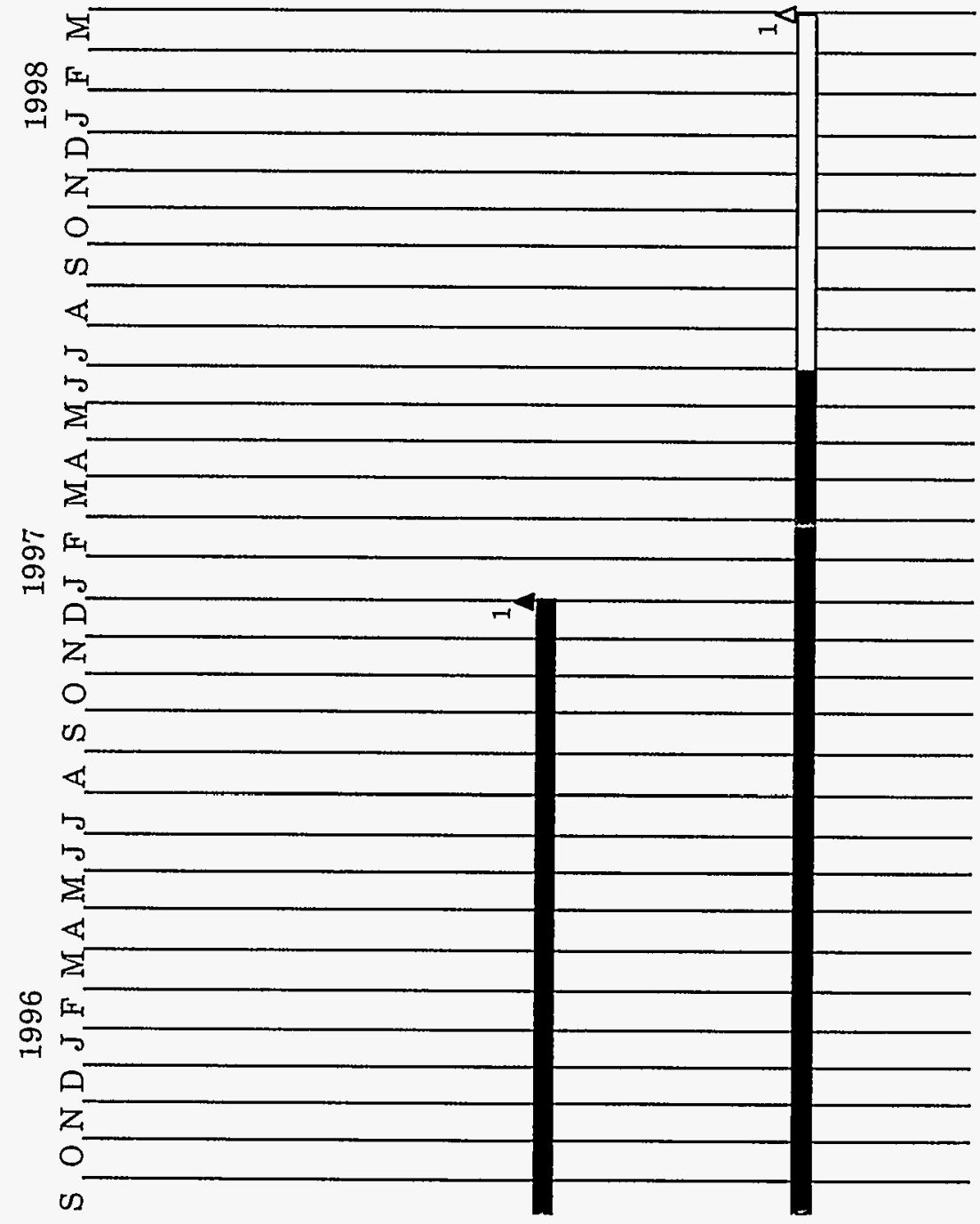




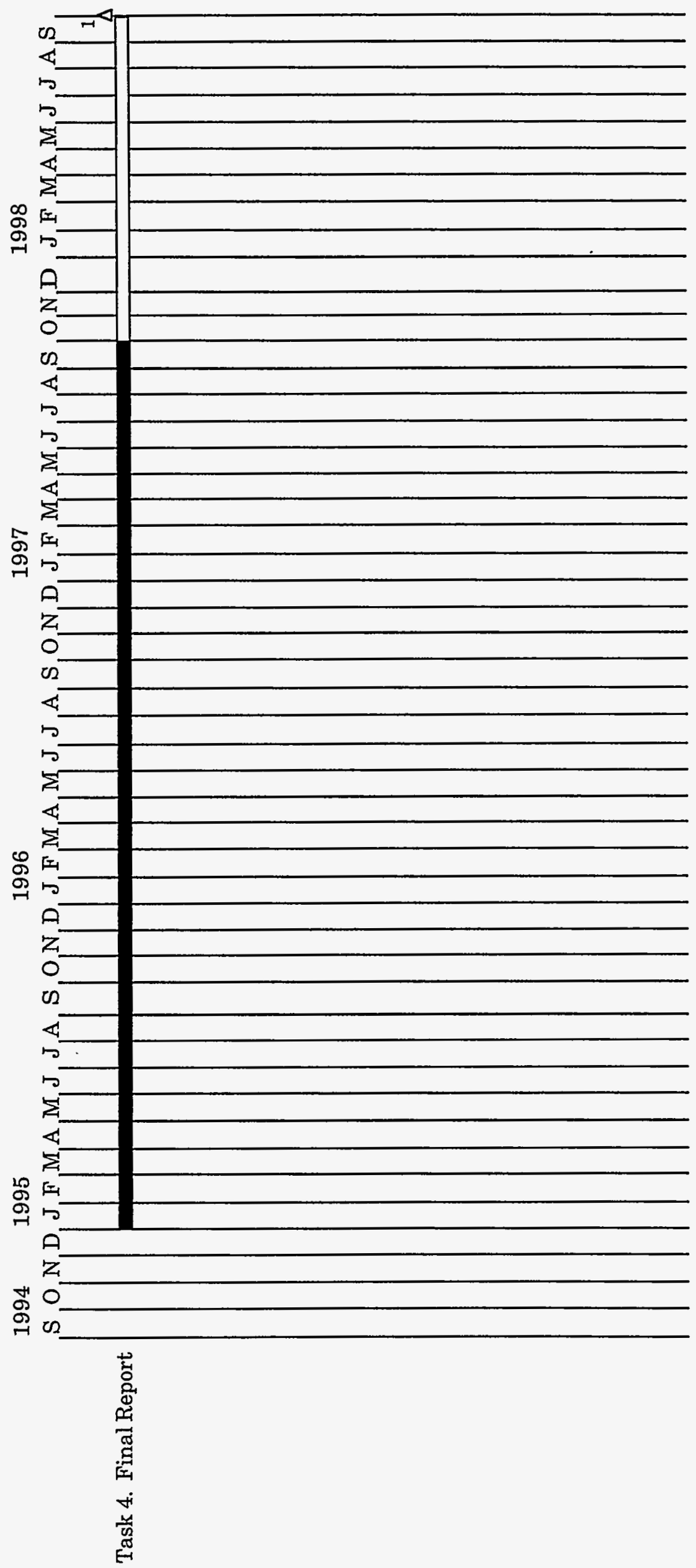


Task 1. Coal Preparation Utilization

Subtask 1.1 - Particle Size Control

Subtask 1.2 - Physical Separations

Subtask 1.3 - Surface-Based Separation Process

Subtask 1.4 - Dry Processing

Subtask 1.5 - Stabilization of Coal-Water Mixtures

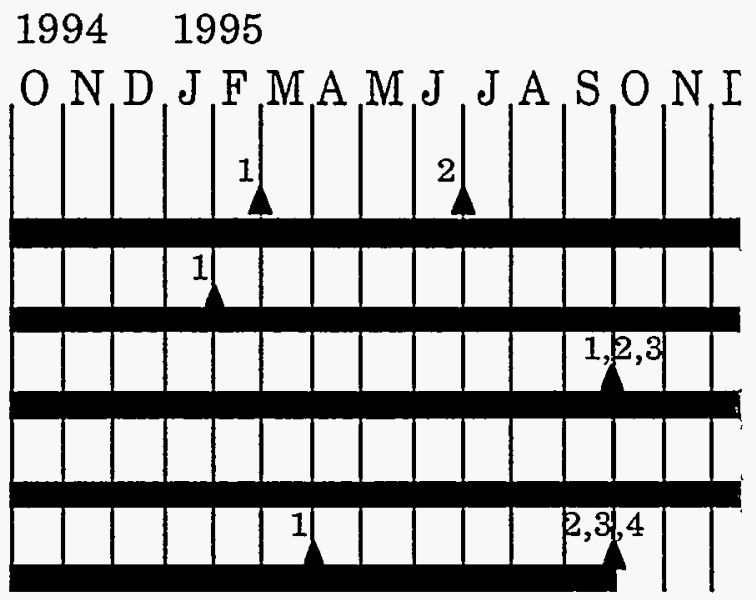

Figure 1-2. DOD PHASE III MILEST 


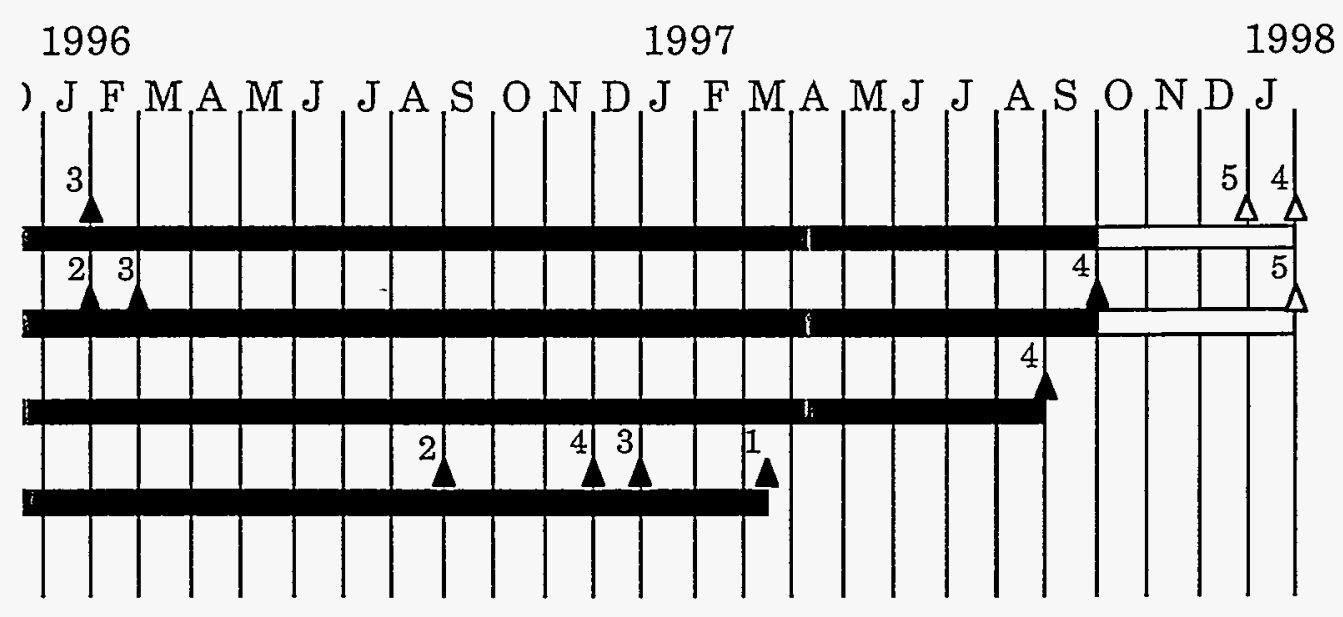

ONE SCHEDULE 


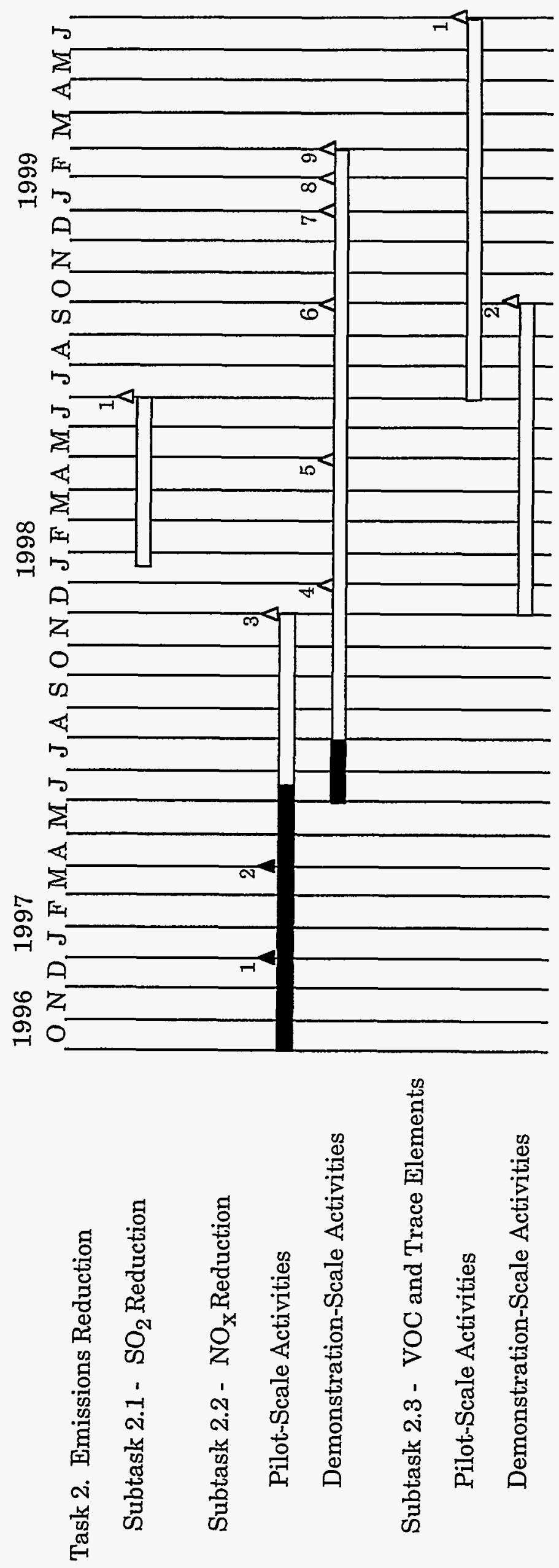


Task 3. Economic Evaluation

Subtask 3.1 - Cost and Market Penetration of Coal-Based Fuel Technologies

Subtask 3.2 - Selection of Incentives for Commercialization of the Coal Using Technology

Subtask 3.3 - Community Sensitivity of Coal Fuel Usage

Subtask 3.4 - Regional-National Economic Impacts of New Coal Utilization Technologies

Subtask 3.5 - Economic Analysis of the Defense Department's Fuel Mix

Subtask 3.6 - Constructing a National Energy Portfolio which Minimizes Energy Price Shock Effects

Subtask 3.7 - Proposed Research on the Coal Markets and their Impact on CoalBased Fuel Technologies

Subtask 3.8 - Integration of Economic Analysis
19941995
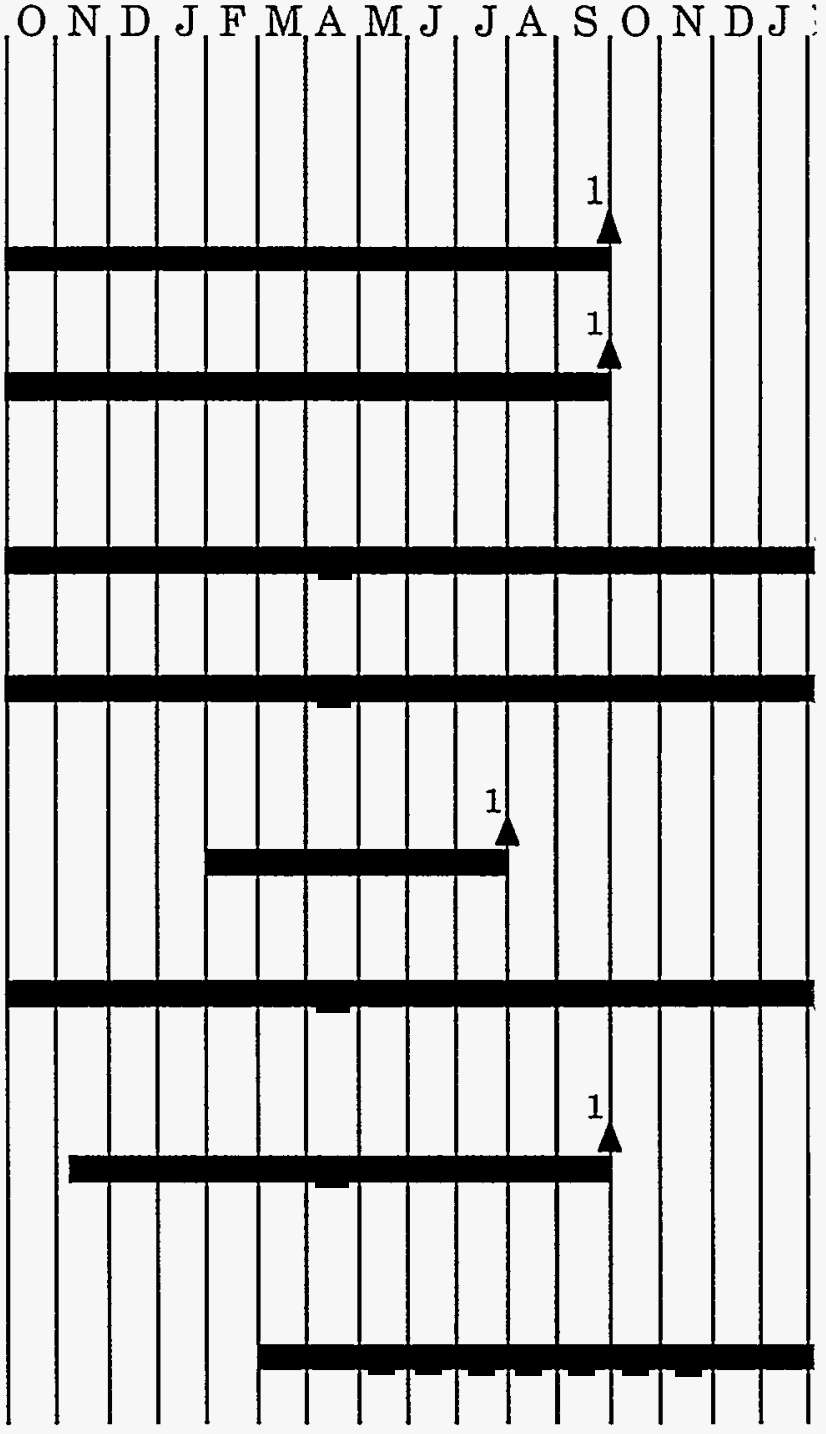


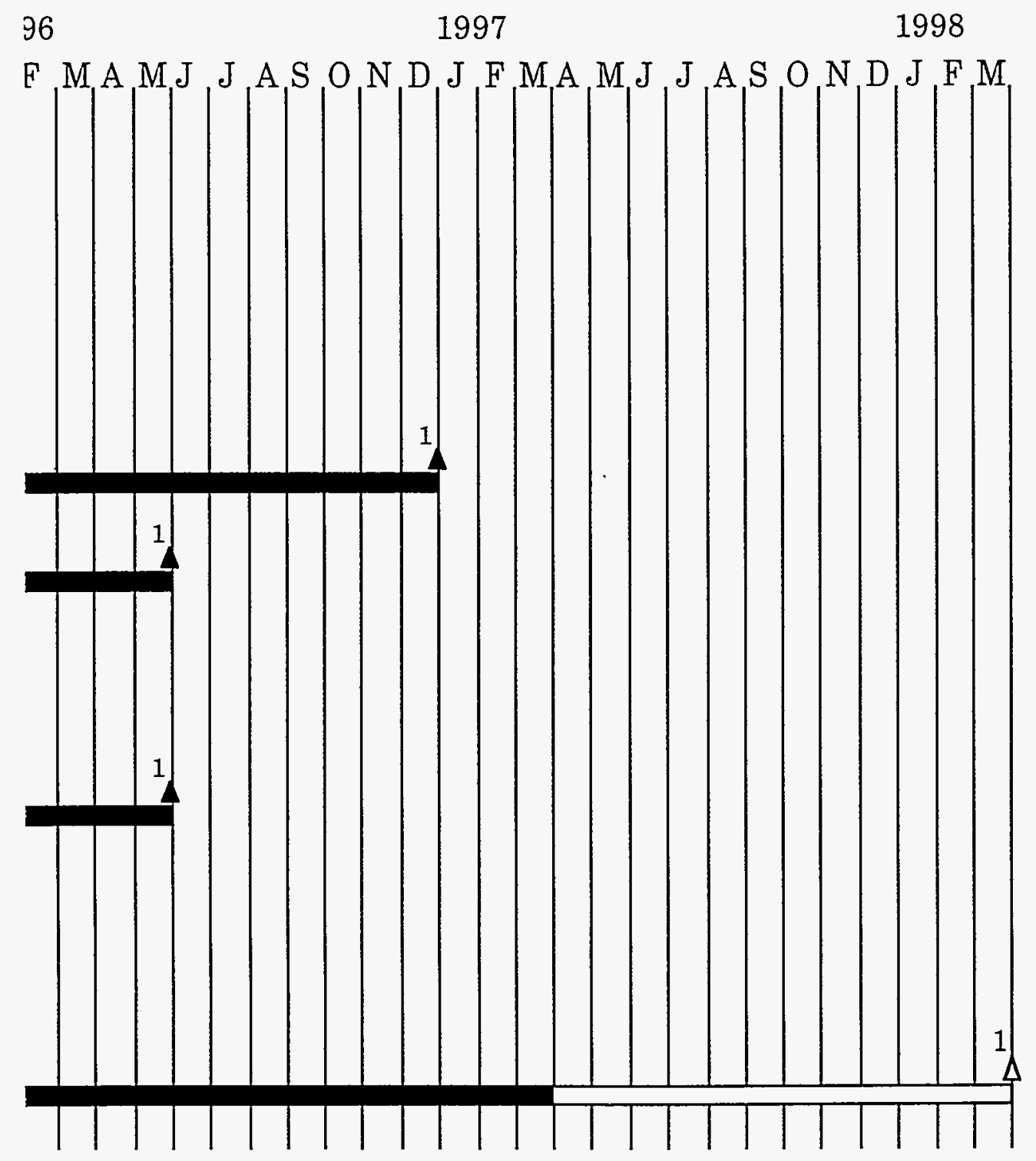


Task 4. Evaluation of Deeply-Cleaned Coal as Boiler Fuel

Subtask 4.1 - Modify MCWMPreparation Circuit

Subtask 4.2 - Fuels Characterization

Subtask 4.3 - Pilot-Scale Combustion Tests

Subtask 4.4 - Demonstration-Scale Combustion Tests

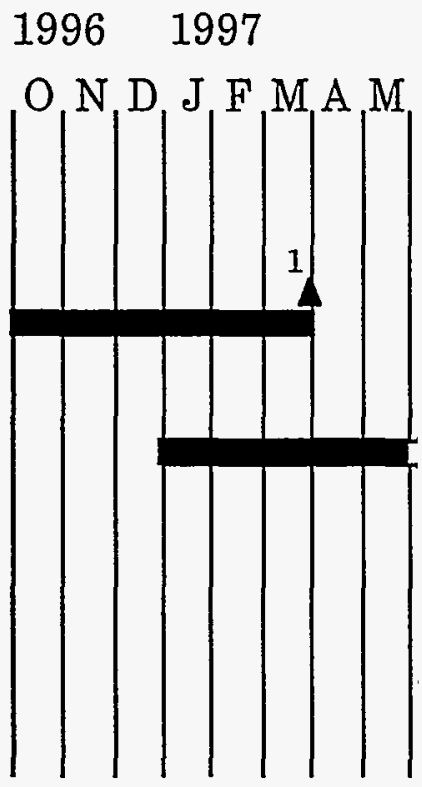

Task 5. Final Report/ Submission of Design Package

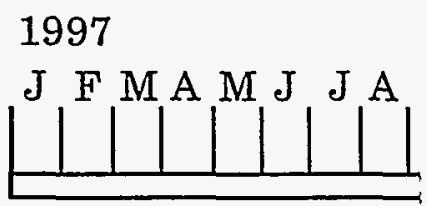




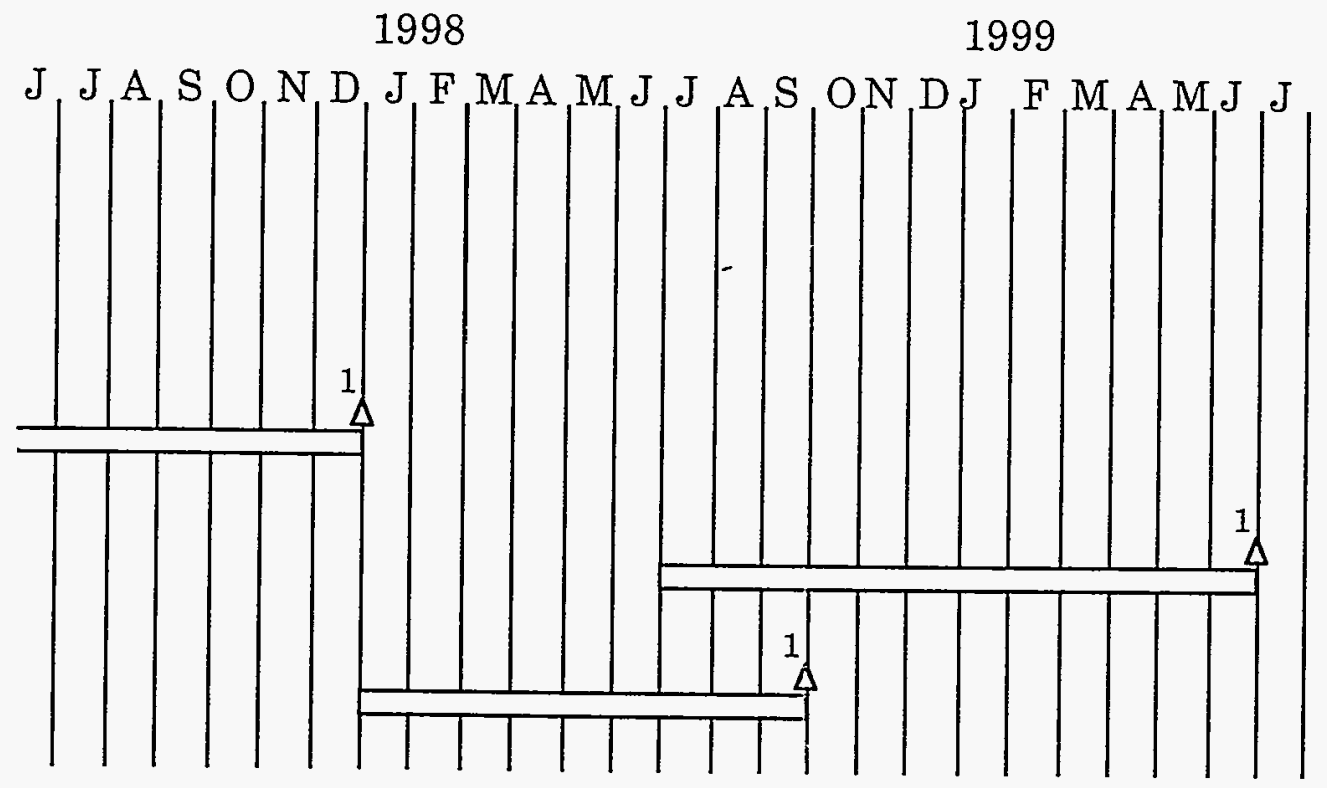

1998

1999

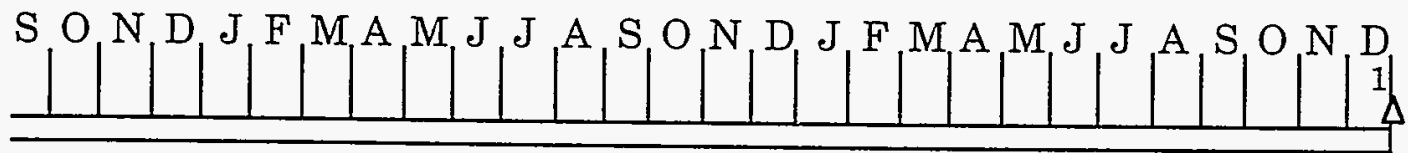


Table 1-1. Phase II. Milestone Description

$\underline{\text { Milestone }} \quad \underline{\text { Description }} \quad \frac{\text { Planned }}{\text { Completion }} \frac{\underline{\text { Actual }}}{\text { Completion }}$

Task 1. Emissions Reduction

Subtask 1.1. Evaluation of Emissions Reduction Strategies

Subtask 1.1, No. $1 \quad$ Receive proposals for pollution control system

Subtask 1.1, No. 2 Complete summary report of pollution control

$12 / 01 / 93$

$03 / 31 / 95 \quad 03 / 31 / 95$

Subtask 1.1, No. $3 \quad$ Select pollution control system

$12 / 31 / 95$

$12 / 31 / 95$

Subtask 1.2. Install System on Demonstration Boiler

$\begin{array}{ll}\text { Subtask 1.2, No. } 1 \quad \text { Design pollution control system } & 05 / 01 / 96\end{array}$

Subtask 1.2, No. $2 \quad$ Complete installation of system $09 / 30 / 97$

$07 / 01 / 96$

09/30/97

Subtask 1.3. Evaluate Emissions Reduction System

Subtask 1.3, No. $1 \quad$ Shakedown system

Subtask 1.3, No. 2 Complete system evaluation

$10 / 31 / 97$

$12 / 31 / 97$

Subtask 1.4. Conduct $\mathrm{NO}_{\mathrm{x}}$ Emissions Study

Subtask 1.4, No $1 \quad$ Review state-of-the art in NO catalysts

$10 / 01 / 94 \quad 10 / 01 / 94$

Subtask 1.4 , No. 2

Design bench-scale flow reactor

$02 / 01 / 95$

$03 / 01 / 95$

Subtask 1.4 , No. 3

Design FTIR gas analysis system for the flow reactor

$04 / 01 / 95$

$04 / 18 / 95$

Subtask 1.4, No. 4

Construct flow reactor and data acquisition system

$10 / 01 / 95$

$12 / 15 / 95$

Shake down system and calibrate FTIR spectrometer

$03 / 01 / 96$

Subtask 1.4, No. 5

Select and acquire catalysts for testing

Subtask 1.4 , No. 6

Develop catalyst characterization database

$03 / 15 / 96$

$04 / 01 / 96 \quad 04 / 01 / 96$

$06 / 15 / 96 \quad 08 / 01 / 96$

Subtask 1.5. Conduct VOC Study

Subtask 1.5, No. 1 Modify research boiler

Subtask 1.5, No. 2 Literature survey on trace organic emissions and analytical procedures

$12 / 31 / 95$

$01 / 15 / 96$

$03 / 31 / 96$

$04 / 01 / 96$

Subtask 1.5, No. 3

Evaluate the GC/MS equipment and upgradation

Subtask 1.5 , No. 4

Procurement of Method 5 apparatus and auxiliaries

$08 / 31 / 97$

$08 / 31 / 97$

Shakedown of the sampling procedures

$10 / 31 / 96$

$10 / 31 / 96$

Subtask 1.5 , No. 5

Conduct test program and analyze samples

$01 / 31 / 97$

Subtask 1.5 , No. 6

Analysis of the results

$12 / 31 / 97$

$01 / 31 / 98$

Subtask 1.6. Conduct Trace Element Study

Subtask 1.6, No. 1 Conduct literature survey on trace element emissions

and analysis techniques

$11 / 30 / 96$

$03 / 01 / 97$

$02 / 28 / 97$

$02 / 28 / 97$

Subtask 1.6, No. 2

Procure sampling equipment

$04 / 30 / 97$

$04 / 30 / 97$

Subtask 1.6, No. 4

Shake down sampling procedure

$07 / 31 / 97$

Analysis of results

$06 / 30 / 97$

Subtask 1.7. Study Nitrogen Containing Groups in Coal

Subtask 1.7, No. 1 Optimization of sample preparation for ${ }^{15} \mathrm{~N} \mathrm{NMR}$ on coals and chars

$01 / 31 / 95$

$01 / 31 / 95$

Subtask 1.7 , No. 2

First solid-state ${ }^{15} \mathrm{~N}$ NMR spectra at natural $15_{\mathrm{N}}$ abundance of coals obtained

$11 / 30 / 94$

$11 / 30 / 94$

Subtask 1.7 , No. 3

First solid-state ${ }^{15_{N}}$ NMR spectra at natural $15_{\mathrm{N}}$

abundance of chars obtained

$01 / 31 / 95$

$01 / 31 / 95$ 
Milestone

Subtask 1.7, No. 4

Subtask 1.7, No. 5

Subtask 1.7, No. 6

Subtask 1.7, No. 7

Subtask 1.7, No. 8

Subtask 1.7 , No. 9

Subtask 1.7, No. 10

\section{Description}

Examination of the $\mathrm{N}$-functionality in vitrinite coals as a function of maturation degree by means of ${ }^{15} \mathrm{~N}$ and

${ }^{13} \mathrm{C}$ NMR spectroscopy

Complete acetylation portion of derivitization work

Complete data analysis of derivitization work

Complete low-temperature ashing of a range of coals

and model polymer systems

Establish methodology of methylation work

Complete analysis of samples for methylation work

Complete FTIR quantitiative analysis of low-

temperature ashes
Actual

Completion Completion

Date Date

$06 / 30 / 95$

$06 / 30 / 95$

$09 / 30 / 97$

$10 / 31 / 97$

$12 / 31 / 97$

$12 / 31 / 97$

$03 / 31 / 98$

$03 / 31 / 98$

$12 / 31 / 97$

$03 / 31 / 98$

$\begin{array}{ll}\text { Subtask } 1.8, \text { No. } 1 & \text { Complete tests in the down-fire } \\ \text { Subtask } 1.8, \text { No. } 2 & \text { Complete analysis of results }\end{array}$

n-fired combustor

Subtask 1.9. Evaluate BioLime as a $\mathrm{SO}_{2} / \mathrm{NO}_{x}$ Reduction Strategy

Subtask 1.9, No.1

Establish baseline reburn limits with BioLime

$12 / 31 / 97$

Establish operating limits for BioLime operating limits

Complete pilot-scale testing of wood feedstock with

High $\mathrm{NO}_{\mathrm{x}}$ Retention Formula

Complete fundamental study of predominant mechanism

Complete scale up of BioLime injection technology
$03 / 31 / 98$

$06 / 30 / 98$

$08 / 31 / 98$

$08 / 31 / 98$

\section{Task 2. Coal Preparation/Utilization}

Subtask 2.1. Optimization of Particle Size Consist for Slurry Formulation

Subtask 2.1, No. 1

Subtask 2.1, No. 2

Subtask 2.1, No. 3

Subtask 2.1, No. 4
Samples of fine and coarse slurry components prepared

Rheological characterization of components completed

Models for rheology of binary mixtures developed

Optimization studies complete
$04 / 30 / 94$

$04 / 30 / 95$

$09 / 30 / 94$

$06 / 30 / 95$

$04 / 30 / 94$

$04 / 30 / 95$

$04 / 30 / 94$

$05 / 31 / 94$

$05 / 15 / 95$

$06 / 30 / 94$

$04 / 30 / 94$

$07 / 31 / 94$

$04 / 30 / 94$

$09 / 30 / 94$

$10 / 15 / 94$

$02 / 28 / 95$

$04 / 30 / 95$

$04 / 30 / 95$

$05 / 31 / 95$
$05 / 30 / 94$

$06 / 30 / 95$

$09 / 30 / 94$

09/30/95

$04 / 30 / 94$

$04 / 30 / 95$

$06 / 30 / 94$

$05 / 31 / 94$

$05 / 15 / 95$

$06 / 30 / 94$

$04 / 30 / 94$

$08 / 15 / 94$

$06 / 30 / 94$

$01 / 15 / 95$

$01 / 31 / 95$

$02 / 28 / 95$

$03 / 31 / 95$

$04 / 30 / 95$

$05 / 31 / 95$

Subtask 2.3, No. 8

Evaluate size classification data

Subtask 2.4. Agglomeration/Flotation Studies

Subtask 2.4 , No. I Set-up device to size separate flotation products of micronized coal 
Milestone

Subtask 2.4 , No. 2

Subtask 2.4, No. 3

Subtask 2.4, No. 4

Subtask 2.4, No. 5
Description

Set-up equipment for larger scale tests using $2.2 \mathrm{cu} . \mathrm{ft}$. flotation cells

Conduct agglomeration-flotation tests for micronized

Type III coal

Conduct agglomeration-flotation tests in larger cells

Determine parameters for scale-up

\section{Planned Actual \\ Completion Completion \\ Date \\ Date}

04/30/94

$04 / 30 / 94$

$09 / 30 / 94$

$09 / 30 / 94$

$03 / 31 / 95 \quad 08 / 31 / 95$

$06 / 30 / 95 \quad 09 / 30 / 95$

Subtask 2.5. Fundamental Studies of Surface-Based Processes

Subtask 2.5, No. 1 Conduct interface characterization studies to determine

flotation reagent-coal interactions

$06 / 30 / 94$

$06 / 30 / 94$

Subtask 2.5, No. 2

Measure contact angles in the coal-oil-surfactant-water

system

$06 / 30 / 95$

$09 / 30 / 95$

Subtask 2.5 , No. 3

Determine effect of surfactants on slurry stability

$05 / 31 / 95$

$07 / 31 / 95$

Subtask 2.6. Column Flotation

Subtask 2.6, No. 1 Test work on Type II coals

$11 / 30 / 94$

$01 / 31 / 95$

Subtask 2.6, No. 2

Test work on Type III coals

$09 / 30 / 94$

$12 / 31 / 94$

Subtask 2.6, No. 3

Determine scale-up parameters

$09 / 30 / 95$

Subtask 2.7. Dry Cleaning of Fine Coal

Subtask 2.7, No. 1

Complete evaluation of Type III coal in batch separator

Subtask 2.7, No. 2

Integration of closed dry grinding circuit with TES

$04 / 30 / 94$

$05 / 31 / 94$

Subtask 2.7, No. 3 Initiate investigation of continuous TES

$04 / 30 / 95$

$04 / 30 / 95$

Subtask 2.7, No. 4

Complete charge measurements on Type II coal

$06 / 30 / 94$

Subtask 2.7, No. 5

Complete charge measurements on Type III

$04 / 30 / 95$
$05 / 31 / 95$

Subtask 2.8. Slurry Density Control

Subtask 2.8, No. 1 Evaluate procedures for reversible flocculation of fine coal

$04 / 30 / 95$

$05 / 31 / 95$

09/30/94

09/30/94

Subtask 2.8, No. 2

Establish process engineering for thickening of fine-coal slurries

$10 / 31 / 94$

$10 / 31 / 94$

Subtask 2.9. Stabilization of CWSF

Subtask 2.9, No. $1 \quad$ Complete stabilization study

$12 / 31 / 94$

$12 / 31 / 94$

Subtask 2.10. Atomizer Testing

Subtask 2.10, No. 1 Complete atomization study

$03 / 31 / 98$

Task 3. Engineering Design and Cost; and Economic Analysis

Subtask 3.1. Determine Basic Cost Estimation of Boiler Retrofits

$02 / 01 / 95$

$02 / 01 / 95$

Subtask 3.2. Determine Process Analysis

$02 / 01 / 95$

$02 / 01 / 95$

$02 / 01 / 95 \quad 02 / 01 / 95$

04/01/95 04/01/95

Subtask 3.4. Determine Transportation Cost Analysis

$04 / 01 / 95$

Subtask 3.5. Determine Technology Adoption

$06 / 01 / 95$

$12 / 31 / 96$

$12 / 31 / 96$

$04 / 01 / 95$

Subtask 3.7. Determine Public Perception of Benefits and Costs

$04 / 01 / 95$

$06 / 01 / 95$

$06 / 01 / 95$

Subtask 3.9. Determine Coal Market Analysis

$02 / 01 / 95$

$02 / 01 / 95$

$03 / 31 / 98$

Task 4. Final Report

09/30/98 
Table 1-2. Phase III. Milestone Description

Milestone $\quad \underline{\text { Description }} \quad \frac{\begin{array}{c}\text { Planned } \\ \text { Completion }\end{array}}{\underline{\text { Date }}} \frac{\begin{array}{c}\text { Actual } \\ \text { Completion }\end{array}}{\text { Date }}$

\section{Task 1. Coal Preparation/Utilization}

Subtask 1.1. Particle Size Control

$\begin{array}{ll}\text { Subtask 1.1, No. } 1 & \begin{array}{l}\text { Evaluate conventional ball milling circuit } \\ \text { Evaluate stimed-media milling circuit }\end{array} \\ \text { Subtask 1.1, No. } 2 & \begin{array}{l}\text { Complete baseline testing of attrition milling for the } \\ \text { production of broad size distributions }\end{array} \\ \text { Subtask 1.1, No. } 4 & \begin{array}{l}\text { Complete preliminary evaluation of dry grinding/ } \\ \text { classifier circuit } \\ \text { Initiate investigation of an integrated grinding/cleaning } \\ \text { circuit }\end{array}\end{array}$

$02 / 28 / 95 \quad 02 / 28 / 95$

$06 / 30 / 95 \quad 06 / 30 / 95$

$01 / 31 / 96 \quad 01 / 31 / 96$

$01 / 31 / 98$

$12 / 31 / 97$

Subtask 1.2. Physical Separations

Subtask 1.2, No. 1 Complete preliminary investigation of magnetic fluid-

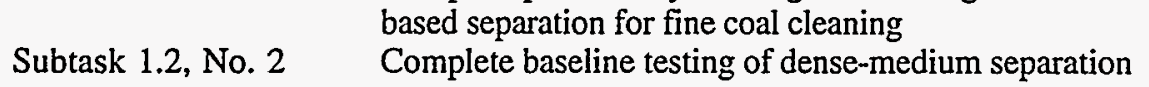

$01 / 31 / 95 \quad 01 / 31 / 95$

$\begin{array}{lll}\text { using the continuous, solid-bowl centrifuge } & 01 / 31 / 96 & 01 / 31 / 96\end{array}$

Subtask 1.2, No. 3 Initiate investigation of magnetic fluid cyclone

separations $\quad 02 / 29 / 96$

$02 / 29 / 96$

Subtask 1.2, No. $4 \quad$ Complete baseline testing of solid-bowl centrifuge for micronized coal classification $\quad 06 / 30 / 97$

Subtask 1.2, No. 5 Initiate testing of integrated centrifugal/flotation system 01/31/98

09/30/97

Subtask 1.3. Surface-Based Separation Processes

$05 / 31 / 95$

09/30/95

Subtask 1.3, No. 2

Evaluate effectiveness of alternative bubble generators in flotation column

$06 / 30 / 95$

$09 / 30 / 95$

Subtask 1.3, No. 3

Baseline testing on selected coal

$08 / 31 / 95$

$09 / 30 / 95$

Subtask 1.3, No. 4

Evaluate flotation system performance

$08 / 31 / 97$

Subtask 1.4 Dry Processing

Subtask 1.4, No. 1 Complete deagglomeration testing using the batch

$03 / 15 / 97$

Subtask 1.4, No. 2

Complete baseline testing of continuous

triboelectrostatic separator unit

$05 / 31 / 96$

$08 / 31 / 96$

Subtask 1.4 , No. 3 Initiate investigation of alternative approaches to charging/deagglomeration

$12 / 31 / 96$

$12 / 31 / 96$

Subtask 1.4, No. 4

Complete preliminary testing of integrated grinding and triboelectrostatic separator unit

$11 / 30 / 96$

$11 / 30 / 96$ 
Milestone

\section{Description}

Subtask 1.5 Stabilization of Coal-Water Mixtures

Subtask 1.5, No. 1

Complete PSD model extension

$04 / 01 / 95$

Complete construction of computer program Complete PSD model comparison to experimental results

Subtask 1.5, No. 3

Subtask 1.5, No. 4

$09 / 27 / 95$

$04 / 01 / 95$

$09 / 27 / 95$

$09 / 27 / 95 \quad 09 / 27 / 95$

$09 / 27 / 95 \quad 09 / 27 / 95$

\section{Task 2. Emissions Reduction}

Subtask 2.1. $\mathrm{SO}_{2}$ Reduction

Subtask 2.1, No. $1 \quad$ Evaluate $\mathrm{SO}_{2}$ reduction system in coordination with $\mathrm{NO}_{\mathrm{x}}$ reduction system

$07 / 01 / 98$

Subtask 2.2. $\mathrm{NO}_{\mathrm{x}}$ Reduction

Subtask 2.2, No. 1 Complete preliminary pilot-scale SCR testing firing

Subtask 2.2, No. 2 natural gas

$12 / 31 / 96$

$12 / 31 / 96$

Subtask 2.2, No. 3

Design pilot-scale $\mathrm{SCR}$ tests for $\mathrm{NO}_{\mathrm{X}}$ reduction system

$04 / 01 / 97$

$04 / 01 / 97$

Subtask 2.2, No. 4

Perform pilot-scale tests of SCR $\mathrm{NO}_{x}$ reduction system

$11 / 30 / 97$

Design selective catalytic $\mathrm{NO}_{\mathrm{x}}$ reduction system $\quad 01 / 31 / 98$

Subtask 2.2, No. 5

Design demonstration boiler modifications for SCR.

$\mathrm{NO}_{\mathrm{X}}$ reduction system

$04 / 01 / 98$

Subtask 2.2, No. 6 Modify demonstration boiler system for SCR NO reduction system

$09 / 30 / 98$

Subtask 2.2, No. 7

Complete testing of SCR $\mathrm{NO}_{\mathrm{x}}$ reduction system

Subtask 2.2, No. 8

Modify demonstration boiler system for BioLime $\mathrm{SO}_{2}$ I $\mathrm{NO}_{\mathrm{x}}$ reduction system

$12 / 31 / 98$

Subtask 2.2, No. 9

Complete testing of BioLime reduction system

$02 / 01 / 99$

$04 / 01 / 99$

Subtask 2.3. Study VOC and Trace Element Production, Reduction, and Capture

Subtask 2.3, No. 1

Complete pilot-scale testing of deeply-cleaned coals Complete demonstration-scale testing of deeply-cleaned coals

$06 / 30 / 99$

$10 / 01 / 98$

\section{Task 3. Economic Evaluation}

Subtask 3.1. Cost and Market Penetration of Coal-Based Fuel Technologies

Subtask 3.1, No. 1 Complete study of cost and market penetration of coalbased fuel technologies

$06 / 01 / 95$

09/27/95

Subtask 3.2. Selection of Incentives for Commercialization of the Coal Using Technology

Subtask 3.2, No. 1 Complete selection of incentives for commercialization of the coal-using technology 
Milestone $\quad$ Description

Planned Actual

Completion Completion

Date Date

Subtask 3.3. Community Sensitivity to Coal Fuel Usage

Subtask 3.3, No. 1 . Complete evaluation of community sensitivity to coal fuel usage

$12 / 31 / 96$

Subtask 3.4 Regional Economic Impacts of New Coal Utilization Technologies

Subtask 3.4 , No. 1 Complete study of regional economic impacts of new coal utilization technologies

06/01/96 06/01/96

Subtask 3.5 Economic Analysis of the Defense Department's Fuel Mix

Subtask 3.5, No. 1 Complete economic analysis of the defense department's fuel mix

$09 / 27 / 95 \quad 06 / 30 / 95$

Subtask 3.6 Constructing a National Energy Portfolio which Minimizes Energy Price Shock Effects

Subtask 3.6, No. $1 \quad$ Complete construction of a national energy portfolio $\begin{array}{ll}\text { which minimizes energy price shock effects } & 06 / 01 / 96\end{array}$

Subtask 3.7 Proposed Research on the Coal Markets and their Impact on Coal-Based Fuel Technologies

Subtask 3.7, No. 1 Complete research on the coal markets and their impact on coal-based fuel technologies

$09 / 27 / 95$

$09 / 27 / 95$

Subtask 3.8 Integrate the Analysis

Subtask 3.8, No.1 Complete integration of the analysis

$03 / 31 / 98$

Task 4. Evaluation of Deeply.Cleaned Coals as Boiler Fuels

Subtask 4.1 Modify MCWM Preparation Circuit

Subtask 4.1, No. 1 Complete modifications to MCWM preparation circuit 04/01/97

03/01/97

Subtask 4.2 Fuels Characterization

$\begin{array}{lll}\text { Subtask 4.2, No. } 1 \quad \text { Complete fuels characterization } & \text { 01/01/98 }\end{array}$

Subtask 4.3 Pilot-Scale Combustion Tests

Subtask 4.3, No. $1 \quad$ Complete pilot-scale testing of deeply-cleaned coals $\quad 06 / 30 / 99$ 
Milestone

Description

$\frac{\begin{array}{c}\text { Planned } \\ \text { Completion }\end{array}}{\text { Date }} \quad \frac{\begin{array}{c}\text { Actual } \\ \text { Completion }\end{array}}{\text { Date }}$

Subtask 4.4 Demonstration-Scale Combustion Tests

Subtask 4.4, No. 1 Complete demonstration-scale testing of deeply-cleaned coals

$10 / 01 / 98$

Task 5. Final Report/Submission of Design Package

$12 / 31 / 99$ 
the weather. Approval was received from the Pennsylvania Department of Environmental Protection to use the system.

\subsubsection{Ceramic Filter Chamber}

Construction of the ceramic filter chamber was completed during the previous reporting period. Shakedown and operation of the system were conducted during this reporting period. The ceramic filter chamber was installed adjacent to the existing baghouse and is capable of filtering the entire flue gas stream. The system has been engineered such that the flue gas stream can be passed through either the baghouse or ceramic filter. Schematic diagrams of the new system and details of the ceramic filter chamber were given in previous semiannual reports (Miller et al., 1996a,b). A generalized schematic diagram of the interior of the ceramic filter chamber showing the baffles and filters is given Figure 3-1.

\subsection{Subtask 1.3 Evaluate Emissions Reduction Systems}

Evaluation of the ceramic filter system began during this reporting period. Evaluation of the $\mathrm{SO}_{2}$ reduction system will begin during the next reporting period after the initial characterization of the ceramic filter system is completed.

\subsubsection{Ceramic Filter System Shakedown}

Shakedown of the ceramic filter system was completed during this reporting period. Shakedown was performed while firing the boiler on natural gas to ensure proper dirty side gas management prior to introducing fly ash into the system. The primary objective of the shakedown period, which occurred during March and April 1997, was to ensure that there was sufficient compressed air flow and filter face pressure when backpulsing the filters to clean them. The air flow and face pressure recommended by CeraMem Separations, Inc., the manufacturer of the filters, is $\sim 1,600 \mathrm{scfm}$ per filter and 3 to $4 \mathrm{psig}$, respectively.

Shakedown activities included systematically modifying the blowtubes in order to provide the proper compressed air flow and pressure to the face of the clean-side of the filters. The blowtubes are 3 " in diameter and are located above the venturis which are, in turn, mounted on the face of the clean side of the filters. Figure 3-2 is a side view showing four of the filter/ venturi/ blowtube/ valve combinations. In addition, Figure 3-2 shows the locations of two ports on one of the venturis where pressure readings were collected. The system has 80 filters located in two sections which each section comprised of 10 rows of 4 filters (see Figure 3-1). Each blowtube has one opening/ nozzle located above the venture for a total of four nozzles on each blowtube. When cleaning the filters, one blowtube ( 4 of 80 filters) at a time is backpulsed. Controls for the cleaning cycle allow for varying the pulse time (time compressed air is introduced into the venturi) from $50 \mathrm{~ms}$ to $180 \mathrm{~ms}$, and 


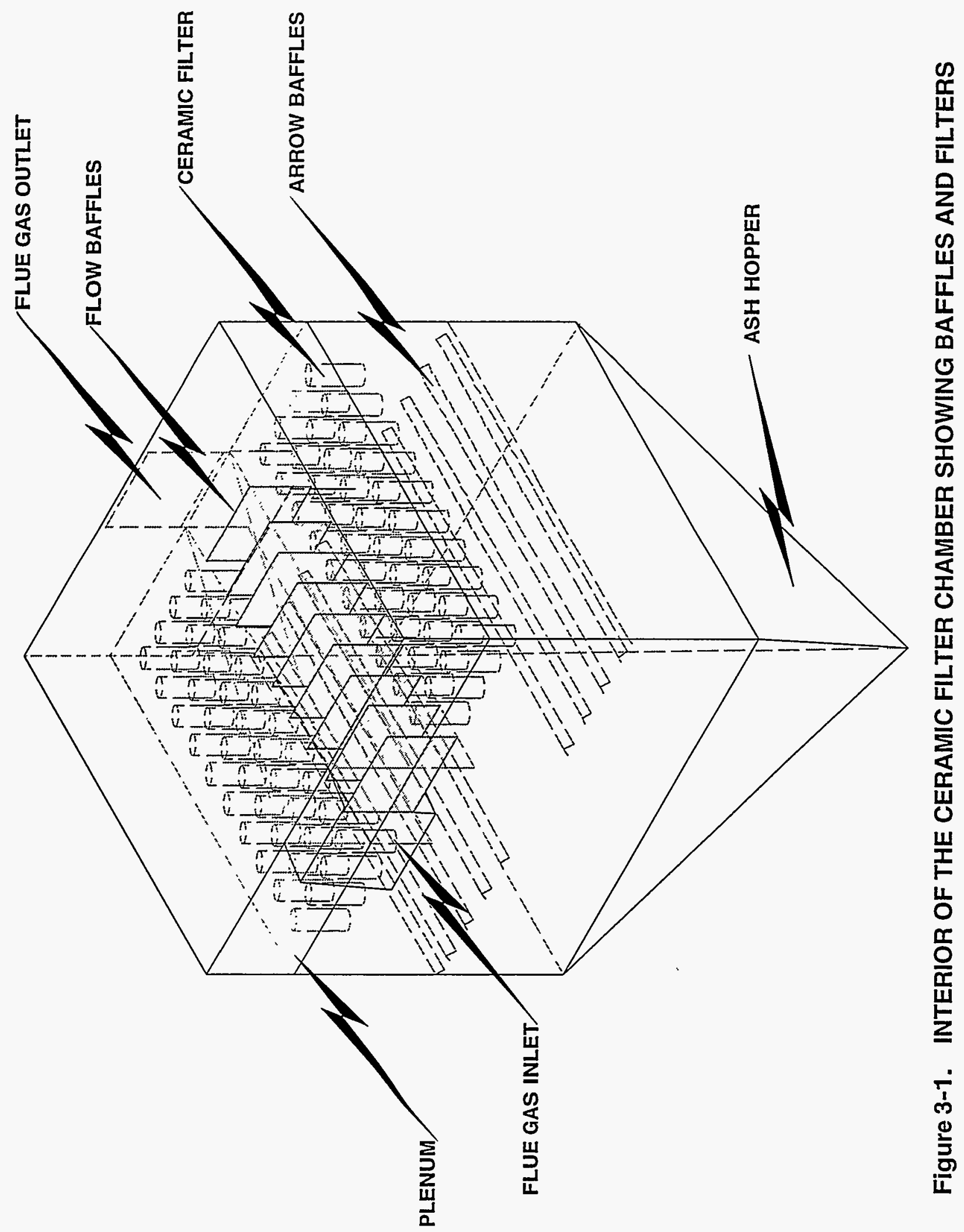




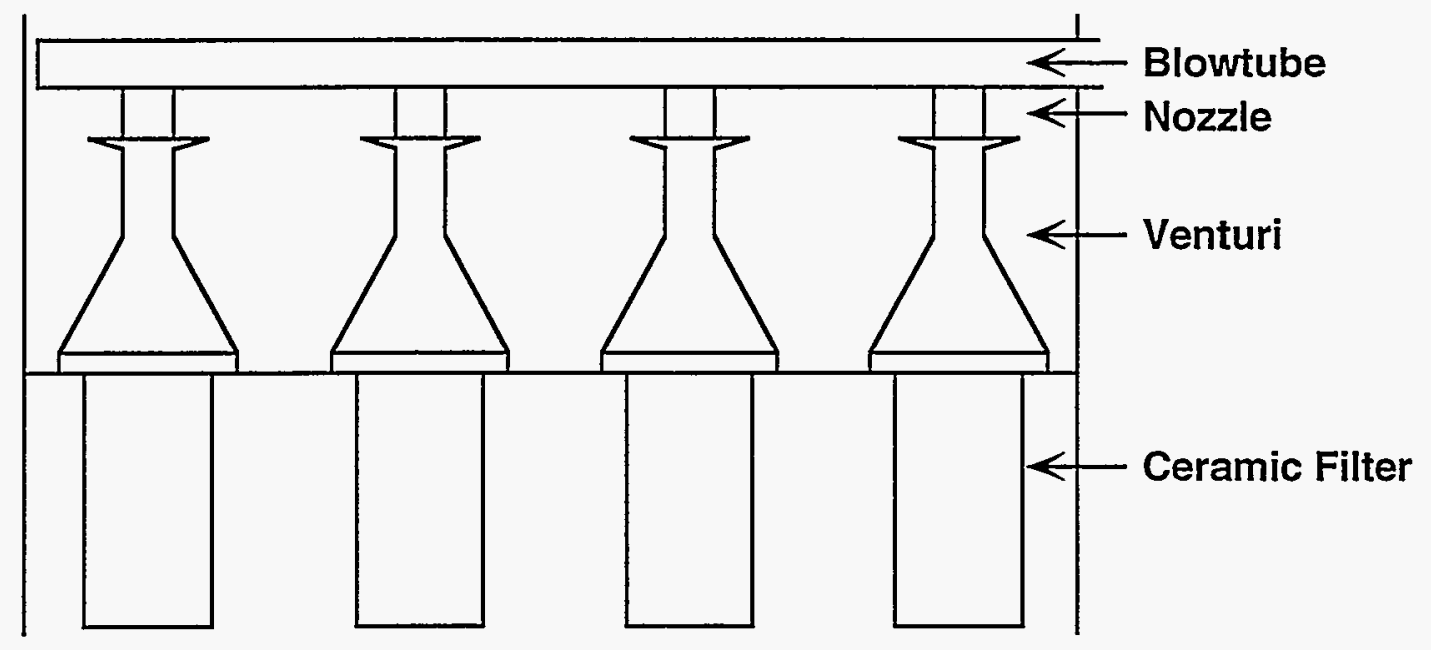

Figure 3-2. SIDE VIEW OF ONE ROW OF CERAMIC FILTERS WITH VENTURIS, BLOWTUBE, AND NOZZLES 
the cycle time (time between pulses from tube to the next) from rapid succession to $\sim 1.75$ minutes between pulses.

The blowtubes were originally installed with $1 / 2$ " holes for directing the nozzle of compressed air into the venturi. They resulted in only $\sim 1,070 \mathrm{cfm}$ of compressed air flow at a filter face pressure of $\sim 1$ psig. The diameter of the holes was increased from $1 / 2$ to $3 / 4$ to $13 / 16$ to 1 to $11 / 4$ " with the compressed air flow and filter face pressure measured at each hole diameter. The compressed air flow increased to $\sim 1,900 \mathrm{cfm}$ exiting the blowtube with a hole diameter of $11 / 4$ "; however, the peak filter face pressure was 1.6 psig with an 1 " hole and decreased to below 1.6" with the $11 / 4$ " hole. There was a concern that insufficient air was entering the venturi with the increased spray angle; therefore, an $11 / 4$ " nozzle was welded onto the blowtube with an increase in the filter face pressure to $\sim 1.7$ psig observed. The nozzle length was then increased to 3-4" which resulted in the air flow being directed into the throat of the venturi. The resulting face filter pressure was 4.2 to 4.6 psig. Consequently, nipples 1 1/4" in diameter and 3-4" long were welded over each of the holes in the blowtubes.

\subsubsection{Ceramic Filter Evaluation}

Evaluation of the system has started and includes $\sim 400$ hours of operation. Parameters that are either currently being monitored/ measured or will be measured include:

1) Pressure drop history of the ceramic filter chamber. This includes monitoring both the pressure drop across the chamber as a function of hours of firing coal as well as the pressure drop recovery (i.e., return to a baseline value). The pressure drop, when firing natural gas at 12 million (MM) Btu/h at $4 \% \mathrm{O}_{2}$ and $400 \mathrm{acfm}$ of transfer air, is measured prior to firing coal at the beginning of a day of operation (normal operation consists of either one or two 8-hour shifts of operation) and after coal feed has been terminated and purged from the coal feed lines;

2) Periodic checks on the filter face pressure and flow;

3) Stack particulate emissions (i.e., dust loadings) measured by EPA Method 5;

4) Ceramic filter chamber particulate collection efficiency (determined by EPA Method 5 dust loading measurements on the filter chamber inlet and outlet);

5) Ceramic filter chamber fine particulate (i.e., $P_{10}$ and $P M_{2.5}$ ) and condensable particulate matter (CPM) emissions measured by EPA Methods $201 \mathrm{~A}\left(\mathrm{PM}_{10}\right)$, modified 201A $\left(\mathrm{PM}_{2.5}\right)$, and 202 (CPM);

6) Ceramic filter chamber fine particulate collection efficiency;

7) Particle size distribution of the fine particulate collected at the ceramic filter chamber inlet and outlet; and 
8) Comparison of particulate emissions and collection efficiency of the ceramic filter chamber with the fabric filter baghouse.

Items \#1 through 4 were conducted during this reporting period and are reported herein. Item \#5 was started; however, the results are preliminary and are not reported. In addition, no testing was performed on Items \#6 through 8 during this reporting period. Items \#5 through 8 will be completed during the next reporting period.

\section{Ceramic Filter Pressure Drop History}

The pressure drop of the ceramic filter chamber was monitored as part of the system evaluation. This included monitoring both the pressure drop as a function of hours firing coal in addition to the pressure drop recovery (i.e., return to a baseline value) when firing natural gas. The pressure drop is recorded using a computerized data acquisition system (DAS) and by taking manual readings.

The typical operating procedure of the boiler is:

1) Preheat the boiler system while firing natural gas at a rate of $12 \mathrm{MM} \mathrm{Btu} / \mathrm{h}$ until the ceramic filter chamber outlet temperature is $\sim 300^{\circ} \mathrm{F}$;

2) Record the chamber pressure drop when the chamber inlet temperature is $\sim 340^{\circ} \mathrm{F}$ when firing natural gas at $12 \mathrm{MM} \mathrm{Btu} / \mathrm{h}$ at $4 \% \mathrm{O}_{2}$ and with a transfer air flow of $400 \mathrm{cfm}$;

3) Transition from natural gas to micronized coal by reducing the quantity of natural gas in increments while simultaneously increasing the micronized coal feed. The total firing rate is slowly increased from $12 \mathrm{MM} \mathrm{Btu/h}$ (when firing $100 \%$ natural gas) to $~ 16.5 \mathrm{MM} \mathrm{Btu} / \mathrm{h}$. When the firing ratio is $12.5 \mathrm{MM} \mathrm{Btu} / \mathrm{h}$ micronized coal and $4 \mathrm{MM} \mathrm{Btu/h}$ natural gas, the natural gas valve is closed. The coal feed is then increased until the desired firing rate, which is typically 15 $M M B t u / h$, is reached;

4) The system is allowed to stabilize then the DAS begins recording (data points are recorded every 30 seconds) and manual readings are taken every half hour. The boiler is typically operated 8 to 16 hours per day which results in 5 to 12 hours of steady-state operation;

5) Upon conclusion of testing, the coal feed is turned off, the coal feed line is purged of coal (by leaving the transfer fan on), and the natural gas rate is increased until the firing rate is $12 \mathrm{MM} \mathrm{Btu} / \mathrm{h}$. After the lines are purged, the ceramic filter chamber pressure drop is recorded at the $12 \mathrm{MM}$ Btu/h firing rate with $4 \% \mathrm{O}_{2}$ and a transfer air flow of $400 \mathrm{cfm}$; and 
6) A series of rapid filter cleanings (i.e., the time between pulses is set to the minimum value for a few minutes) is conducted prior to shutting the boiler down.

\section{Ceramic Filter Chamber Pressure Drop When Firing Coal}

Figure 3-3 is a plot of the ceramic filter chamber pressure drop as a function of firing coal from April 28, 1997 to October 2, 1997. The data points are the manual readings taken every half hour. Over this time period, approximately 420 hours of coalfired operation was obtained.

The data in Figure 3-3 exhibit four regions of performance. In the first region, from 0 to $\sim 100$ hours of coal-fired operation, the filters are being seasoned and the pressure drop increases from $\sim 3.5$ to between 6 and 7" W.C. (water column). The pressure drop then remains in the 6 to 7" W.C. range for the next $\sim 160$ hours (Run Hour 260) with a slight increasing trend (Region 2). At Run Hour 260, the pressure drop begins to increase more rapidly over the next 70 hours until it reaches $\sim 8$ " W.C. (Region 3 ). The pressure drop then unexplainably drops to slightly below 7" W.C. and fluctuates between 6.5 and 8" W.C. (Region 4).

The behavior of the ceramic filter system observed in the first two regions was as expected. The pressure drop was expected to increase as the filters came to steady state with respect to fly ash being deposited in the filters. Not all the fly ash that is captured will be removed from the filters during backpulsing.

The second region was one of relatively steady-state performance, with the pressure drop ranging from $\sim 6$ to 7" W.C. This observed ceramic filter pressure drop was less than the design pressure drop of 8 to $10^{\prime \prime}$ W.C. (for a flue gas flow of $\sim 8,150 \mathrm{acfm}$, which was the baghouse design flow) at $400^{\circ} \mathrm{F}$. However, the actual flue gas flow is $\sim 6,500$ to 7,000 acfm rather than 8,150 acfm; therefore, the lower pressure drop was expected.

Pressure drop readings that are significantly higher than those around them (e.g., at Run Hours 100 and 120) tend to be the result from sootblowing the convective chamber of the boiler. This is better observed in Figures 3-4 through 3-11 which are plots of the pressure drop as a function of firing coal for every 50 hours of operation showing the sootblowing events. The pressure drop significantly increases when the sootblower is operated because a large quantity of steam is introduced into the system and, to a lesser extent, ash deposits from the boiler are transported to the ceramic filter chamber.

The relatively rapid increase in pressure drop in Region 3 is unexplained at this time as is the decrease in pressure drop at Run Hour 330. The pressure drop exhibited a fairly wide range in Region 4 varying from $\sim 6.5$ to 8 " W.C. Additional operating time will be obtained during the next reporting period to see if the pressure drop has stabilized. 


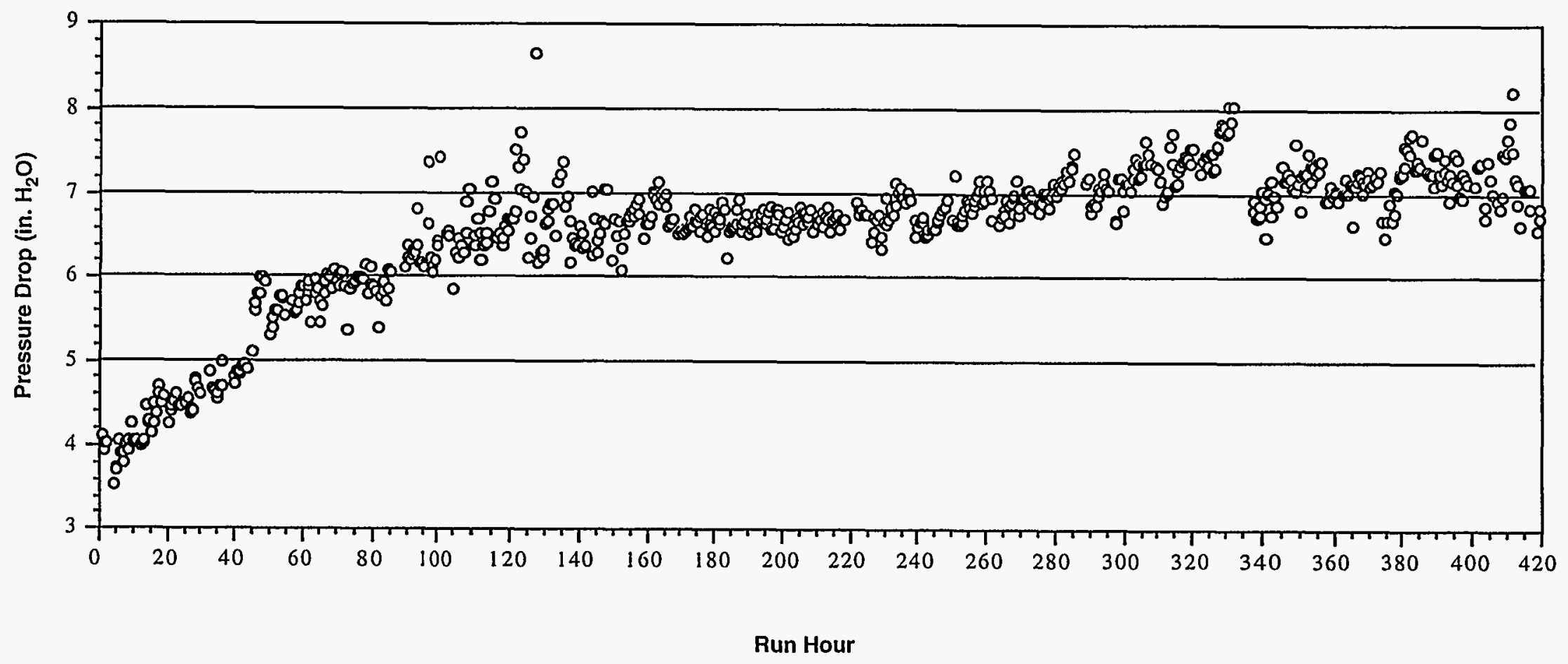

Figure 3-3. CERAMIC FILTER CHAMBER PRESSURE DROP AS A FUNCTION OF TIME FIRING COAL FROM APRIL 28, 1997 THROUGH OCTOBER 20, 1997 

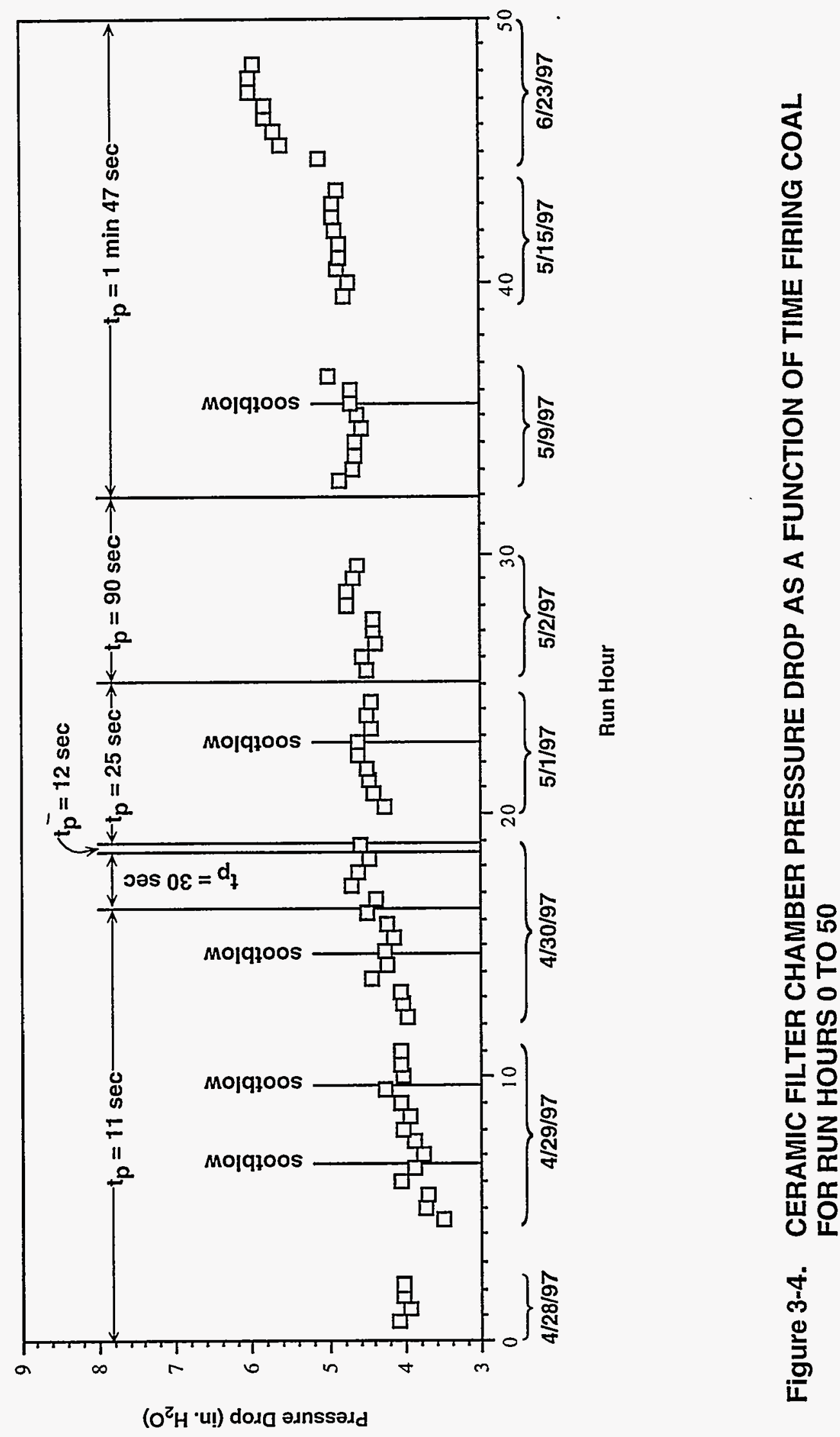


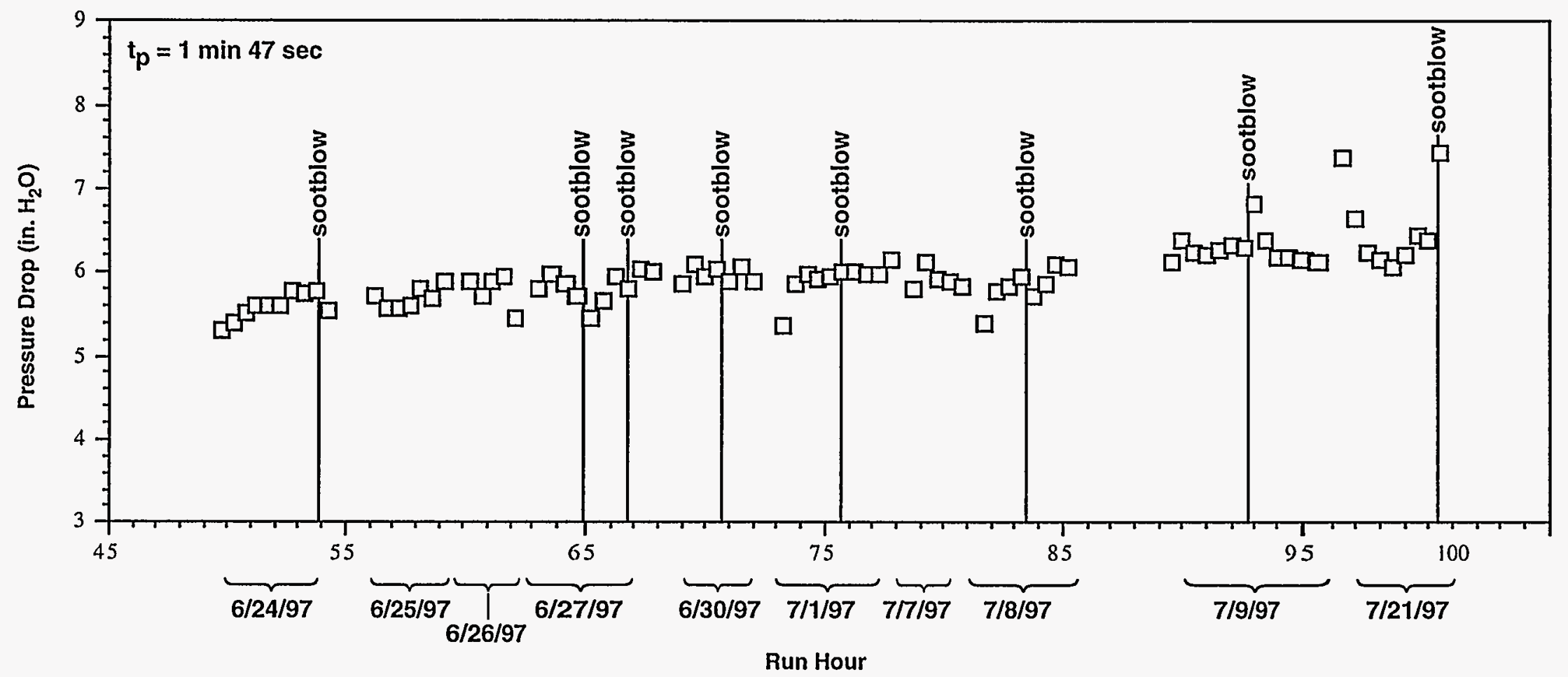

Figure 3-5. CERAMIC FILTER CHAMBER PRESSURE DROP AS A FUNCTION OF TIME FIRING COAL FOR RUN HOURS 50 TO 100 


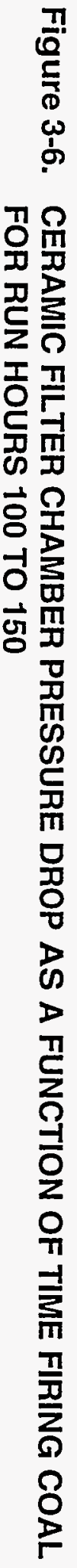

Pressure Drop (in. $\mathrm{H}_{2} \mathrm{O}$ )

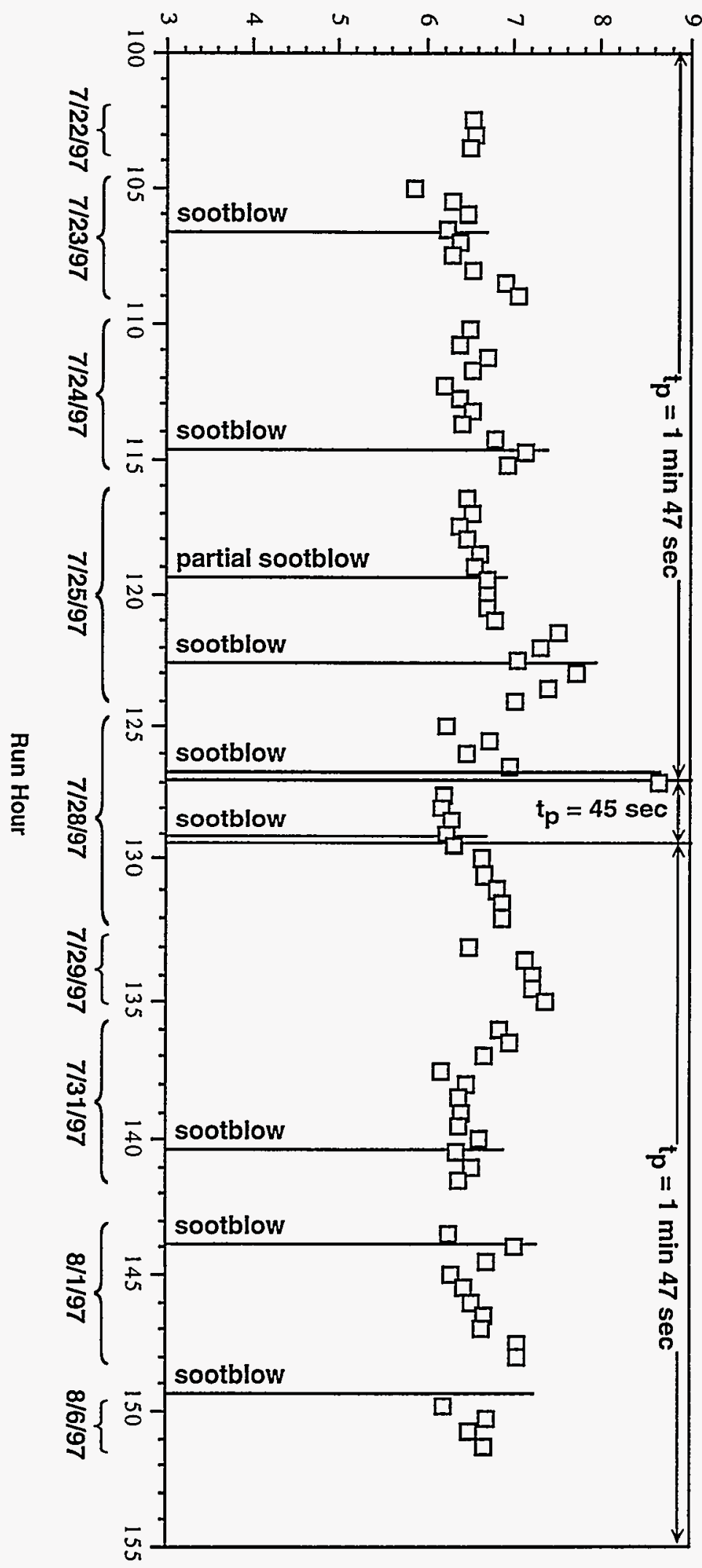



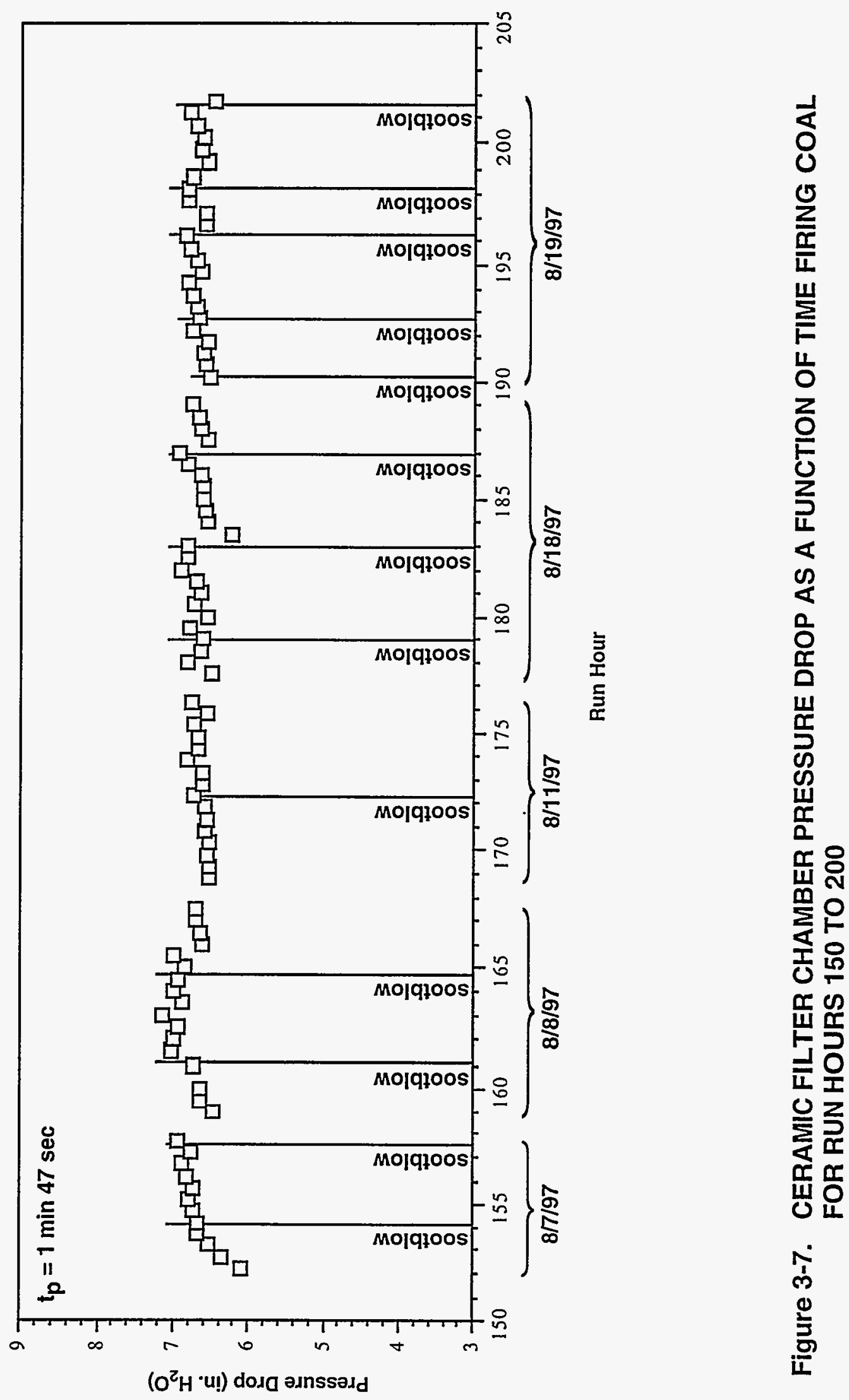


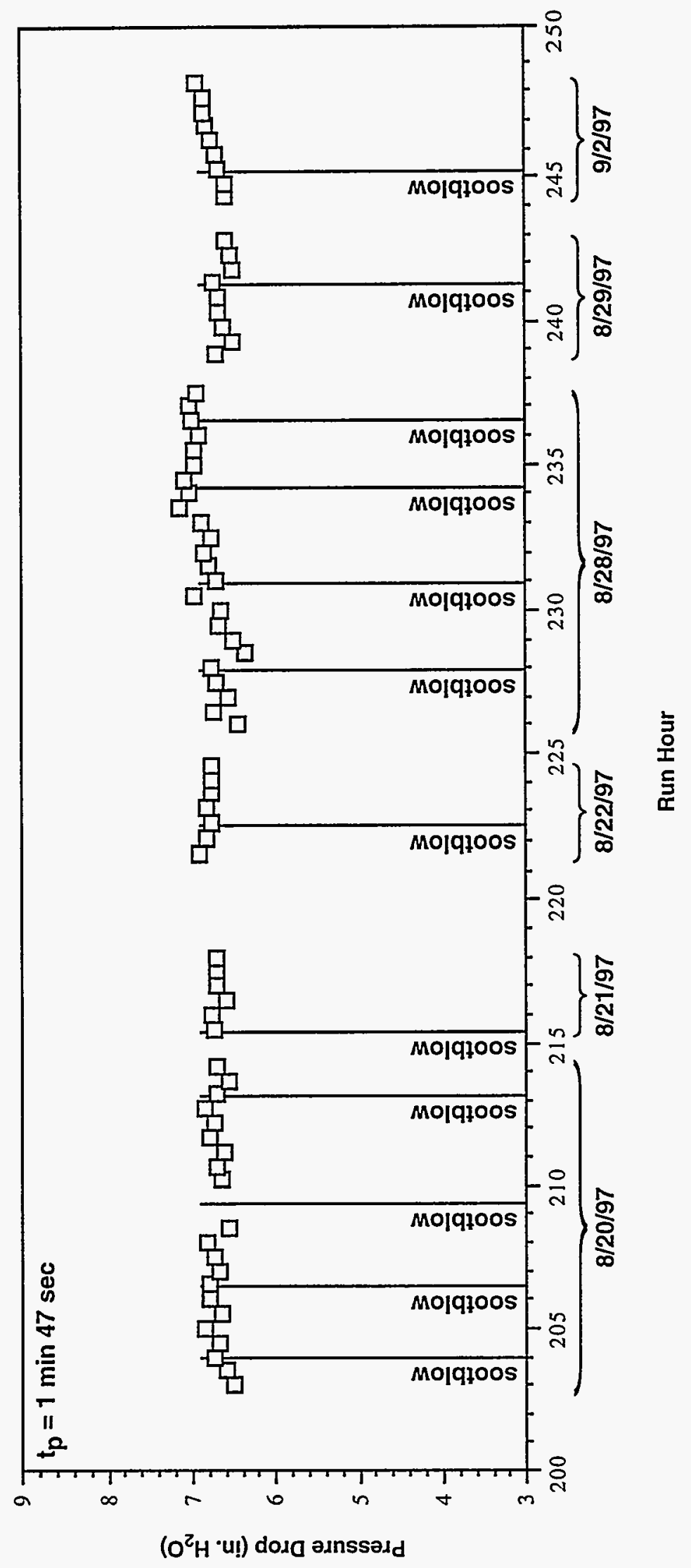

客

崩

ㅍ

$\underline{\Xi}$

亗

은

$\varangle$

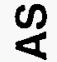

옹

山

$\frac{\Upsilon 1}{2}$

(

w

口

또 누

品

$\sum$ 안

조용

ง 요

똠

뜸

공

포오

윽

和

뚜

닌은

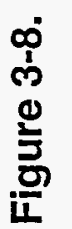



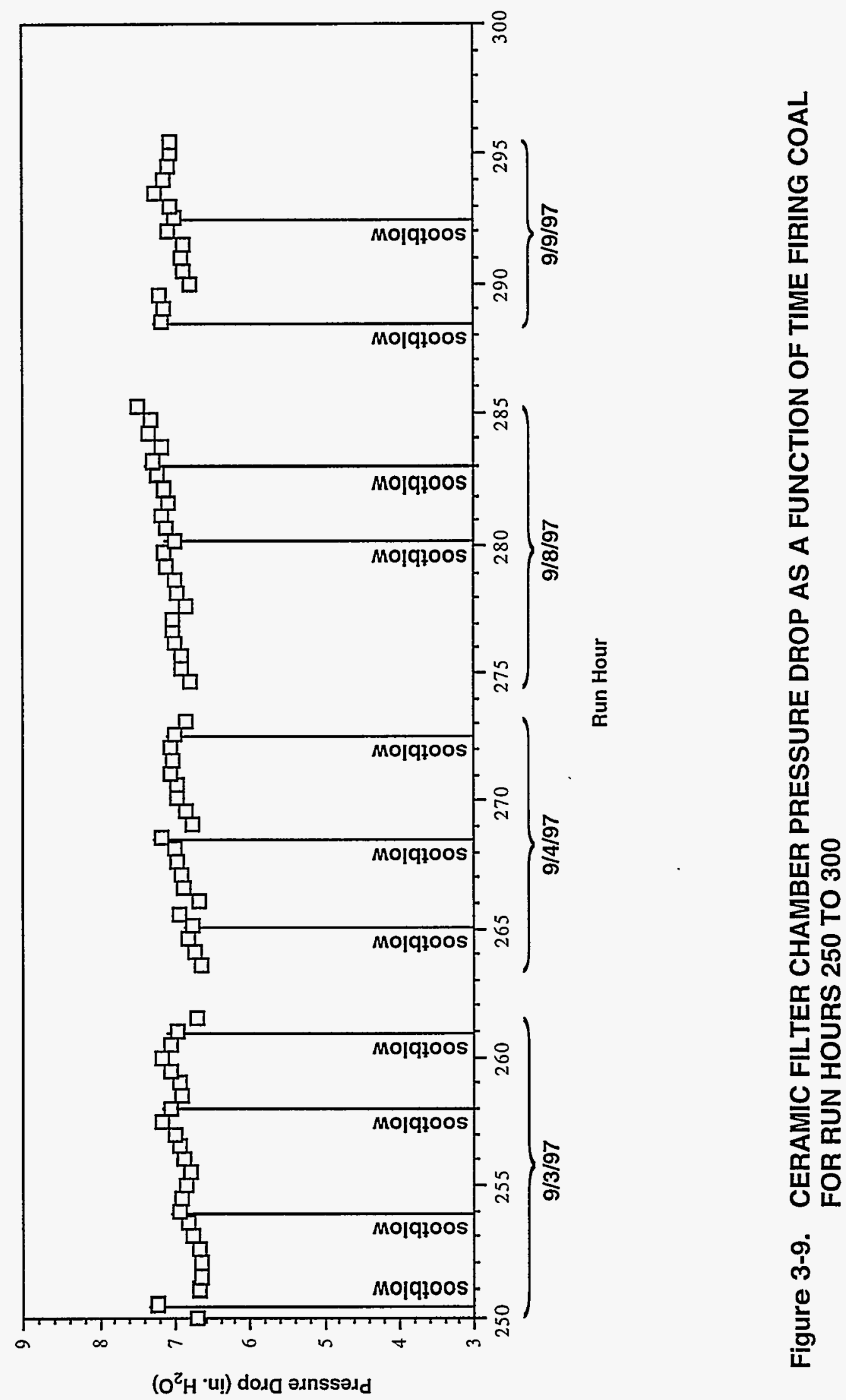


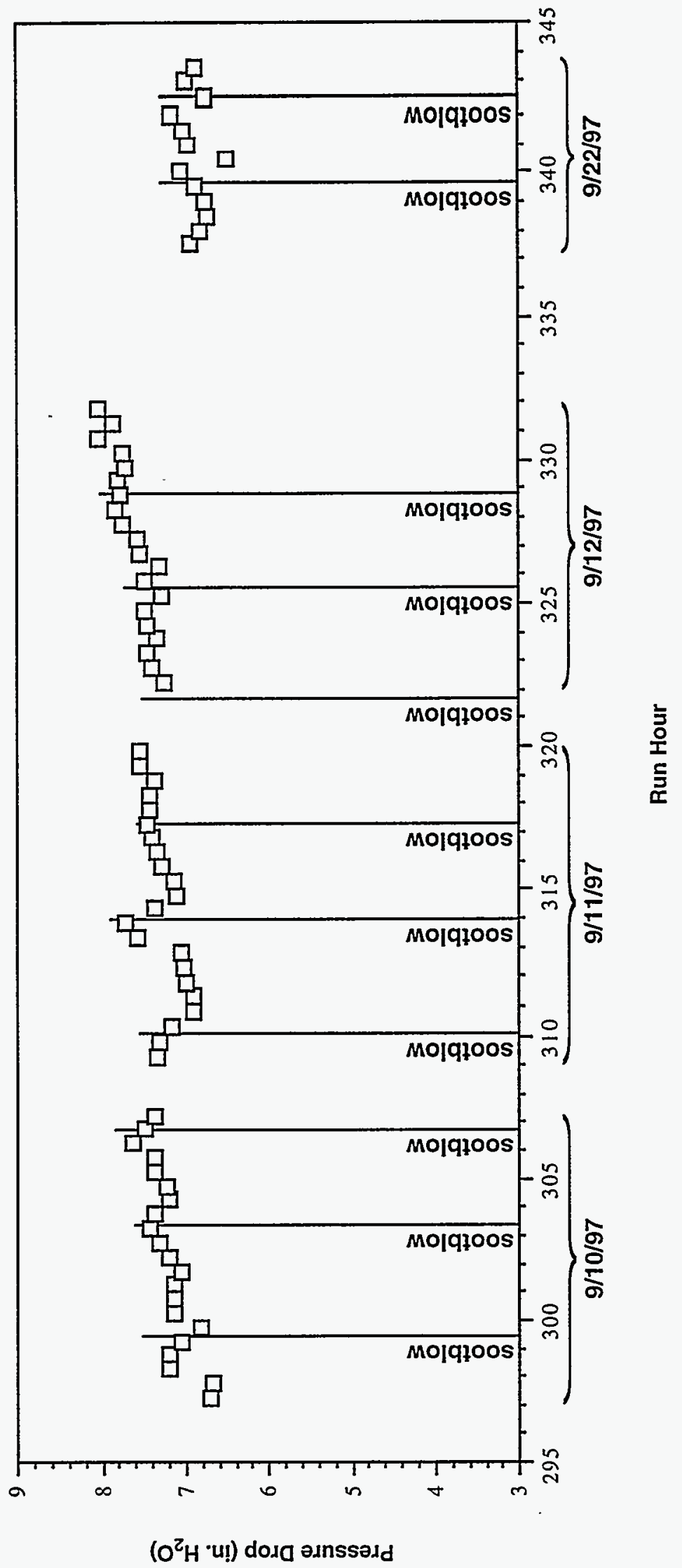

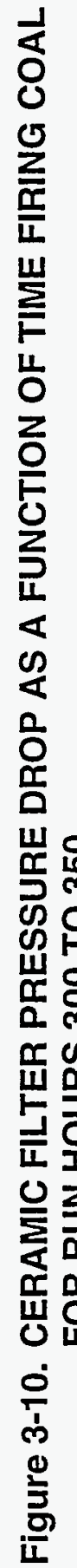



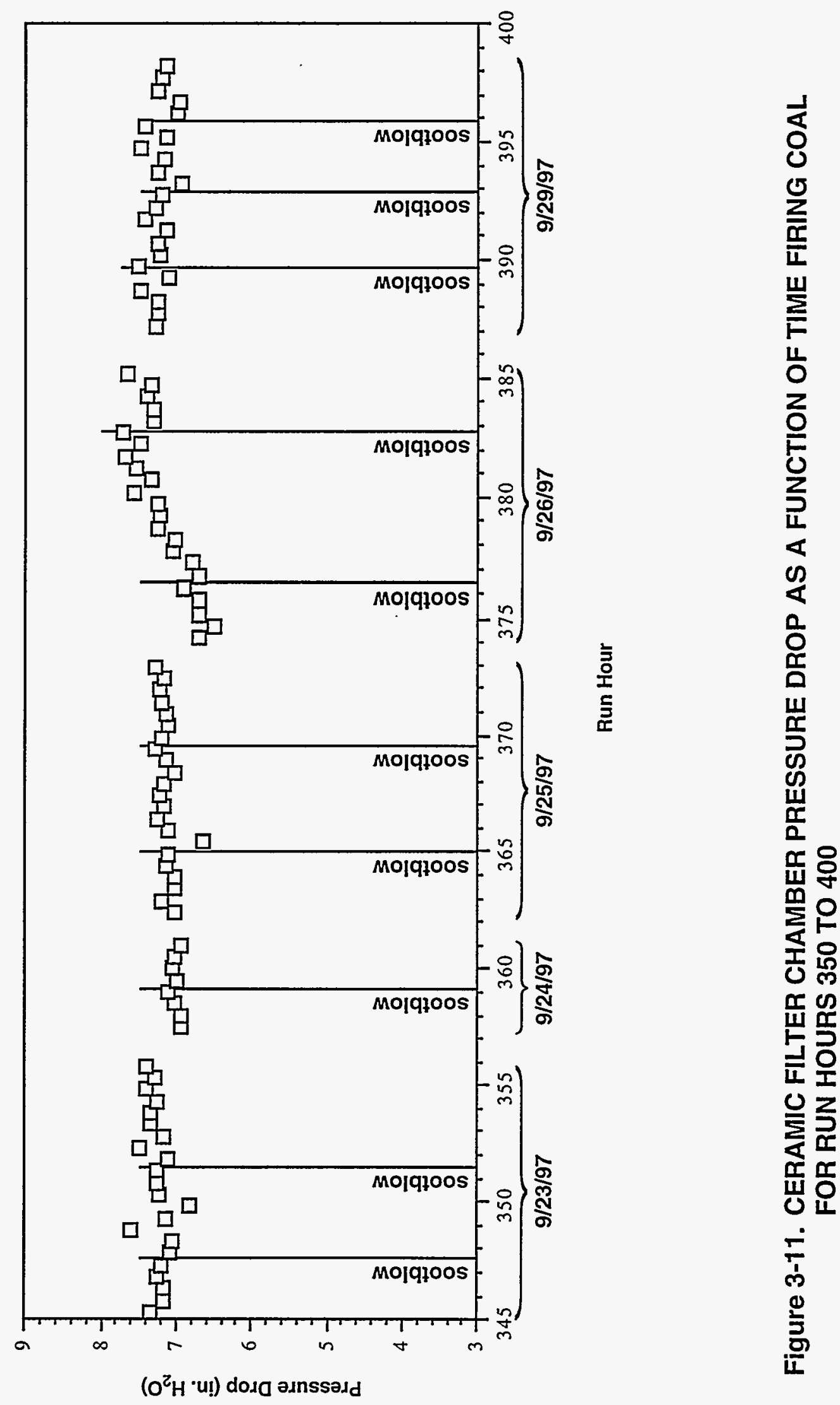


\section{Ceramic Filter Chamber Pressure Drop When Firing Natural Gas}

There was concern that fly ash may be building up in the filters when the pressure drop was observed to increase in Region 3. Tests were then conducted to determine if the pressure drop returned to a baseline value when firing natural gas. Table 3-1 lists the results from the pressure drop recovery tests. The pressure drop was recorded when preheating the system firing natural gas prior to firing micronized coal. The chamber pressure drop was recorded when the chamber inlet temperature reached $\sim 340^{\circ} \mathrm{F}$, when firing natural gas at $12 \mathrm{MM} \mathrm{Btu} / \mathrm{h}$ at $4 \% \mathrm{O}_{2}$, and with a transfer air flow of $400 \mathrm{cfm}$. Similarly, when testing was completed, the coal feed was turned off, the coal feed line was purged of coal (by leaving the transfer fan on), and the natural gas rate was increased until the firing rate reached $12 \mathrm{MM} \mathrm{Btu} / \mathrm{h}$. After the lines were purged, the ceramic filter chamber pressure drop was recorded at a firing rate of $12 \mathrm{MM} \mathrm{Btu} / \mathrm{h}$ with $4 \% \mathrm{O}_{2}$ and a transfer air flow of $400 \mathrm{cfm}$.

As can be seen from the tests conducted prior to firing coal (which correspond to run hours after Run Hour 332), the pressure drop is relatively constant and is between 5.8 and 6.0" W.C. This indicates that the filters appear to be cleaning with no appreciable material remaining in the filters. These tests will be continued during the next reporting period, along with tests measuring the pressure drop across the chamber with the induced and forced draft fans operating (prior to firing natural gas).

There was more variability observed during the tests conducted after coal was fired and the boiler was firing natural gas. This appears to be due to the range in flue gas temperatures after coal testing.

\section{Ceramic Filter Face Pressure and Compressed Air Flow When Backpulsing}

Periodic tests were conducted on the ceramic filter face pressure and compressed air flow when backpulsing to ensure that they were adequate for cleaning. These checks showed that the face pressure and air flows are within CeraMem Separations, Inc. recommended ranges.

\section{Stack Particulate Emissions and Ceramic Filter Collection Efficiency}

A series of EPA Method 5 particulate emissions tests were conducted to determine the dust loadings and collection efficiency of the ceramic filter. The preliminary results from the testing, which were conducted in July and September 1997, are summarized in Table 3-2. For comparison, Table 3-2 also contains the results from Method 5 testing that was performed on the fabric filter baghouse, when the site was commissioned in order to obtain an operating permit from the Pennsylvania Department of Environmental Protection.

The tests listed in Table 3-2 are those where reportable data were obtained. Additional activities in August included modifying the sampling locations for ease of 
Table 3-1. Ceramic Filter Chamber Pressure Drop and Inlet and Outlet Temperatures When Firing Natural Gas

\begin{tabular}{|c|c|c|c|c|c|c|}
\hline \multirow[b]{2}{*}{ Date } & \multicolumn{3}{|c|}{ Prior to Firing Coal } & \multicolumn{3}{|c|}{ After Firing Coal } \\
\hline & $\begin{array}{c}\Delta \mathbf{P} \\
\text { ("W.C.) }\end{array}$ & $\begin{array}{l}\mathbf{T}_{\text {inlet }} \\
\left({ }^{\circ} \mathbf{F}\right)\end{array}$ & $\begin{array}{l}\mathrm{T}_{\text {outlet }} \\
\left({ }^{\circ} \mathrm{F}\right)\end{array}$ & $\begin{array}{c}\Delta \mathbf{P} \\
\left(" \mathrm{~W} . \mathrm{C}_{.}\right)\end{array}$ & $\begin{array}{l}\mathrm{T}_{\text {inlet }} \\
\left({ }^{\circ} \mathrm{F}\right)\end{array}$ & $\begin{array}{l}\mathrm{T}_{\text {outlet }} \\
\left({ }^{\circ} \mathbf{F}\right)\end{array}$ \\
\hline 09/12/97 & N.M. ${ }^{a}$ & N.M. & N.M. & 7.3 & 379 & 366 \\
\hline 09/16/97 & 5.7 & 322 & 254 & N.M. & N.M. & N.M. \\
\hline $09 / 17 / 97$ & 5.8 & 345 & 290 & N.M. & N.M. & N.M. \\
\hline $09 / 24 / 97$ & 5.8 & N.R. ${ }^{b}$ & N.R. & 6.3 & 360 & N.R. \\
\hline $09 / 25 / 97$ & N.M. & N.M. & N.M. & 6.2 & 372 & 360 \\
\hline $09 / 26 / 97$ & $6.6^{c}$ & 342 & 300 & 5.6 & 358 & 349 \\
\hline 09/29/97 & 5.9 & 343 & 267 & N.M. & N.M. & N.M. \\
\hline 09/30/97 & 5.9 & 337 & 270 & 5.9 & 342 & 320 \\
\hline $10 / 01 / 97$ & 6.0 & 338 & 275 & 6.4 & 361 & 348 \\
\hline $10 / 02 / 97$ & 5.9 & 335 & 273 & 6.3 & 368 & 353 \\
\hline
\end{tabular}

${ }^{a}$ Not measured

${ }^{b}$ Not reported

${ }^{c}$ Measured shortly after sootblowing convective section 
Table 3-2. Preliminary Summary of EPA Method 5 Testing on the Ceramic Filter Chamber When Firing Middle Kittanning Seam Micronized Coal

\begin{tabular}{|c|c|c|c|c|c|}
\hline \multirow[b]{2}{*}{ Date } & \multicolumn{2}{|c|}{ Inlet } & \multicolumn{2}{|c|}{ Outlet } & \multirow{2}{*}{$\begin{array}{c}\text { Collection } \\
\text { Efficiency } \\
(\%)\end{array}$} \\
\hline & $\begin{array}{l}\text { (grains/ } \\
\text { dscf }^{\mathrm{a}} \text { ) }\end{array}$ & $\begin{array}{l}\text { pounds/ } \\
\text { MM Btu }\end{array}$ & $\begin{array}{l}\text { (grains/ } \\
\text { dscf) }\end{array}$ & $\begin{array}{l}\text { pounds/ } \\
\text { MM Btu }\end{array}$ & \\
\hline $01 / 17 / 92^{6}$ & 4.728 & 7.660 & 0.015 & 0.0247 & 99.68 \\
\hline $07 / 09 / 97$ & 2.2791 & 4.4574 & & & \\
\hline $07 / 21 / 97$ & & & 0.0056 & 0.0110 & $99.75^{\mathrm{c}}$ \\
\hline $07 / 24 / 97$ & 2.4609 & 4.6727 & & & \\
\hline $09 / 03 / 97^{d}$ & 1.6707 & 3.4405 & & & \\
\hline $09 / 08 / 97$ & 1.6654 & 3.5274 & 0.0028 & 0.0063 & 99.83 \\
\hline $09 / 12 / 97$ & 1.2621 & 2.8657 & 0.0025 & 0.0054 & 99.80 \\
\hline $09 / 22 / 97$ & & & 0.0024 & 0.0051 & $99.86^{\mathrm{e}}$ \\
\hline $09 / 23 / 97$ & 1.7068 & 3.5947 & & & \\
\hline
\end{tabular}

a Grains per dry standard cubic foot of flue gas

b These tests were performed on the fabric filter baghouse when firing Brookville seam coal-water slurry fuel for the baghouse performance test.

c Collection efficiency was determined using inlet results from 07/09/97. Due to operational problems encountered in July, both inlet and outlet sampling could not be conducted on the same day.

' Outlet sample was collected but is not reported because seal on the sampling train was broken. A new coal shipment was received in August which resulted in lower inlet dust loadings for September 1997.

e Collection efficiency was determined using inlet results from 09/23/97. The boiler shut down during the inlet sampling on 09/22/97 because of a loss in coal feed. The inlet sample was collected the next day. 
sampling, and conducting both Methods 5 and 201A $\left(\mathrm{PM}_{10}\right)$ sampling. However, because of problems encountered during sampling (i.e., inadvertent sootblowing, broken nozzles, broken seals on the sampling train, etc.) the August tests are not reported. In addition, the ceramic filter chamber was opened and inspected in August to see if there was any leakage from the dirty side to the clean side of the chamber. Tests were conducted injecting lime and a fluorescent material to see if there was any leakage at welds, filter gasket seals, or the filters themselves.

The results listed in Table 3-2 are considered preliminary because coal samples are currently being analyzed for calorific value. Coal samples are collected as the tests are conducted and are then analyzed for their composition and heating value. The boiler was fired at $\sim 15 \mathrm{MM}$ Btu/h for each test; however, the exact firing rate, which does not vary much, will be determined after the coals are analyzed and this rate will be used for determining the emissions rate reported as pounds per million Btu. Past operating experience shows that the heating value remains fairly constant for each shipment of coal.

The collection efficiency of the ceramic filters ranged from 99.75 to $99.86 \%$ which tended to be better than that of the fabric filters. The tests conducted on the baghouse were done, when the system was new, as part of a performance test to obtain an operating permit when firing Brookville seam coal-water slurry fuel. Additional tests will be conducted during the next reporting period to determine if the collection efficiency of the baghouse has changed after several years of operation and the installation of bags of different composition.

Although the collection efficiency of the ceramic filters is good, it is not as high as the $99.99 \%$ that CeraMem Separations, Inc. reports to be achievable. In addition to CeraMem Separations, Inc., individuals from several organizations (i.e., Stanley Miller Energy and Environmental Research Corporation who conducted bench-scale collection tests, and John Vaklyes and Tony Andriola from Fisher-Klosterman Inc. who market collection systems using the filters) claim that the collection efficiency should be higher than that currently achieved. Consequently, the ceramic filter chamber will be opened, the clean side of the plenum checked again for leakage and silicone added on every welded joint and around the filter gaskets before the next series of tests.

Due to boiler operational problems (coal accumulating on the booster fan blades) encountered in July, both inlet and outlet samples could not be collected on the same day. The boiler could only be fired on micronized coal for approximately six hours each day. After the problem was remedied, the boiler could be operated for an unlimited amount of time; therefore, both inlet and outlet tests were conducted in September unless problems with sampling were encountered. 
Middle Kittanning seam coal was used for the Method 5 testing firing micronized coal. A new shipment of coal was received in August 1997 which had a similar ash content $(\sim 5 \mathrm{wt} . \%)$ but resulted in a lower inlet dust loading. Another observation noted was that the inlet dust loadings tended to show an inverse relationship with combustion efficiency, that is, the lower dust loadings were the result of higher combustion efficiency. Combustion efficiencies are affected by the cleanliness of the boiler. They tend to be lower after the ash has been cleaned out of the boiler and will increase as ash deposition and accumulation occurs.

Table 3-3 is a comparison between the emissions results of the fabric filter baghouse and the ceramic filter chamber. In addition, the emissions results of the ceramic filter chamber are compared to the New Source Performance Standards (NSPS) and DOE's LEBS (Low Emissions Boiler System) and HIPPS (High Performance Power Systems) targets. As previously stated, the performance of the ceramic filter chamber is better than the fabric filter baghouse. In addition, the ceramic filter chamber emissions obtained to date meet the NSPS and LEBS target. One objective of the testing, during the next reporting period, is to meet the HIPPS target after ensuring there are no leaks in the system prior to performing additional Method 5 sampling tests.

\subsection{Subtask 1.4 Conduct $\mathrm{NO}_{\mathbf{x}}$ Emissions Study}

Subtask 1.4 is completed.

\subsection{Subtask 1.5 Conduct VOC Study}

A majority of the 190 species listed in the Clean Air Act Amendments of 1990, including polycyclic aromatic hydrocarbons (PAHs), can be collected by what is generically termed a Modified Method 5 (MM5) sampling train. The train is used to isokinetically collect samples at desired locations in flue gas streams. The collected flue gas stream sample can be separated into solid, condensed liquid and gaseous phases (for PAH determinations, the gaseous phase is not retained or analyzed.). The PAHs of interest are extracted from the collected sample, concentrated, then separated and quantified by gas chromatography/mass spectrometry (GC/MS) techniques. Samples have been collected from Penn State's research boiler and down-fired combustor (DFC).

\section{Test Matrix}

The DFC is a 500,000 Btu/h pilot-scale combustor. The first series of tests was conducted to determine the effect of firing rate and excess air on PAH formation. A Middle Kittanning seam coal was pulverized to $80 \%$ passing $75 \mu \mathrm{m}$ (commonly referred to as a pulverized coal, or "PC" grind). The coal was fed into the combustor at two rates: 315,000 Btu/h (designated "low fire") and 425,000 Btu/h (designated "high fire"). The combustion air was fed into the combustor at two rates and monitored as the oxygen concentration in 
Table 3-3. Comparison of Ceramic Filter Chamber and Fabric Filter Baghouse Particulate Emissions

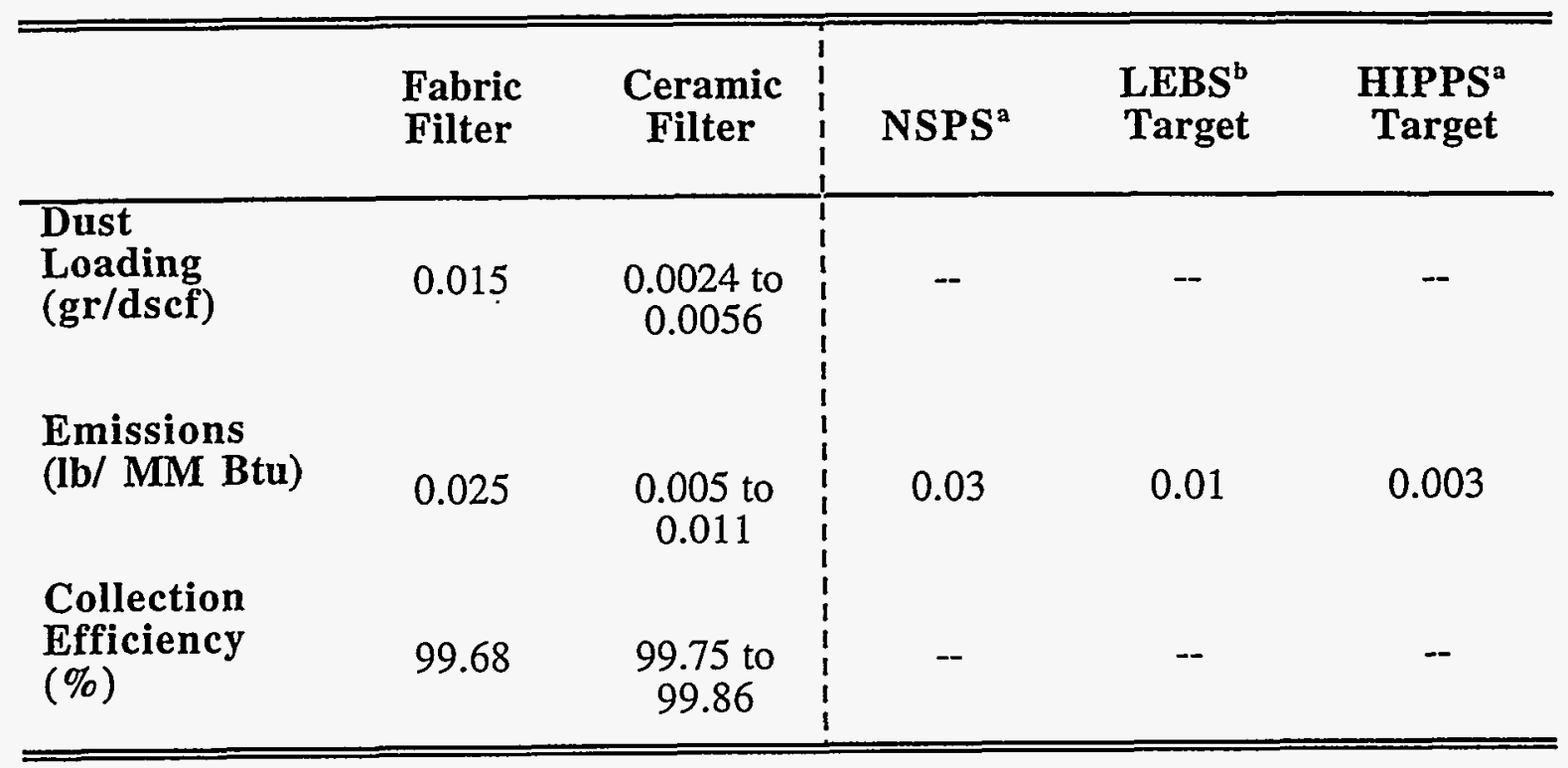

${ }^{a}$ New Source Performance Standards

${ }^{b}$ Low Emssions Boiler System

${ }^{c}$ High Performance Power System 
the flue gas stream. The excess oxygen was held at either 3\% (designated "low air") or 5.5\% (designated "high air").

The second series of tests investigated the effect of fuel on PAH formation. All fuels in this series of tests were burned at low fire, high air conditions. A Freeport seam uncleaned (As Received; A.R.) and cleaned coal were prepared as PC and burned in the DFC. Additionally, the Middle Kittanning seam coal was retested at these conditions, but with a different temperature profile in the combustor than the earlier test. Finally, the Middle Kittanning seam coal was tested as a CWM in the DFC.

A third series of tests was conducted to see the effect of combustor type on PAH formation. The research boiler is a $2 \mathrm{MM} \mathrm{Btu/h} A$-frame watertube package boiler. The Middle Kittanning seam coal was tested as both PC and CWM in the research boiler.

A summary of the testing that was conducted is:

\begin{tabular}{ccccc}
$\begin{array}{c}\text { Furnace } \\
\text { Type }\end{array}$ & Coal Seam & Fuel Form & $\begin{array}{c}\text { Coal Rate } \\
(\mathbf{B t u} / \mathbf{h})\end{array}$ & $\begin{array}{c}\text { Air Rate } \\
\left(\mathbf{\%} \mathbf{O}_{\mathbf{2}}\right)\end{array}$ \\
\hline DFC & Mid. Kittanning & PC & 425,000 & 5.5 \\
DFC & Mid. Kittanning & PC & 425,000 & 3.0 \\
DFC & Mid. Kittanning & PC & 325,000 & 5.5 \\
DFC & Mid. Kittanning & PC & 315,000 & 3.0 \\
DFC & Freeport (A.R.) & PC & 315,000 & 5.5 \\
DFC & Freeport (A.R.) & PC & 315,000 & 5.5 \\
DFC & Freeport Clean & PC & 315,000 & 5.5 \\
DFC & Freeport Clean & PC & 315,000 & 5.5 \\
DFC & Mid. Kittanning & PC & 315,000 & 5.5 \\
DFC & Mid. Kittanning & CWM & 315,000 & 5.5 \\
DFC & Mid. Kittanning & CWM & 315,000 & 5.5 \\
Research Boiler & Mid. Kittanning & PC & $1,600,000$ & 5.0 \\
Research Boiler & Mid. Kittanning & PC & $1,600,000$ & 5.0 \\
Research Boiler & Mid. Kittanning & CWM & $1,600,000$ & 5.0 \\
Research Boiler & Mid. Kittanning & CWM & $1,600,000$ & 5.0
\end{tabular}

Approximately 250 gallons of a highly loaded CWM was prepared from a Middle Kittanning feedstock for the PAH testing and trace element testing (which is discussed in Section 3.6). The CWM was produced by wet ball milling a nominal $-1 / 4$ inch feed in a 2 $\mathrm{x} 4 \mathrm{ft}$ ball mill using a $0.8 \mathrm{wt} . \%$ A-23M (active solids basis) as the dispersant and grinding at a $65 \mathrm{wt} . \%$ solids target. The ball mill discharge was diluted to $61 \mathrm{wt} . \%$ and then pumped to an Union Process 15-S Attritor Mill where the CWM was ground to minus 100 mesh. The CWM was discharged and then thoroughly mixed with $0.04 \mathrm{wt}$.\% Flocon $4800 \mathrm{C}$ stabilizer in a ribbon mixer. The ribbon mixer discharge was then pumped to a 250 gallon baffled storage tank where it was agitated until its use. 


\section{Presampling Considerations}

Prior to any sampling, both the research boiler and the DFC underwent retrofitting in order to meet the specifications for sampling and pitot tube ports as described in EPA Method 1. A modular sampling train meeting all of the requirements of EPA Methods 5 and 0010 was purchased from Clean Air Engineering. EPA Methods 1 through 4 were utilized to determine various parameters needed for isokinetic sampling of both units. EPA Method $8270-\mathrm{C}$ was selected as the analytical method that would be used in determining the concentrations of PAHs in the collected samples. Extraction of PAHs from the collected particulate matter and the XAD-2 polymeric resin fractions would be done by EPA Method 3540-C, Soxhlet Extraction. Extraction of PAHs from the collected liquid fraction would be done by EPA Method 3510-C, Separatory Funnel Liquid-Liquid Extraction. Sample cleanup would be accomplished by EPA Method 3630-C, Silica Gel Cleanup. All ancillary materials pertinent to these methods were purchased prior to sampling.

\section{The EPA Method 5 Sampling Train}

The EPA Method 5 sampling train is designed to isokinetically sample a flue gas stream. A portion of the gas stream is withdrawn from the duct through a heated probe where the particulate matter is filtered out of the stream. The remaining portion of the gas stream is passed through a condenser, a module containing the polymeric resin, and a series of glass impingers immersed in ice water where the remaining condensable species are collected.

Specifically, the sampling train contains the following components. They are listed from the most upstream component to the most downstream component.

A buttonhook borosilicate glass nozzle is located at the end of a sampling probe. The nozzle opening is placed into the flue gas stream facing upstream with pitch and yaw angles of $0^{\circ}$. The inside diameter of the nozzle is precisely known, as its size affects the sampling rate.

The nozzle is connected to a borosilicate probe. The probe is long enough to completely traverse the duct or stack of interest. The probe is encased in a stainless steel heated jacket. While sampling, the probe is maintained at $250^{\circ} \mathrm{F}$ by a temperature controller. The nozzle is connected to the probe by a Teflon union.

The probe is connected to a glass filter assembly located within a heated oven. The filter assembly is also maintained at $250^{\circ} \mathrm{F}$. A filtering media was selected to retain particles larger than $0.2 \mu \mathrm{m}$.

Gases exiting the filter assembly are passed through a water-cooled glass condenser to condense PAHs that may be in the vapor phase to the liquid phase. This condensate and 
remaining gas phase components are passed over the water-cooled porous polymeric resin contained in a glass module. Many PAHs are adsorbed onto this resin.

Gases and condensed liquids exit the glass resin module into a chilled condensate knockout trap. This trap is similar in design to an empty impinger. The PAHs not retained on the resin are collected in this knockout impinger.

The next 3 downstream chilled impingers are used to collect additional water condensate. The final impinger contains indicating-type silica gel to protect the pump from unwanted moisture. The temperature of the gas stream exiting this final impinger is maintained at or below $68^{\circ} \mathrm{F}$. All glass ball-and-socket connections are clamped and made airtight with Teflon O-rings.

The gases are passed through an air tight pump, dry gas meter, across a manometer, (gas samples may be collected at this point if desired), and vented. These devices, along with thermocouple readouts, temperature controllers, manometers, valves, timer and other equipment are contained in a metering console.

Operation of the MM5 Sampling Train

Prior to sampling, data sheets must be prepared, stack access ports must be cleaned, and leak checks must be performed on the sampling system and the pitot system. Using the data generated by EPA Methods 1 through 4, the train is isokinetically operated at the designated traverse points for predetermined durations to ensure EPA sample collection requirements. Proper temperatures and flow rates must be maintained. Leak checks are also performed at the conclusion of the sampling run.

\section{Sample Recovery and Preparation for Analysis}

The collected sample is separated into six parts. The subsamples contain materials collected from these particular sections of the sampling train. The first subsample contains the filter paper, filtered solids, and other solids removed from the filter-holder gasket. The second subsample contains recovered materials from the nozzle to the front half of the filter holder. The third subsample contains recovered materials from the resin module. The fourth subsample contains recovered materials from the condensate knockout trap. The fifth subsample contains recovered materials from the back half of the filter paper assembly and the first wet impinger. The sixth and final subsample contains recovered materials from silica gel-filled impinger. These six samples are processed and combined into three sample extracts for analysis. The three final sample extracts include materials extracted from the particulate matter filter and front half rinse; the condensate and condensate rinse; and the sorbent resin, condenser and back half rinse.

The first of the three sample extracts is generated using the following procedure. The recovered particulate matter from the front half rinse, recovered particulate matter from 
the filter and the filter itself are spiked with a known amount of a surrogate spiking solution transferred into a glass Soxhlet extraction thimble. (The surrogate compounds are compounds chemically similar to the analytes of interest, but not expected to be contained in the extract. The surrogate compounds are utilized to monitor unusual matrix effects or sample processing errors during the extraction and recovery process.) The glass thimble is placed into a Soxhlet extractor and connected to a round bottom flask containing approximately 10 clean Teflon boiling chips and enough methylene chloride to maintain extraction cycling. A bulb type condenser is connected atop the extractor. A heating mantle is placed under the flask and adjusted to cycle the extractor about once every thirty minutes or less for a total of approximately 18 hours.

The front half rinse is quantitatively transferred to a separatory funnel, and serially extracted three times with methylene chloride. The $\mathrm{pH}$ of the rinse is then adjusted to at least 11 with sodium hydroxide and serially extracted three more times. The $\mathrm{pH}$ is then adjusted to below 2 using sulfuric acid and serially extracted three additional times. This extract is combined with the Soxhlet extracted material. A Kuderna-Danish (K-D) concentrator is assembled by attaching a $10 \mathrm{ml}$ concentrator tube with Teflon ${ }^{(1)}$ boiling chips to a $500 \mathrm{ml}$ evaporatory flask. The extracts are passed through a sodium sulfate filter to remove any residual water and transferred into the concentrator. A prewet three-ball macro Snyder column is placed atop the concentrator. The concentrator assembly is placed into a hot water bath and concentrated to 6-8 $\mathrm{ml}$ within 30 minutes. The apparatus is allowed to cool. The three-ball macro column and evaporatory flask are removed and replaced with a two-ball micro Snyder column and the extraction is further concentrated to approximately $4 \mathrm{ml}$. The extract is then quantitatively transferred to a vial, diluted to a final volume of $5 \mathrm{ml}$, and stored at or below $4^{\circ} \mathrm{C}$ until analyzed.

The second of the three sample extracts is generated using the following procedure. The condensate and condensate rinse samples are combined and transferred to a separatory funnel, spiked, and serially extracted with methylene chloride exactly as is done with the front half rinse.

The third of the three sample extracts is generated using the following procedure. The porous polymeric resin is transferred to a glass extraction thimble, spiked and processed identically as the particulate matter sample.

The condensate and resin extracts are combined, residual water is removed, and then concentrated as described above. Blank samples are extracted concurrently with the collected samples. All extract samples are spiked with internal standards just prior to analysis. 


\section{Gas Chromatography/Mass Spectrometry System Evaluation}

A Gas Chromatograph/Mass Spectrometer (GC/MS) system is used for extract analysis. The system must be temperature programmable suitable for splitless injection. A fused-silica capillary column capable of PAHs separation is required. Other specifications for the GC/MS system including GC/MS interface, data acquisition system and other ancillary equipment is described in EPA Method 8270.

The GC/MS system must be properly hardware-tuned. Background subtraction should be designed only to eliminate column bleed or instrument background ions. GC column performance must be evaluated and injection port inertness must be confirmed. Calibration standards are analyzed and their response factors are calculated and evaluated. A system performance check using approved System Performance Check Compounds is performed and the results are evaluated. The percent relative standard deviation of the compounds are calculated as is the linearity of the calibration curve. If system tuning, calibration check, performance check, internal standard response and retention time data meet minimum method requirements, analysis of the extracts can begin.

\section{GC Analysis}

Prior to GC/MS analysis, $1 \mu \mathrm{l}$ aliquot of the samples are analyzed on a Perkin Elmer $8500 \mathrm{GC}$ system. The system is equipped with a J\&W Scientific DB-5 capillary column. This screening procedure will check the concentration of the analytes and determine if dilution or further concentration of the samples is necessary. GC screening is underway.

\section{GC/MS Analysis}

Finally, a spiked $1 \mu \mathrm{l}$ aliquot of concentrated extract is injected into the GC/MS system. The species are separated by the gas chromatograph and analyzed by the mass spectrometer. Analysis is being conducted currently.

\section{Data Interpretation}

Data interpretation will be performed during the next reporting period

\subsection{Subtask 1.6 Conduct Trace Element Study}

The objective of Subtask 1.6 is to characterize trace element emissions from coalfired industrial boilers. Activities that were conducted during this reporting period included finalizing the sampling protocol and analytical methods, setting up a 'clean' laboratory for assembling sample trains and recovering the samples, training personnel in sampling and recovery techniques, and performing pilot-scale tests.

Pilot-scale tests were conducted firing pulverized coal and coal-water mixtures (CWMs) in Penn State's down-fired combustor (300,000 Btu/h) and research boiler (1.5 million Btu/h) while sampling the flue gas for trace element emissions. The objectives of 
the testing were to become familiar with the sampling methods and obtain preliminary information on the partitioning (solid vs. gas) of the trace elements in the flue gas, the effect of fuel form (pulverized coal or CWM) on trace element emissions, overall and baghouse penetration, and scale up (down-fired combustor vs. research boiler).

A listing of the tests conducted is given in Table 3-4. The tests were conducted to investigate the following parameters on trace element emissions:

- The effect of coal type -- Tests 1 and 2;

- The effect of coal cleaning -- Tests 2 and 3 ;

- The effect of fuel form -- Tests 1,6,7A and 7B and Tests 4 and 5; and

- The effect of scale up -- Tests 1 and 4 and Tests 5, 6,7A, and 7B.

- Reproducibility -- Tests 6,7A, and 7B.

In addition, Tests 7A and 7B were conducted to determine reproducibility of sampling at one location on the same day as well as to determine reproducibility between sampling on different days (i.e., Tests 6 (inlet), 7A, and 7B).

All samples have been analyzed and the results tabulated. It was found after the first three tests that insufficient sample was being analyzed by the laboratory and many of the results were below the detection limits. Consequently, the sample preparation technique was modified such that more of the sample was used by the laboratory. This technique was used for analyzing the samples from Tests 4 through 7A. Because the first three tests are used in nearly all the comparisons listed above, the tests will be repeated during the next reporting period. The interpretation of the results will be presented in the next semiannual report after the testing is completed.

\subsection{Subtask 1.7 Nitrogen Containing Groups in Coal Study}

During this reporting period, a project to study the nitrogen containing groups in coal was added. The work to be accomplished and the progress to date are discussed in Section 8.4 .

\subsubsection{Work to be Accomplished}

The analysis of nitrogen containing functional groups in coal is a difficult analytical problem, but an important one in terms of understanding the extent and origin of pollutants such as the various oxides that are formed in combustion.

It is well established that nitrogen is predominantly present in the form of heterocyclic aromatic structures, presumably as both basic nitrogen and $\mathrm{N}-\mathrm{H}$, but the relative proportions of each and their propensity to form oxides are not easily measured. In this part of the program, an approach is used that is based on the use of FTIR to quantitatively determine the amount of various types of nitrogen containing groups in coal. 
Table 3-4. Matrix Summary for the Trace Element Testing

\begin{tabular}{|c|c|c|c|c|c|c|c|c|}
\hline $\begin{array}{l}\text { Test } \\
\text { Number }{ }^{a}\end{array}$ & 1 & 2 & 3 & 4 & 5 & 6 & $7 \mathrm{~A}$ & $7 B$ \\
\hline Date & $04 / 23 / 97$ & $04 / 28 / 97$ & $04 / 30 / 97$ & 06/09/97 & $06 / 11 / 97$ & $06 / 16 / 97$ & $06 / 18 / 97$ & $06 / 18 / 97$ \\
\hline Coal Seam & $\begin{array}{c}\text { Middle } \\
\text { Kittanning }\end{array}$ & $\begin{array}{l}\text { Freeport } \\
\text { (Raw) }^{b}\end{array}$ & $\begin{array}{l}\text { Freeport } \\
{\text { (Cleaned })^{c}}^{c}\end{array}$ & $\begin{array}{c}\text { Middle } \\
\text { Kittanning }\end{array}$ & $\begin{array}{c}\text { Middle } \\
\text { Kittanning }\end{array}$ & $\begin{array}{c}\text { Middle } \\
\text { Kittanning }\end{array}$ & $\begin{array}{c}\text { Middle } \\
\text { Kittanning }\end{array}$ & $\begin{array}{c}\text { Middle } \\
\text { Kittanning }\end{array}$ \\
\hline $\begin{array}{l}\text { Furnace } \\
\text { Type }\end{array}$ & $\begin{array}{l}\text { Down-Fired } \\
\text { Combustor }\end{array}$ & $\begin{array}{l}\text { Down-Fired } \\
\text { Combustor }\end{array}$ & $\begin{array}{l}\text { Down-Fired } \\
\text { Combustor }\end{array}$ & $\begin{array}{l}\text { Research } \\
\text { Boiler }\end{array}$ & $\begin{array}{c}\text { Research } \\
\text { Boiler }\end{array}$ & $\begin{array}{c}\text { Down-Fired } \\
\text { Combustor }\end{array}$ & $\begin{array}{l}\text { Down-Fired } \\
\text { Combustor }\end{array}$ & $\begin{array}{l}\text { Down-Fired } \\
\text { Combustor }\end{array}$ \\
\hline $\begin{array}{l}\text { Firing } \\
\text { Rate } \\
\text { (Btu/h) }\end{array}$ & 362,000 & 345,000 & 360,000 & $1,652,000$ & $1,680,000$ & 372,000 & 362,000 & 362,000 \\
\hline
\end{tabular}

a All tests, except for Tests 7A and 7B, consisted of baghouse inlet and outlet sampling. Baghouse inlet sampling only was conducted during Tests 7A and 7B to determine reproducibility between tests.

b Parent coal before cleaning

c Cleaned by $\mathrm{CQ}$, Inc. 
These measurements can then be used to correlate structure to the propensity of different coals to form oxides.

Two different approaches are being used to measure nitrogen containing groups in coal. The first depends upon derivatization. Pyrrole type structures can be acetylated to give amide groups that are readily measured in the infrared. This methodology is already established. Basic nitrogen groups are more difficult to analyze. The approach being investigated involves the formation of complexes with alkyl halogens and because infrared spectroscopy is particularly sensitive to species with strong dipoles, the resulting bands should be extremely intense, allowing the measurement of low concentrations of basic nitrogen. This is in the process of being investigated.

The second approach being utilizing depends upon fixing organic nitrogen as inorganic nitrates in the low temperature ashing process.

\subsubsection{Progress to Date}

The establishment of the low temperature ashing methodology has been delayed by the need for repair of the instrument. In the meantime, samples have been sent to an outside vendor for ashing. These are to be returned in October so that the analysis can begin.

In terms of the derivatization work, a large number of coal samples have been acetylated and the spectra are presently being curve-resolved. NH content as a function of rank will be determined during the next reporting period.

The methylation procedure has proved more difficult, as the reaction conditions are crucial. In preliminary work, a styrene/vinyl pyridine copolymer is being characterized to establish methodology. The spectra of the methylated sample and the original copolymer are compared in Figure 3-12. Practically all the bands are changed upon methylation, which suggests that we are reacting aromatic ring $\mathrm{CH}$ groups in addition to the basic nitrogen functionality. Milder conditions of methylation are being studied in current work.

\subsection{Subtask 1.8 Conduct $\mathrm{NO}_{\mathrm{x}}$ Reduction Study}

The main objective of this study is to understand the detailed mechanism by which $\mathrm{NO}_{x}$ emissions are lowered when cofiring coal and MCWM compared to coal firing. The study will be conducted in Penn State's down-fired combustor (DFC).

\subsubsection{Conduct Cofiring Tests in the DFC}

Coal will be fired through the central pipe of the burner, and slurry fuel will be injected in Port 2 or 3 (as appropriate) downstream to simulate the reburn conditions. CWSF will be fired with coal at $0,10,20$, and $30 \%$ of the thermal input. A total of thirteen tests in the DFC will be performed. 


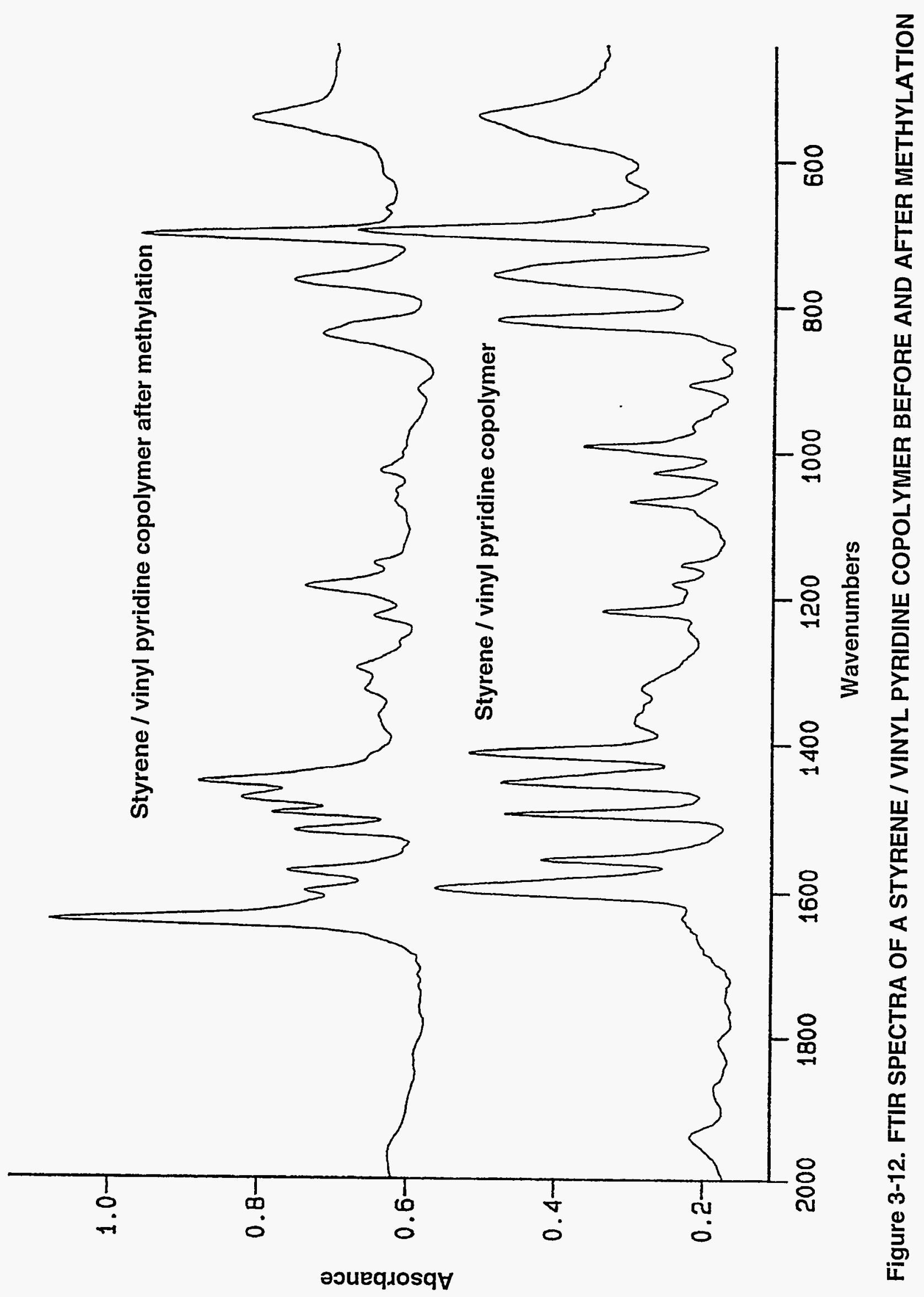


Baseline flue gas concentration and temperature profiles along the combustor will be generated with coal firing. This will provide the controlled conditions to study and demonstrate the influence of cofiring coal amnd coal water slurry fuel on the $\mathrm{NO}_{x}$ emisions. CEM system will be used to measure $\mathrm{O}_{2}, \mathrm{NO}_{x}$ and $\mathrm{CO}$ at various port levels to clearly identify the location at which $\mathrm{No}_{x}$ is produced and destroyed. Axial oxygen concentration will also provide the information on the stoichiometric ratio at the CWSF injection level. Char samples will be extracted from the combustor to measure the char composition $(\mathrm{C}, \mathrm{H}$ and N). Data on nitrogen distribution between char and volatiles will be obtained. All testing will be completed by December 31, 1997.

\subsubsection{Analysis of the Results}

The analysis of the results will be completed by March 31, 1998.

\subsection{Subtask 1.9 Evaluate BioLime as a $\mathrm{SO}_{2} / \mathrm{NOx}$ Reduction Strategy}

\subsubsection{Establish Baseline Reburn Limits with BioLime ${ }^{T M}$}

The objective of this work is to establish the limits under which BioLime ${ }^{\mathrm{TM}}$ injection can reduce the $\mathrm{NO}_{x}$ levels by $50 \%$ and $\mathrm{SO}_{2}$ levels by $90 \%$. The data generated so far was using high inlet $\mathrm{NO}_{x}$ and $\mathrm{SO}_{2}$ levels. Therefore, this work will establish the lower limits for its use. This task will be performed using the DFC with an inlet $\mathrm{NO}_{x}$ concentration of 100, 200 and $300 \mathrm{ppm}$. These tests will be conducted using natural gas flame and doping the flue gases with $\mathrm{SO}_{2}$ and $\mathrm{NO}_{x}$ gases and injecting the Biolime ${ }^{\mathrm{TM}}$ down stream.

\subsubsection{Establish Operating Limits for BioLime ${ }^{\mathrm{TM}}$}

The objective of this work is to establish the lower $\mathrm{SO}_{2}$ limits for $90 \%$ sulfur capture.

\subsubsection{Pilot-Scale Testing of Wood Feedstock with High $\mathrm{NO}_{\mathrm{x}}$ Retention Formula}

This work involves at least six tests with the High $\mathrm{NO}_{x}$ Retention Formula in the DFC to optimize the conditions and understand the emission control behavior of BioLime $^{\mathrm{TM}}$. The burner on the DFC will be modified to accommodate air staging or to use another reburn fuel upstream to reduce $\mathrm{NO}_{x}$ levels by about $50 \%$ from the baseline values in the previous subtasks (ie.,to about $0.4 \mathrm{lb} / \mathrm{MM}$ Btu). High NO $\mathrm{N}_{x}$ Retention Formula injected down stream will be optimized such that $\mathrm{NO}_{x}$ level can be reduced by an additional $75 \%$ to about $0.1 \mathrm{lb} / \mathrm{MM}$ Btu. 


\subsubsection{Fundamental Study of the Predominant Mechanism}

Primary objective of this work is to study the fundamentals to improve the understanding of the mechanisms that are involved in the process of $\mathrm{NO}_{\mathrm{x}}$ reduction by specifically studying:

1) homogeneous gas phase reaction of $\mathrm{HC}$ radicals and $\mathrm{NO}$ by simulated species in a laboratory-scale reactor

2) the influence of water in the production of $\mathrm{CO}$ that may react with $\mathrm{NO}_{x}$.

\subsubsection{Scale up of BioLime ${ }^{\mathrm{TM}}$ Injection Technology}

The optimum parameters that are identified in the DFC tests will be used to inject the High $\mathrm{NO}_{\mathrm{x}}$ Retention Formula into the $1,000 \mathrm{lb}$ steam/h watertube research boiler to study the scale-up factors. Handling behavior of the BioLime ${ }^{\mathrm{TM}}$ will be studied and a circuit will be developed to avoid the pluggage of nozzles by incorporating online strainers etc. Tests will be performed to study the effect of boiler load variation to establish the performance of BioLime ${ }^{\mathrm{TM}}$.

This task also involves demonstration of the technology under the conditions determined in the previous activities in the $15,000 \mathrm{lb}$ steam $/ \mathrm{h}$ demonstration boiler for at least a two week period. This demonstration involves looking at preparation and handling, and emission control aspects to facilitate further scale-up to a commercial unit. The demonstration will be based on 16 hour tests each day (operated for two shifts 8 hours each including heat up time). A low to medium sulfur coal will be used for the study. No major modifications to the Boiler are anticipated at this stage.

\subsection{PHASE II, TASK 2: COAL PREPARATION/UTILIZATION}

Activities in Phase II, Task 2 primarily focused on preparing the final report and initiating a study with Carnegie Mellon University to study the fundamental behavior of atomization. Results of the study are presented in Section 4.1.

\subsection{Subtask 2.10 Conduct Atomization Study}

No work was conducted on this subtask during this reporting period.

\subsection{PHASE II, TASK 3 ENGINEERING DESIGN AND COST; AND ECONOMIC ANALYSIS}

Phase II, Task 3 has been completed except for Subtask 3.10, integration of analysis.

\subsection{Subtask 3.10 Integration of Analyses}

Activities during this reporting period focused on investigating the regional economic benefits of decreased dependence on imported oil and using new coal combustion technologies. 


\subsubsection{Introduction}

Many policymakers have extolled the benefits of decreased reliance on imported oil. The gains would stem from lowering expected losses from potential embargoes and other political actions that cause shortages or price spikes. In addition, there would be gains from the positive economic stimulus of increased domestic production of energy resources. These would include not only direct output and employment impacts in domestic energy industries, but also general equilibrium effects by way of the stimulus to other sectors. Of course, the gains would be relatively greater in those regions providing the domestic energy substitutes.

In place of foreign oil, there are several domestic alternatives. For example, the U.S. has more energy in coal than the Middle East has in oil reserves. Moreover, recent advances in technology hold the promise of burning coal more efficiently, thereby lowering its cost and pollution emissions (e.g., Miller et al., 1997). In addition, there are a range of renewable resource options whose technological development is progressing as well.

Estimates of the value of the "security premium" on imported oil have dropped in recent years (see, e.g., Bohi and Toman, 1993). The adjustments are based on revisions of estimates of the actual macroeconomic shocks associated with the Arab oil embargo and Iranian revolution. Also noted is the fact that while the U.S. is now importing as large a percentage of oil as before the embargo about (45\%), most of these imports are from countries considered friendly to the U.S. or that are at least politically stable.

Even if the security issue wanes, however, the economic stimulus from increased domestic energy production remains an attractive benefit of increased coal utilization. But just how significant is it? $1.0 \%$ of GNP, $0.1 \%$, of GNP or some infinitesimal amount. Even the $0.1 \%$ figure represents $\$ 7$ billion of GNP and nearly 150,000 jobs.

The purpose of this chapter is to measure the economic stimulus effect of replacing foreign oil with domestic energy resources. Specifically, a computable general equilibrium model developed by $\mathrm{Li}$ (1994) to examine the widespread adoption of coal-fired industrial boilers in Pennsylvania as determined by Schaal $(1995 ; 1997)$ was employed. Although the impacts in the state of Pennsylvania are likely to be higher than most other parts of the U.S., and therefore represent an upward bound for generalization purposes, they are indicative of the extent of potential benefits from oil imports substitution policies. Ordinarily, if it is assumed that an economy is already in equilibrium, the existing pattern of international trade in energy would be optimal, and any import substitution policy would imply a decrease in economic activity. However, a factor that makes the opposite outcome possible is the development of a new technology that lowers the effective price of coal visà-vis imported oil. 


\subsubsection{Market Penetration Model}

This section summarizes the market penetration of a technology that allows retrofitting of oil- or gas-fired industrial boilers to utilize coal potential in forms such as a micronized coal-water mixture (MCWM). The decision to retrofit a boiler to fire MCWM must include consideration of the practical difficulties to be overcome. Recent pilot operations, however, have successfully demonstrated the capability of advanced burner design and operations to utilize coal-based slurries with no cofiring of other fossil fuels and limited derating of the boiler's total capacity (Miller et al., 1997).

Significant advantages are realized through the use of coal-based slurry fuels. The first is the elimination of fine coal particles during transport of solid by coal trucks, trains, conveyors, etc. This shipment of the coal fines constitutes a potential explosion hazard, and the dispersal of fines in the atmosphere constitutes a health hazard. Also, coal fines are much harder to dry, and the increased moisture can interfere with equipment operations. Little effort is expended in retrieving fine coal particles from coal mining and washing activities, and they are predominantly discarded as refuse. Slurrying the coal fines, however, mitigates these problems since the slurry can be pumped like oil and stored in similar tanks to reduce fugitive dust emissions. A second advantage is that it is easier to clean coal fines since the ash- and sulfur dioxide-producing mineral matter distributed throughout the coarse coal are more easily separated from the cleaner-burning coal. Third, with a long tradition of coal use, Pennsylvania has large quantities of such refuse available as a potential resource of coal-based slurry fuels.

A model that considers the costs to produce the boiler retrofit fuel, the costs to transport MCWM to the retrofitted boilers, and the capital and operation/maintenance costs of retrofitting was used to estimate the market penetration of the technology. The model minimizes the cost to boiler owners given the location of each boiler, its individual characteristics, and the location of each possible source of MCWM. The decision to retrofit is assumed to be made if the total costs of retrofitting are less than the costs to continue firing oil or gas. The model is a partial equilibrium analysis, since it is assumed that there are no substitution effects on oil or natural gas prices due to their displacement by MCWM (general equilibrium impacts are taken into account below). Another assumption is that there would be no increase or decrease of boiler utilization due to displacing other types of boilers at a given site. A firm may own several different types of boilers at a single site and choose to operate the ones that provide the greatest competitive advantage at a particular point in time.

Cost curves for transportation, capital costs of retrofitting, and operation were developed. One of the key features of this model is its recognition that the production of 
fuels at each supply point is subject to economies of scale. That is, the per unit cost of MCWM production fell as production at a single supply point increased.

Ideally, the model would be run with detailed data on several thousand boilers in Pennsylvania. The approach taken by Schaal (1995) was to simplify the data gathering effort by concentrating the detailed analysis to a subregion and then generalizing the results to the State as a whole.

Candidate industrial boiler retrofits were drawn from a census of boilers obtained from the Pennsylvania Department of Labor and Industry (1994). This census included all types of boilers that were insured for use during 1992-1993. The data provided were classified as to the particular boiler type in use at each location as summarized in Table 5-1. This allowed for a 'first-pass' sifting of the database to isolate a subset of boilers for further analysis. Since the retrofit technology only applied to water-tube boilers, the total number of existing retrofit candidates was reduced to 6,936. Limiting the analysis to the Indiana-Cambria two-county region further reduced the number of boilers to 462 . Reducing the population space to a few hundred boilers enabled detailed data to be gathered on nearly 60 percent of these boilers.

This analysis provides a range of boiler adoption estimates based on a combination of pessimistic and optimistic assumptions. On the low side, the two-county market penetration model identified only 6 boilers out of 462 , or 1.3 percent, as economically viable for retrofit, which translate into only 90 boilers in the entire State. A further pessimistic assumption made to establish a floor on market penetration was to consider the distribution of boilers throughout Pennsylvania. As shown in Figure 5-1, it can be seen that the boilers located in the eastern part of the State are not readily served from the coal producing regions of the west central to southwestern parts of the State. With this consideration in mind, it was estimated that only $40 \%$ of water-tube boilers are located in areas that could consider retrofitting as a viable option. This result left an estimated 36 boilers in the State as economic to retrofit, with a total consumption of only 660 thousand tons of coal per year (Schaal, 1995).

In further work, Schaal (1997) considered several factors that may alter the outlook for market penetration of the technology. The first was that the distribution of boilers by size in the two-county region may not be representative of the Statewide boiler distribution. The capital costs of retrofitting also follow economies of scale with increasing boiler size, and a different size distribution of boilers may reveal a greater concentration of ideal boiler retrofits. The second factor was the sensitivity of the number of retrofits to the differential in cost between the incumbent fossil fuel (oil or gas) and the coal-based slurry fuel. Other sensitivities included interest rates and boiler utilization factors. In addition, the 
Table 5-1. Summary of Pennsylvania Boilers by Type

\begin{tabular}{lrc}
\hline \hline Boiler & Number & Percent \\
\hline Cast Iron & 30,760 & 46.4 \\
Fire Tube & 12,093 & 18.3 \\
Water Tube & 6,936 & 10.5 \\
Electric & 4,228 & 6.4 \\
Other & $\underline{12.245}$ & $\underline{18.5}$ \\
Total & 66,262 & 100.0 \\
\hline \hline
\end{tabular}




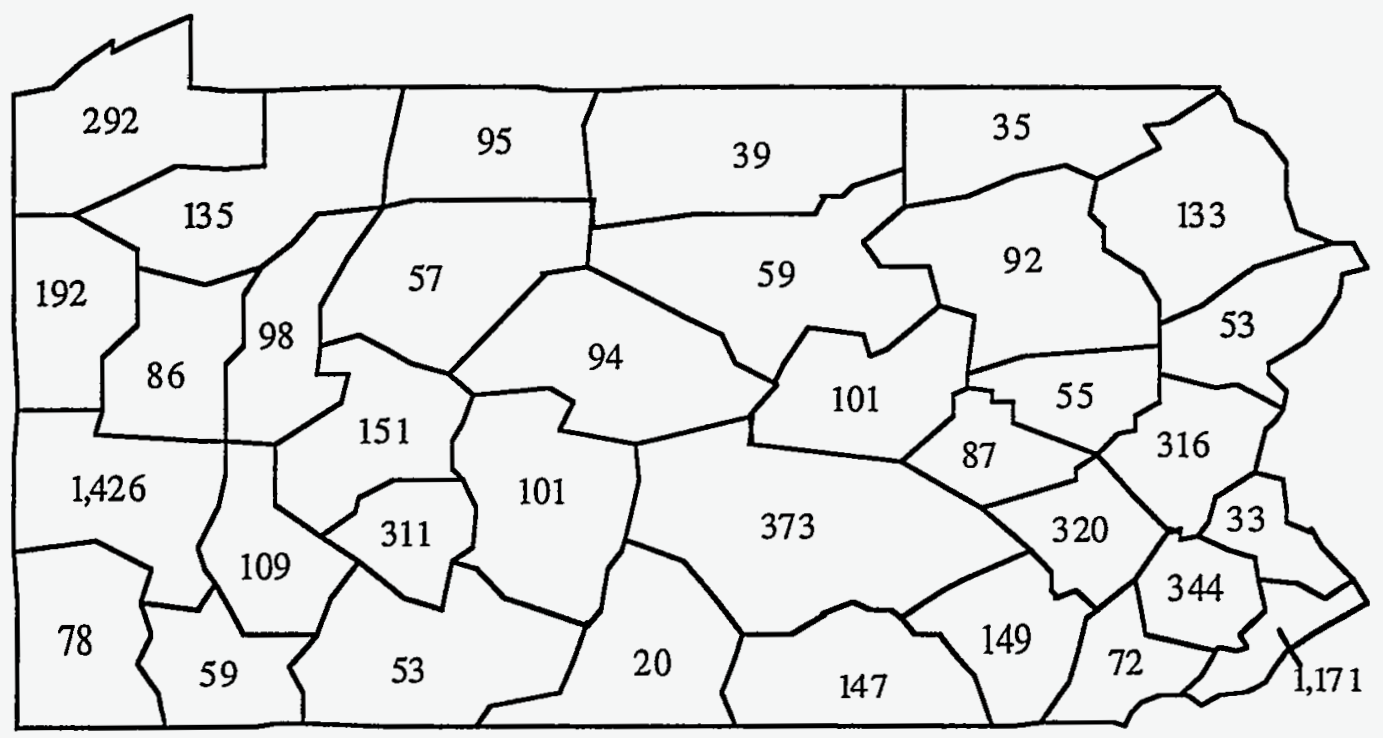

Figure 5-1. Pennsylvania Water-Tube Boilers by 3-Digit Zip Code Region 
assumption regarding eastern Pennsylvania boilers not having access to coal-based fuel sources was relaxed.

The retrofit technology is appropriate for boilers with allowable working pressures of at least 200 psig and under a maximum output of $200 \mathrm{MM}$ Btu per hour. Data gathered from the two-county sample allowed estimation of boiler output from working pressure. The estimate of output allowed winnowing the population space for boiler retrofit candidates to 950 for the entire State and provided an improved estimate of their capital and operating costs of retrofitting.

The market penetration of the technology was found to be highly sensitive to the differential in fuel costs. Coal-based slurry fuel was projected to have a delivered price of $\$ 1$ per MM Btu. The weighted average price paid by the industrial sector for the fuels to be displaced was \$3.79 per MM Btu in 1993 (U.S. DOE/EIA, 1995). Combining a sensitivity analysis of differential fuel costs with the improved state-wide model of boiler size resulted in a more optimistic outlook for the market penetration of the technology as shown in Table 5-2. A minimum of $\$ 2$ per MM Btu is required before any retrofits are undertaken, while at $\$ 3.80$ per MM Btu all candidates are economic to retrofit. Table 5-3 summarizes the Pessimistic, Base, and Optimistic levels of market penetration of the retrofit technology used in modeling the impacts of technology adoption on the Pennsylvania economy.

\subsubsection{The Pennsylvania CGE Model}

This section summarizes the model used to perform the general equilibrium impacts of new coal-water slurry boilers. The reader is referred to $\mathrm{Li}$ (1994) for a detailed presentation of the model equations, data upon which it is based, and the manner of model construction.

The selection of a model framework was based on the following criteria:

1. It must reflect the economic characteristics of Pennsylvania — an industrialized and highly interdependent economy.

2. It must include the manufacturing sector's ability to adopt new technologyindustries' ability to substitute among fuel inputs in the production process.

3. It must be able to model the economy's energy trade balance-the relative competitiveness of indigenous fuels with respect to those imported from other states and other countries.

4. It must be able to address both microeconomic and macroeconomic aspects of energy and environmental policy-both sectoral and economy-wide impacts.

The modeling framework chosen was the computable general equilibrium (CGE) analysis. This approach depicts an economy-wide equilibrium, in which all agents 
Table 5-2. Pennsylvania Market Penetration Results at Varying Differential Fuel Cost

\begin{tabular}{|c|c|c|c|c|c|c|}
\hline $\begin{array}{c}\text { Differential } \\
\text { Fuel Cost } \\
\text { (\$/MM Btu) }\end{array}$ & $\begin{array}{l}\text { Number of } \\
\text { Retrofits }\end{array}$ & $\begin{array}{c}\text { Viable } \\
\text { Population } \\
\text { (percent) }\end{array}$ & $\begin{array}{l}\text { Retrofit } \\
\text { TCR } \\
\left(10^{6} \$\right)\end{array}$ & $\begin{array}{l}\text { Retrofit } \\
\text { Savings } \\
\left(10^{6} \$ / \mathrm{yr}\right)\end{array}$ & $\begin{array}{c}\text { MCWM } \\
\text { Consumption } \\
\left(10^{12} \text { Btu }\right)\end{array}$ & $\begin{array}{l}\text { Increased Coal } \\
\text { Consumption } \\
\left(10^{3} \text { tons }\right)\end{array}$ \\
\hline $\begin{array}{l}2.04 \\
2.29 \\
2.54 \\
2.79 \\
3.04 \\
3.29 \\
3.54 \\
3.79\end{array}$ & $\begin{array}{r}63 \\
122 \\
140 \\
237 \\
360 \\
611 \\
635 \\
950\end{array}$ & $\begin{array}{r}7 \\
13 \\
15 \\
25 \\
38 \\
64 \\
67 \\
100\end{array}$ & $\begin{array}{r}459 \\
806 \\
897 \\
1,304 \\
1,748 \\
2,607 \\
2,678 \\
3,545\end{array}$ & $\begin{array}{r}4.5 \\
14.1 \\
26.6 \\
41.1 \\
59.2 \\
86.6 \\
116.0 \\
150.9\end{array}$ & $\begin{array}{r}28.8 \\
47.4 \\
51.7 \\
68.6 \\
85.4 \\
116.3 \\
118.6 \\
145.1\end{array}$ & $\begin{array}{l}1,210 \\
1,988 \\
2,171 \\
2,887 \\
3,584 \\
4,879 \\
4,976 \\
6,088\end{array}$ \\
\hline
\end{tabular}

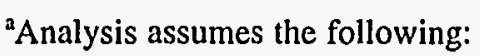

Boiler utilization rate-40\%

Transportation radius -25 miles

Interest rate- $8 \%$

Useful life-20 yrs. 
Table 5-3. Market Penetration Estimates for Three Scenarios

\begin{tabular}{lccc}
\hline \hline & Pessimistic & Base & Optimistic \\
\hline Number of Retrofitted Boilers & 36 & 276 & 551 \\
$\begin{array}{l}\text { Estimated Additional Coal Consumption, } \\
\text { thousand tons per year }\end{array}$ & 662 & 2,534 & 5,068 \\
$\begin{array}{l}\text { Percentage Change in Pennsylvania } \\
\text { Industrial Sector Coal Demand }\end{array}$ & $5 \%$ & $18 \%$ & $35 \%$ \\
$\begin{array}{l}\text { Percentage Change in Pennsylvania } \\
\text { Total Coal Demand }\end{array}$ & $1 \%$ & $5 \%$ & $9 \%$ \\
\hline \hline
\end{tabular}


independently maximize their own objective functions in response to price signals and subject to resource, technology, and income constraints. CGE modeling is a widely used approach in taxation, trade, and regulatory impact modeling (see e.g., surveys by Shoven and Whaley, 1984; and Bandara, 1991). CGE overcomes the drawbacks of other models by including aggregate macro information, sectoral distinctions, economic interdependencies, price-response mechanisms, competitiveness features, resource constraints, and substitution possibilities. Its strong features best satisfy our model selection criteria.

\section{Overview of the Model}

The Pennsylvania CGE model is a long-run, static, single-region model based on the following assumptions:

1. The product and factor markets are competitive, i.e., no economic agents are able to exercise monopoly power in the markets.

2. The State of Pennsylvania is a small, open economy, i.e., it has little or no influence on the supply and demand of goods in the national economy or their prices.

3. Monetary variables do not play an explicit role, i.e., transactions are in real terms.

4. Technological change (both embodied and disembodied), other than that associated with new boiler adoption, is not explicitly taken into account in the period of study.

5. Prices are flexible enough to assure the existence of a general equilibrium; producers and consumers can fully adjust without any time lag after external shocks.

The major features of the model are its emphasis on production technology and its focus on trade theory. The structure of input demand in this model resembles that of several well-known national and regional CGE models (e.g., the model developed by Robinson et al., 1990, 1993, and the regional model by Kraybill, 1990). Important modifications are made in the specification of the production technology for energy and materials. The model adopts a two-part production function, in which the intermediate inputs are assumed to follow a fixed-coefficient Leontief technology, and the two primary inputs, capital and labor, are modeled using a two-tiered, or nested, Generalized Leontief cost function. The first tier allows substitutions among capital (K), labor (L), energy $(E)$, and materials $(\mathrm{M})$. The second tier specifies interfuel and intermaterial substitutions inside the energy and material aggregates. 
The overall structure of this model is illustrated by a schematic diagram in Figure 52. Basically, there are four interrelated components: production, trade, demand, and income. Each component is further decomposed into several parts. The arrows in the diagram show the interlinkages of different parts in the model. When all economic agents interact together and jointly optimize their objective functions, a set of endogenous equilibrium prices is determined to clear all markets in the economy.

\section{The Choice of Functional Form}

The specification of production technology in an empirical analysis requires the selection of a suitable functional form. Cobb-Douglas, CES, and Leontief functions were rejected because of their undesirable properties, such as predetermined restrictions on the elasticities of substitution. Instead, flexible function forms were chosen, which are second-order approximations of a technology and place no a priori restriction on substitution possibilities.

The use of flexible functional forms is not without limitations. The separability assumption widely adopted in economic research imposes restrictions on their flexibility. Another problem lies in the ability of flexible functions to approximate arbitrary technologies globally, because these functions are only second-order numerical or differential approximations at a point. Still another is the possibility of violating concavity conditions.

The two-tiered Generalized Leontief (GL) cost functions approach chosen for the models was used for the following reasons:

1. The elasticities of substitution between inputs may be a mix of low and high levels.

2. GL functions involve fewer parameters to be calibrated or estimated than other flexible functional forms.

3. For intermediate inputs other than $\mathrm{K}, \mathrm{L}, \mathrm{E}$, and $\mathrm{M}$, fixed input proportions were assumed. Since the GL form collapses to a Leontief function under certain conditions, intuitively, it seems desirable to choose the GL form for consistency. The GL form generally performs better in cases with low elasticities or a mixture of high and low elasticities, while the TL form is apparently preferable for high elasticities (see e.g., Caves and Christensen, 1980; Despotakis, 1986). In addition, different functional forms may yield quite different results for the same data set and the same economic assumptions (Baffes and Vasavada, 1989). 


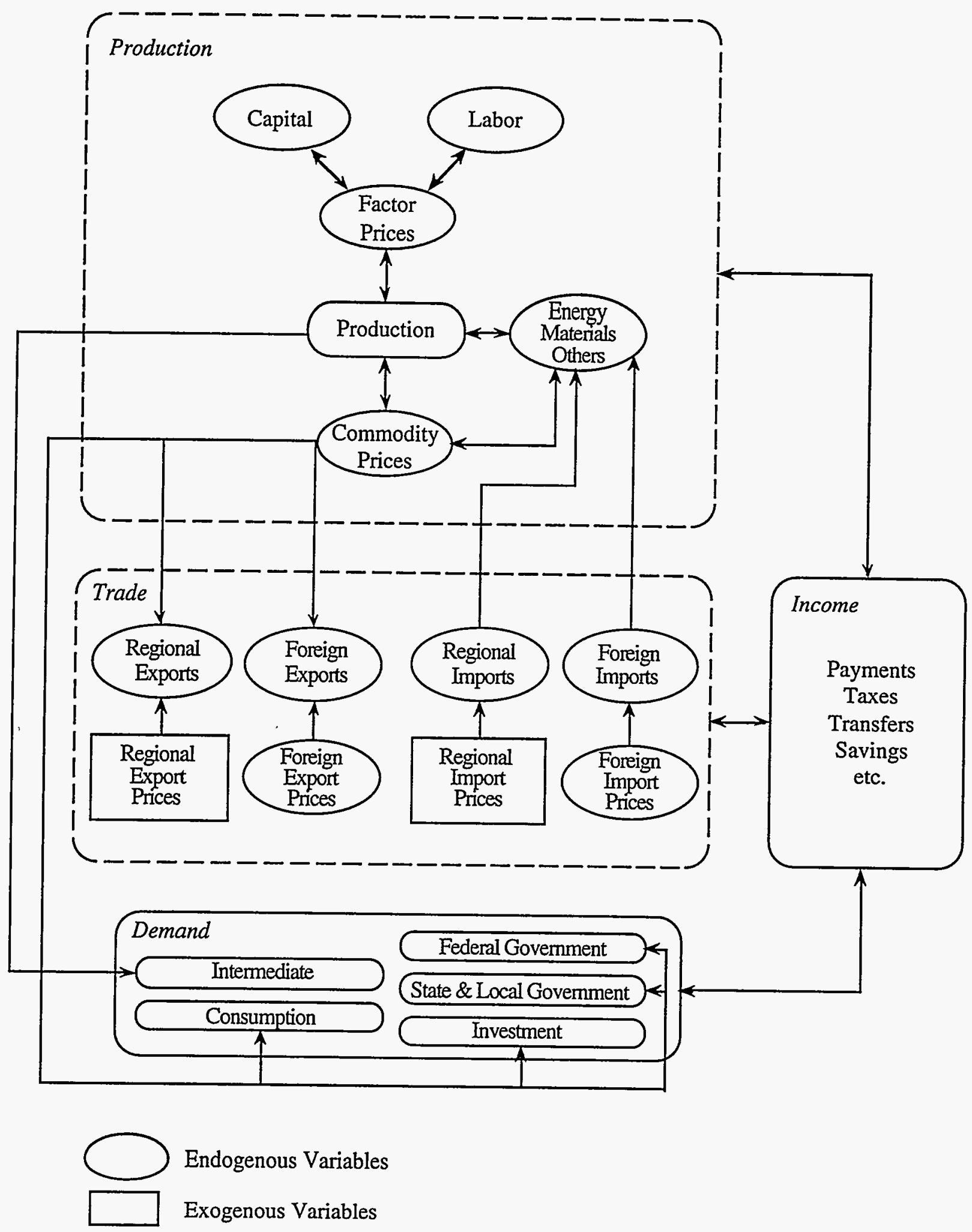

Figure 5-2. Schematic Diagram of the Pennsylvania CGE Model 


\section{Trade}

For an open, regional economy like that of Pennsylvania, trade is very important and must be carefully handled conceptually and empirically. In CGE analysis, there are two approaches to modeling the terms of trade in a small, open economy. One method assumes product homogeneity among countries or regions. The other approach specifies product differentiation by country (or region) of origin into the demand structure.

The first approach can be regarded as an application of traditional trade theory. It is theoretically attractive but may turn out to be too restrictive for a large scale CGE model. The widely accepted Armington (1969) assumption can free CGE models from the limitation of traditional trade theory, by stipulating that similar goods originating from different countries (or regions) are imperfect substitutes. Thus, domestic consumers of commodities within one aggregated sector actually consume a mixture of domestically produced and imported goods.

There are various reasons to justify this approach. Bergman (1982) found that in a relatively aggregated CGE model, the aggregated indices for import prices, import quantities, domestic production costs, and domestic production are correlated. Another reason is the commonly observed cross-hauling problem associated with imperfect trade statistics or highly aggregated data. This phenomenon can be easily explained and handled by the Armington assumption. In addition, the Armington assumption can avoid the occurrence of unrealistically strong specialization effects when a change in trade policy is modeled with traditional trade theory.

The treatment of trade in the Pennsylvania CGE model follows the traditional small, open economy assumption, with the application of the Armington assumption on the import demand side. Trade with other regions and foreign countries is modeled as a two-stage decision process. The world prices of imports, the prices of imports from other regions, the world prices of exports, and the prices of exports to other regions are all exogeneously given. On the import side, the consumer, at the first stage, maximizes the utility of consuming composite goods subject to a budget constraint by substituting between foreign goods and domestic goods. At the second stage, a choice is again made between locally produced goods and goods from other regions. At each stage, the Armington assumption is employed and a constant elasticity of substitution (CES) function is used to aggregate imperfect substitutes. On the export side, the producer, at the first stage, minimizes the cost of producing joint products to furnish domestic consumption and foreign demand. Then, at the second stage, the producer again makes supply decisions between local sale and export supply to other regions. At each stage, a constant elasticity of transformation (CET) function is used for aggregation. This two-stage decision structure and the 
specification of imperfect substitution and transformation imply assumptions of separability and the lack of income effects.

\section{Model Closure and Macro Balances}

The model closure problem in general equilibrium models is synonymous with the overidentification problem in a mathematical simultaneous equation system. To solve this problem, either one constraint has to be dropped from the model, or one previously exogenous variable or model parameter must be determined endogenously. This process is called the imposition of a closure rule in general equilibrium models. Following Sen's taxonomy (Sen, 1963), four types of closure rules are usually adopted by modelers in CGE analysis:

1. Classical: Full employment is achieved, and the economy-wide wage rate is forced to adjust endogenously. Aggregate investment is endogenous and financed by total savings.

2. Keynesian: Unemployment is allowed to happen in the economy. The economy-wide average wage rate is fixed, and labor supply is determined endogenously.

3. Kaldorian: Full employment is attained, and aggregate investment is set exogenously. Aggregate investment is equated to total savings through the endogenous adjustment of the price level and the functional distribution of income.

4. Johansen: Full employment is achieved and aggregate investment is set exogenously. Government expenditures and tax revenues adjust endogenously to restore the savings-investment balance.

The closure rule adopted here is classical, which is consistent with the long-run nature of the Pennsylvania CGE model. In addition to the closure rule, a set of macro balancing identities is necessary to make the CGE model consistent. These are producer's equilibrium, goods market clearing, the government budget deficit, the balance of trade, and an investment-savings identity.

\section{Factor Mobility}

Factor mobility is an important empirical issue, especially in regional economic modeling. Two types of mobility must be considered: factor mobility across sectors and factor movements across regions. In most CGE models, labor is assumed to be perfectly mobile across sectors, while capital is modeled as sector specific in the short run and fully mobile across sectors in the long run. In the Pennsylvania CGE model, both labor and capital are assumed to be fully mobile across industries. Given the long-term nature of the model and the fact that the Pennsylvania economy is well developed and highly 
industrialized, this modeling decision should have less impact on the accuracy of the estimates than other simplifications that were adopted.

Interregional capital movement can be easily modeled by setting net regional savings as endogenous. Interregional labor movement, on the other hand, poses more difficulty. Interregional labor movement may be the result of natural migration, a change of workers' preference, and a change in spatial employment patterns due to external shocks. For example, a more stringent environmental regulation may exert relatively heavier pressure on Pennsylvania coal industries compared to the other states. Therefore, the unemployed Pennsylvania coal miners may consider moving to adjacent coal producing states or exiting the industry.

The ideal approach to modeling interregional labor mobility is the expression of migration as a function of explanatory variables based on observed data. Such attempts in CGE analysis have been limited, however, as in the treatment of partial labor mobility by Whalley and Trela (1986) and the impressive work by Norrie and Percy (1983). Alternatively, in a manner consistent with the Classical closure rule, a fixed labor supply is assumed for the initial simulations. This assumption is then relaxed in a sensitivity test that calls for any unemployed workers migrating to other states, or any excess demand for labor being completely satisfied by workers immigrating to Pennsylvania from other states. This approach essentially models labor mobility as a residual; however, it is an endogenous determination of this important variable. Note that, although the labor supply is varied, a pure Keynesian closure rule is not used, which would allow for an underemployment equilibrium. Such an outcome is reasonable for a (closed) national economy in the long run, but it is more typical (and reasonable) in regional modeling to assume that labor migration moves the non-structural unemployment rate toward zero in the long run for any given region (see also Kelkenny and Robinson, 1990).

\subsubsection{Application}

MCWM conversion was simulated in the five major sectors that contain the majority of industrial boilers in Pennsylvania: Plastics, Glass, Stone and Clay, Nonferrous Metals, and Other Manufacturing. For lack of more detailed information, it was assumed that the same target conversion for each sector in terms of increased coal consumption (see the second row of each partition of Table 5-4). This, however, results in differing percentages of petroleum replacement among sectors (see the last row of each partition in Table 5-4), with the Stone and Clay product sector being the locus of the greatest percentage displacement of oil.

The results of the simulations are presented in Tables 5-5 and 5-6 under varying conditions relating to CGE model closure and import conditions. The former refers to 
Table 5-4. Calculation of Coal Substitution for Petroleum in Boiler Retrofit Sectors

\begin{tabular}{|c|c|c|c|c|c|}
\hline Pessimistic Scenario (4.6\%) & $\begin{array}{l}\text { Nonferrous } \\
\text { Metals }\end{array}$ & Plastic & Glass & Stone & $\begin{array}{l}\text { Other } \\
\text { Manufac }\end{array}$ \\
\hline $\begin{array}{l}\text { Base Coal consumption (\$) } \\
\text { Increased coal consumption }(\% \Delta) \\
\text { Increased coal consumption (\$) } \\
\text { Increased coal consumption (ton) } \\
\text { Increased coal consumption (mmBtu) } \\
\text { Replaced petroleum consumption (mmBt } \\
\text { Replaced petroleum consumption (bbl) } \\
\text { Replaced petroleum consumption }(\$) \\
\text { Base petroleum consumption }(\$) \\
\text { Replaced petroleum consumption }(\% \Delta)\end{array}$ & $\begin{array}{r}2137 \\
4.60 \\
98 \\
3 \\
86 \\
86 \\
86 \\
14 \\
312 \\
24870 \\
1.25\end{array}$ & $\begin{array}{r}1190 \\
4.60 \\
55 \\
2 \\
48 \\
48 \\
8 \\
174 \\
20846 \\
0.83\end{array}$ & $\begin{array}{r}334 \\
4.60 \\
15 \\
1 \\
13 \\
13 \\
2 \\
49 \\
10730 \\
0.45\end{array}$ & $\begin{array}{r}20045 \\
4.60 \\
922 \\
31 \\
804 \\
804 \\
134 \\
2927 \\
11201 \\
26.13\end{array}$ & $\begin{array}{r}76564 \\
4.60 \\
3522 \\
117 \\
3071 \\
3071 \\
512 \\
11179 \\
417309 \\
2.68\end{array}$ \\
\hline Mid-Range Scenario (17.5\%) & $\begin{array}{l}\text { Nonferrous } \\
\text { Metals }\end{array}$ & Plastic & Glass & Stone & $\begin{array}{c}\text { Other } \\
\text { Manufac }\end{array}$ \\
\hline $\begin{array}{l}\text { Base coal consumption }(\$) \\
\text { Increased coal consumption }(\% \Delta) \\
\text { Increased coal consumption (\$) } \\
\text { Increased coal consumption (ton) } \\
\text { Increased coal consumption (mmBtu) } \\
\text { Replaced petroleum consumption (mmBto } \\
\text { Replaced petroleum consumption (bbl) } \\
\text { Replaced petroleum consumption (\$) } \\
\text { Base petroleum consumption }(\$) \\
\text { Replaced petroleum consumption }(\% \Delta)\end{array}$ & $\begin{array}{r}2137 \\
17.50 \\
374 \\
12 \\
326 \\
326 \\
54 \\
1187 \\
24870 \\
4.77\end{array}$ & $\begin{array}{r}1190 \\
17.50 \\
208 \\
7 \\
182 \\
182 \\
30 \\
661 \\
20846 \\
3.17\end{array}$ & $\begin{array}{r}334 \\
17.50 \\
58 \\
2 \\
51 \\
51 \\
8 \\
186 \\
10730 \\
1.73\end{array}$ & $\begin{array}{r}20045 \\
17.50 \\
3508 \\
117 \\
3059 \\
3059 \\
510 \\
11134 \\
11201 \\
99.40\end{array}$ & $\begin{array}{r}76564 \\
17.50 \\
13399 \\
447 \\
11684 \\
11684 \\
1947 \\
42529 \\
417309 \\
10.19\end{array}$ \\
\hline Optimistic Scenario (35.0\%) & $\begin{array}{l}\text { Nonferrous } \\
\text { Metals }\end{array}$ & Plastic & Glass & Stone ${ }^{a}$ & $\begin{array}{c}\text { Other } \\
\text { Manufac }\end{array}$ \\
\hline $\begin{array}{l}\text { Base coal consumption }(\$) \\
\text { Increased coal consumption }(\% \Delta) \\
\text { Increased coal consumption }(\$) \\
\text { Increased coal consumption (ton) } \\
\text { Increased coal consumption (mmBtu) } \\
\text { Replaced petroleum consumption (mmBtu } \\
\text { Replaced petroleum consumption (bbl) } \\
\text { Replaced petroleum consumption }(\$) \\
\text { Base petroleum consumption }(\$) \\
\text { Replaced petroleum consumption }(\% \Delta)\end{array}$ & $\begin{array}{r}2137 \\
35.00 \\
748 \\
25 \\
652 \\
652 \\
109 \\
2374 \\
24870 \\
9.55\end{array}$ & $\begin{array}{r}1190 \\
35.00 \\
417 \\
14 \\
363 \\
363 \\
61 \\
1322 \\
20846 \\
6.34\end{array}$ & $\begin{array}{r}334 \\
35.00 \\
117 \\
4 \\
102 \\
102 \\
17 \\
371 \\
10730 \\
3.46\end{array}$ & $\begin{array}{r}20045 \\
17.50 \\
3508 \\
117 \\
3059 \\
3059 \\
510 \\
11134 \\
11201 \\
99.40\end{array}$ & $\begin{array}{r}76564 \\
35.00 \\
26797 \\
893 \\
23367 \\
23367 \\
3895 \\
85057 \\
417309 \\
20.38\end{array}$ \\
\hline
\end{tabular}

Price of coal is $\$ 30 /$ ton; price of refined petroleum is $\$ 21.84 / \mathrm{bbl}$.

Heat content of coal is 26.16 million Btu/ton; heat content of refined petroleum is 6 million Btu/bbl.

${ }^{2}$ Figures are the same as Mid-Range Scenario so as not to exceed 100\% substitution. 
Table 5-5. Macroeconomic Impacts of Industrial Boiler Retrofit using MCWM Technology --All Scenarios (percentage change)

\begin{tabular}{llllll}
\hline \hline Variable & Case I & Case II & Case III & Case IV \\
\hline
\end{tabular}

Pessimistic Scenario (4.6\%)

Real GRP

Price Index

Total industry output

Total employment

Total regional exports

Total regional imports

Total foreign exports

Total foreign imports

$\begin{array}{rrrr}0.010 & 0.043 & 0.003 & 0.021 \\ 0.002 & 0.004 & 0.003 & 0.004 \\ 0.001 & 0.036 & -0.014 & 0.000 \\ -0.022 & 0.044 & -0.029 \\ -0.022 & -0.004 & -0.046 & -0.048 \\ 0.044 & 0.093 & 0.031 & 0.057 \\ -0.060 & -0.020 & -0.083 & -0.070 \\ -0.048 & -0.014 & -0.068 & -0.057\end{array}$

Mid-Range Scenario (17.5\%)

Real GRP

Price Index

Total industry output

Total employment

Total regional exports

Total regional imports

Total foreign exports

Total foreign imports

Optimistic Scenario (35.0\%)

Real GRP

Price Index

Total industry output

Total employment

Total regional exports

Total regional imports

Total foreign export s

Total foreign imports

$\begin{array}{rrrr}0.026 & 0.107 & 0.009 & 0.051 \\ 0.011 & 0.014 & 0.012 & 0.014 \\ 0.001 & 0.087 & -0.038 & -0.005 \\ -\overline{-} & 0.108 & -\overline{0} & 0.068 \\ -0.049 & -0.006 & -0.113 & -0.118 \\ 0.119 & 0.239 & 0.081 & 0.141 \\ -0.145 & -0.046 & -0.206 & -0.175 \\ -0.117 & -0.033 & -0.169 & -0.143\end{array}$

0.051

0.014

0.068

$-0.118$

0.175

$-0.143$

Case I: No restrictions on regional coal imports, classical closure rule.

Case II: $\quad$ No restrictions on regional coal imports, Keynesian closure rule.

Case III: Fixed regional coal imports, classical closure rule.

Case IV: Fixed regional coal imports, Keynesian closure rule. 
Table 5-6. Microeconomic Impacts of Industrial Boiler Retrofit Using MCWM Technology -Mid-range Scenario for Key Sectors (percentage change)

Sector/

Variable

Case I

Case II

Case III

Case IV

Coal

Price

Industry output

$\begin{array}{rrrr}0.027 & 0.023 & 0.053 & 0.047 \\ 0.700 & 0.794 & 1.544 & 1.612 \\ 0.686 & 0.806 & 1.538 & 1.625 \\ 0.669 & 0.766 & 1.508 & 1.579 \\ 0.894 & 0.958 & -1.383 & 1.482 \\ 0.536 & 0.673 & - & -\end{array}$

Employment

Regional exports

Regional imports

Foreign exports

Foreign imports

Oil \& natural gas

Price

Industry outputs

Employment

Regional exports

Regional imports

Foreign exports

Foreign imports

$\begin{array}{rrrr}-0.086 & -0.060 & -0.080 & -0.062 \\ 0.020 & -0.044 & 0.010 & -0.039 \\ 0.023 & -0.012 & 0.022 & -0.007 \\ 0.024 & -0.042 & 0.029 & -0.024 \\ -0.488 & -0.380 & -0.481 & -0.421 \\ -0.122 & -0.145 & -0.135 & -0.151 \\ -0.344 & -0.279 & -0.351 & -0.321\end{array}$

Nonferrous metals

Price

Industry output

Employment

Regional exports

Regional imports

Foreign exports

Foreign imports

$\begin{array}{rrrr}0.029 & 0.032 & 0.030 & 0.033 \\ -0.205 & -0.068 & -0.428 & -0.444 \\ -0.214 & -0.056 & -0.430 & -0.432 \\ -0.237 & -0.112 & -0.463 & -0.490 \\ 0.107 & 0.255 & -0.106 & -0.115 \\ -0.412 & -0.236 & -0.627 & -0.616 \\ 0.459 & 0.503 & 0.224 & 0.139\end{array}$

Case I: No restrictions on regional coal imports, classical closure rule.

Case II: $\quad$ No restrictions on regional coal imports, Keynesian closure rule.

Case III: Fixed regional coal imports, classical closure rule.

Case IV: Fixed regional coal imports, Keynesian closure rule. 
whether we assume a full employment economy (classical closure rule) or allow for underemployment equilibrium (Keynesian). The latter refers to whether we allow for some of the increased coal use to be imported from other states versus insisting it all be Pennsylvania coal.

The results of the various cases (in effect, sensitivity analyses) are relatively similar in qualitative terms. For example, in the Pessimistic Scenario, coal boiler conversion has a positive impact on the Pennsylvania economy, but only in the range of a $0.003 \%$ to $0.043 \%$ increase in Gross Regional Product (GRP). It also results in upward pressure on prices, though only to a minuscule extent. The Optimistic Scenario calls for GRP increases ranging from $0.014 \%$ to $0.169 \%$. The fact that the GRP effects increase by a factor of 4 when the conversion target increases by a factor of 8 reflects the nonlinearities inherent in the model.

Just how significant are these numbers? The Pennsylvania GRP is about $\$ 200$ billion annually, so a $0.1 \%$ increase is $\$ 200$ million. A $0.1 \%$ increase in employment is 6,000 jobs, which is a significant impact in human terms.

The impacts on selected sectors are presented in Table 5- 6 for the Mid-Range Scenario (17.5\% substitution). For example, coal industry output is projected to increase by $0.7 \%$ to $1.6 \%$. There is also a slight increase in coal prices, but the results in Table 5-5 indicate that this has no overall injurious effect on the State's economy.

The impact on the State's Oil and Gas sector is much smaller in percentage terms than the increase in coal output, for the main part, because the majority of the feedstock for oil-fired boilers is imported from other states. Moreover, the decrease in the price of oil and gas as a result of lower demand following conversion is a positive stimulus to the State's economy.

The results for the Nonferrous Metals industry indicate a very slight price increase and a small decrease in output. The model is still being examined to provide more insight into why these take place.

\subsection{PHASE II, TASK 4 FINAL REPORT/SUBMISSION OF DESIGN PACKAGE}

Work in preparing the final report continued. Tasks 2 (except for Subtask 2.10) and 3 (except for Subtask 3.10) have been completed.

\subsection{PHASE III, TASK 1 COAL PREPARATION/UTILIZATION}

\subsection{Subtask 1.1 Particle Size Control}

\subsubsection{Evaluation of Dry Grinding/Classifier Circuit}

Experimental data obtained from laboratory studies of jet milling and air classification of Upper Freeport seam coal are being used to evaluate the use of closed- 
circuit dry grinding for fine coal production. The classification results were obtained using a Donaldson, Acucut classifier and have been used to establish performance data (sizeselectivity curves) for that device. The grinding studies were carried out in a Majac Mini-

Grinder (jet mill) operated in closed-circuit with the Acucut classifier. Because of the very limited amount of grinding which occurs in each pass through the mill, it is not feasible to obtain direct measures of the breakage characteristics (breakage rate, primary breakage distribution). Consequently, this information has to be obtained indirectly by circuit simulation using the experimental classifier size-selectivity data and an iterative search procedure to estimate the breakage parameters. In the absence of a general body of information on the breakage characteristics associated with jet milling, it is necessary to evaluate a variety of potential models for the breakage process and, in particular, for the size dependence of the breakage parameters.

\subsection{Subtask 1.2 Physical Separations}

\subsubsection{Fine Coal Classification}

The fine-coal classification tests using the continuous, solid-bowl centrifuge were completed. The last series of tests was conducted using weir setting 3 , which gave the second deepest pool setting (i.e., setting $1=$ shallowest pool, setting $4=$ deepest pool). These tests were also run at a slurry feed rate of $11.4 \mathrm{~L} / \mathrm{m}(3 \mathrm{gpm})$ and a solids concentration of $10 \%$ coal (by weight) using -100 mesh Upper Freeport seam coal. The centrifuge bowl and scroll speeds were both varied as before. Table 7-1 summarizes the operating conditions for this series of tests.

As was done previously, the coarse (scroll discharge) and fine (weir overflow) streams were sampled and dried. A sample of each product was then analyzed using a Microtrac X-100 particle size analyzer. Figure 7-1 shows the reconstituted (calculated) feed size distribution and product size distribution curves for centrifuge tests 1 and 2 . As can be seen, the product size distribution of the weir discharge stream for test 2 was finer than that of test 1 , while the scroll discharge was coarser. This demonstrates the ability to change the size distributions of the product streams by varying the scroll speed.

The circulation ratio (defined as the mass flow rate of the coarse fraction divided by the mass flow rate of the fine fraction) was calculated using the size distribution data and the least absolute sum technique (as decribed in a previous report). Using the circulation ratio, along with the size distribution data, the size selectivity values were determined. These values were then fitted to the logistic function using a non-linear optimization routine to determine the cut size $\left(\mathrm{d}_{50}\right)$, sharpness index (SI), and apparent bypass (a). The fitted parameters are given in Table 7-1, and the curves are shown in Figure 7-2. Overall, the cut size of the centrifuge ranged from about 7 to $10 \mu \mathrm{m}$. The sharpness indexes were very 
Table 7-1. Summary of the Operating Conditions and Test Results for the Solid-Bowl Centrifuge (feed rate $=11.4 \mathrm{~L} / \mathrm{min}$, weir setting three (second deepest pool), solids concentration $=10 \%$ by weight).

\begin{tabular}{ccccccc}
\hline \hline Test & $\begin{array}{c}\text { Main } \\
\text { Speed } \\
(\mathrm{rpm})\end{array}$ & $\begin{array}{c}\text { Back } \\
\text { Drive } \\
(\mathrm{rpm})\end{array}$ & $\begin{array}{c}\text { Circulation } \\
\text { Ratio }\end{array}$ & $\begin{array}{c}\mathrm{d}_{50} \\
(\mu \mathrm{m})\end{array}$ & $\mathrm{\kappa}$ & $\mathrm{a}$ \\
\hline 1 & 4,600 & 4,125 & 7.93 & 7.4 & 0.52 & 0.41 \\
2 & 4,600 & 3,650 & 5.83 & 7.0 & 0.59 & 0.22 \\
3 & 4,600 & 2,700 & 4.10 & 10.5 & 0.54 & 0.29 \\
4 & 4,600 & 800 & 14.42 & 7.2 & 0.50 & 0.65 \\
5 & 3,750 & 1,850 & 9.01 & 8.6 & 0.53 & 0.48 \\
\hline \hline
\end{tabular}




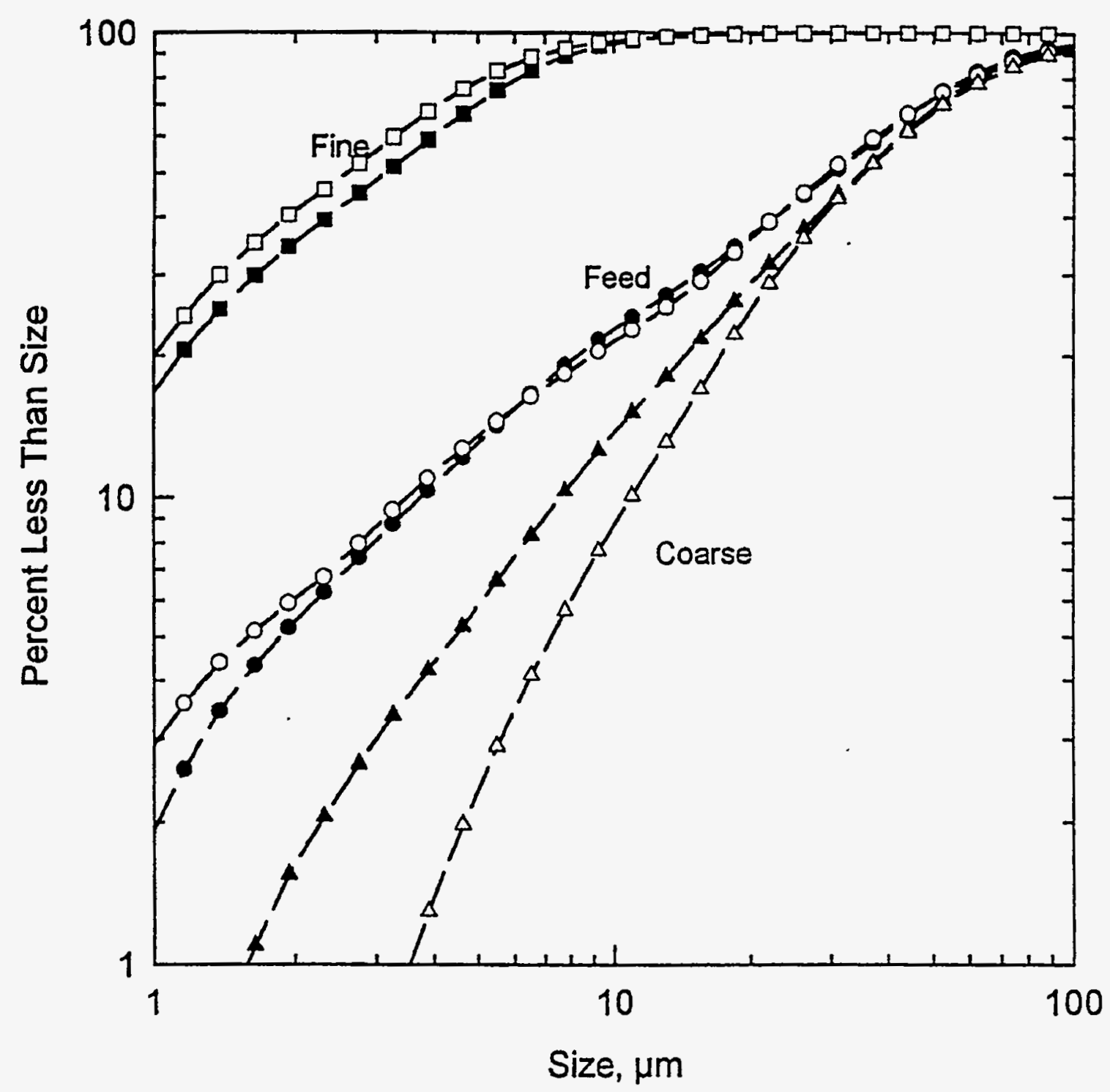

Figure 7-1. FEED AND PRODUCT SIZE DISTRIBUTIONS FOR CENTRIFUGE TESTS 1 AND 2 WHEN SEPARATING -100 MESH UPPER

FREEPORT SEAM COAL

(test 1: filled symbols, test 2: open symbols) 


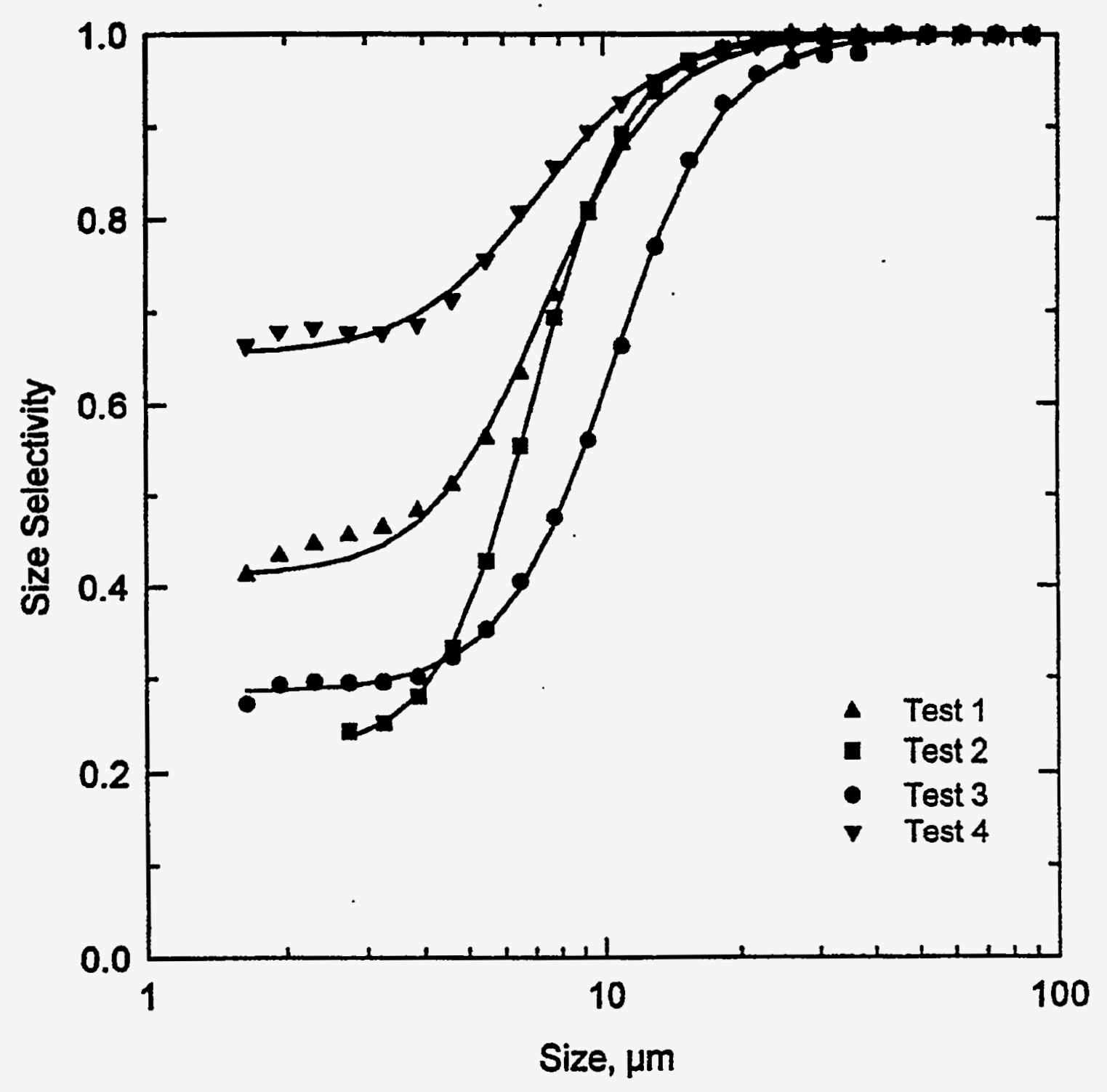

Figure 7-2. EFFECT OF BACK DRIVE SPEED ON THE SIZE SELECTIVITY CURVES IN THE SOLID-BOWL CENTRIFUGE 
similar and ranged from 0.50 to 0.59 . As was seen at other weir settings, the bowl and scroll speeds impacted the apparent bypass values significantly, which ranged from 0.22 to 0.65 (Table 7-1). Such high bypass values indicate that a substantial fraction of the feed coal is reporting to the coarse stream, resulting in a finer size distribution of the coarse material. On the other hand, the bypass does not affect the size distribution of the fine stream.

In cases when the sharpness indexes are similar (as for these tests), it is possible to reduce the size selectivity curves to a single reduced classification curve. First, the classification values for a given test are calculated by

$$
c_{i}=\left(s_{i}-a\right) /(1-a)
$$

where $\mathrm{s}_{\mathrm{i}}$ is the size selectivity value for a given size interval and $\mathrm{a}$ is the apparent bypass. A plot of the classification values versus size gives a curve ranging from 0 to 1 . As noted in a previous report, the cut size and sharpness index are derived directly from the classification curve. The reduced classification curve is then generated by plotting the classification values versus the reduced size (defined as the size divided by the cut size). The reduced curve for centrifuge tests 1-4 is shown in Figure 7-3.

Except for test 1, the values fall on a single curve. In such cases, this curve can be used to predict separator performance. For example, by selecting an appropriate cut size and apparent bypass, it is possible to generate the corresponding size selectivity values, which in turn can be used to calculate the product size distribution for a given feed size distribution.

\subsection{Subtask 1.3 Surface-Based Separation Processes}

\subsubsection{Evaluation of Flotation System Performance}

The rate constants for the batch, batch with no paddling (batch*), and pilot plant tests are given in Table 7-2 for different frother concentrations. In these tests the batch data refers to a typical kinetics test in which froth is removed continuously by manual paddling. A comparison of the rate constants for the three cases is given in Figure 7-4 in which the data are plotted as a function of frother concentration. The plant data refers to the flotation kinetics tests obtained in the pilot plant circuit consisting of four cells. The data marked as batch* refers to the tests in which no paddling was employed and the froth was allowed to flow on its own accord. The results confirm that froth mobility plays a very significant role in determining the overall kinetics in a continuous operation. This effect is commonly ignored in laboratory testing. At the beginning of this project motorized paddles were placed on top of the laboratory cell but were found to be unsatisfactory. A large number of particles were sticking to the paddles. The froth factor, defined as the ratio of the rate constant for the laboratory test to the pilot plant test or the batch flotation rate without 


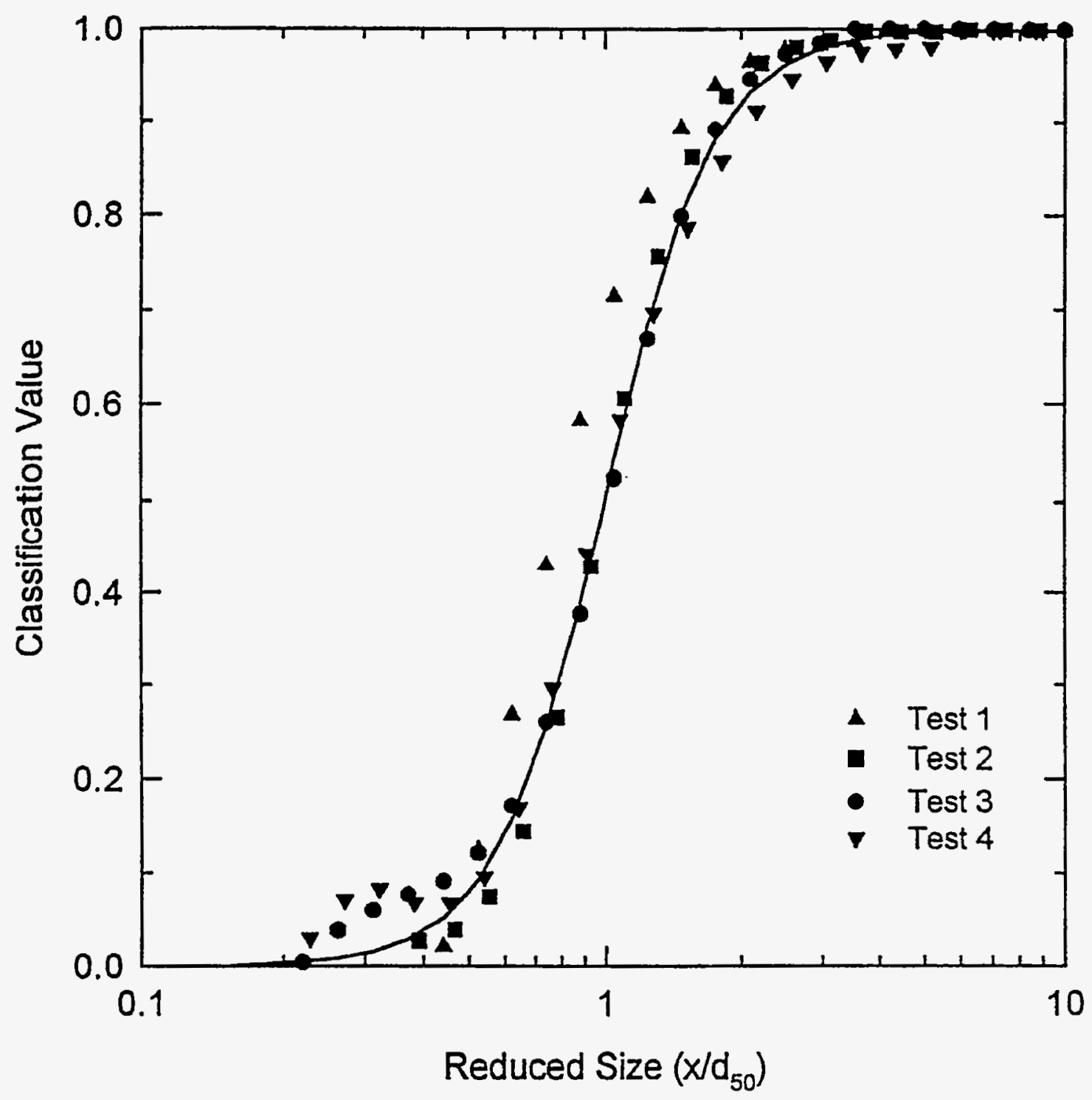

Figure 7-3. REDUCED CLASSIFICATION CURVE FOR CENTRIFUGE TESTS 1-4 
Table 7-2. Flotation Rate Constants and Froth Factors

\begin{tabular}{|c|ccc|cc|}
\hline \multirow{2}{*}{$\begin{array}{c}\text { Frother } \\
\text { conc. }(\mathrm{kg} / \mathrm{T})\end{array}$} & \multicolumn{3}{|c|}{ Rate constants $\left(\mathrm{min}^{-1}\right)$} & \multicolumn{2}{c|}{ Froth Factor $\left(\mathrm{k}_{\text {lab }} / \mathrm{k}_{\text {plan }}\right)$} \\
\cline { 2 - 6 } & Batch & Batch* & Plant & Batch* & Plant \\
\hline 0.2 & 1.7517 & 0.5995 & 0.1149 & 2.92 & 15.25 \\
0.3 & 1.9205 & 0.7198 & 0.1356 & 2.67 & 14.61 \\
0.4 & 2.1737 & 0.9704 & 0.2505 & 2.24 & 8.68 \\
0.45 & 2.0228 & 0.9068 & 0.2601 & 2.23 & 7.78 \\
0.5 & 2.0528 & 0.8636 & 0.1912 & 2.38 & 10.74 \\
\hline
\end{tabular}

Table 7-3. Change in Flotation Rate Constants and Froth Factors Due to the Addition of Collector for the Batch, Batch with no Paddling (Batch*), and Pilot-Plant Tests.

\begin{tabular}{|c|ccc|cc|}
\hline \multirow{2}{*}{$\begin{array}{c}\text { Collector } \\
\text { conc. }(\mathrm{kg} / \mathrm{T})\end{array}$} & \multicolumn{3}{|c|}{ Rate constants $\left(\mathrm{min}^{-1}\right)$} & \multicolumn{2}{c|}{ Froth Factor $\left(\mathrm{k}_{\text {lab }} / \mathrm{k}_{\mathrm{plann}}\right)$} \\
\cline { 2 - 6 } & Batch & Batch $^{*}$ & Plant & Batch* & Plant \\
\hline 0 & 1.9205 & 0.7198 & 0.1356 & 2.67 & 14.16 \\
0.1 & 2.5493 & 0.9068 & 0.2964 & 2.81 & 8.60 \\
\hline
\end{tabular}




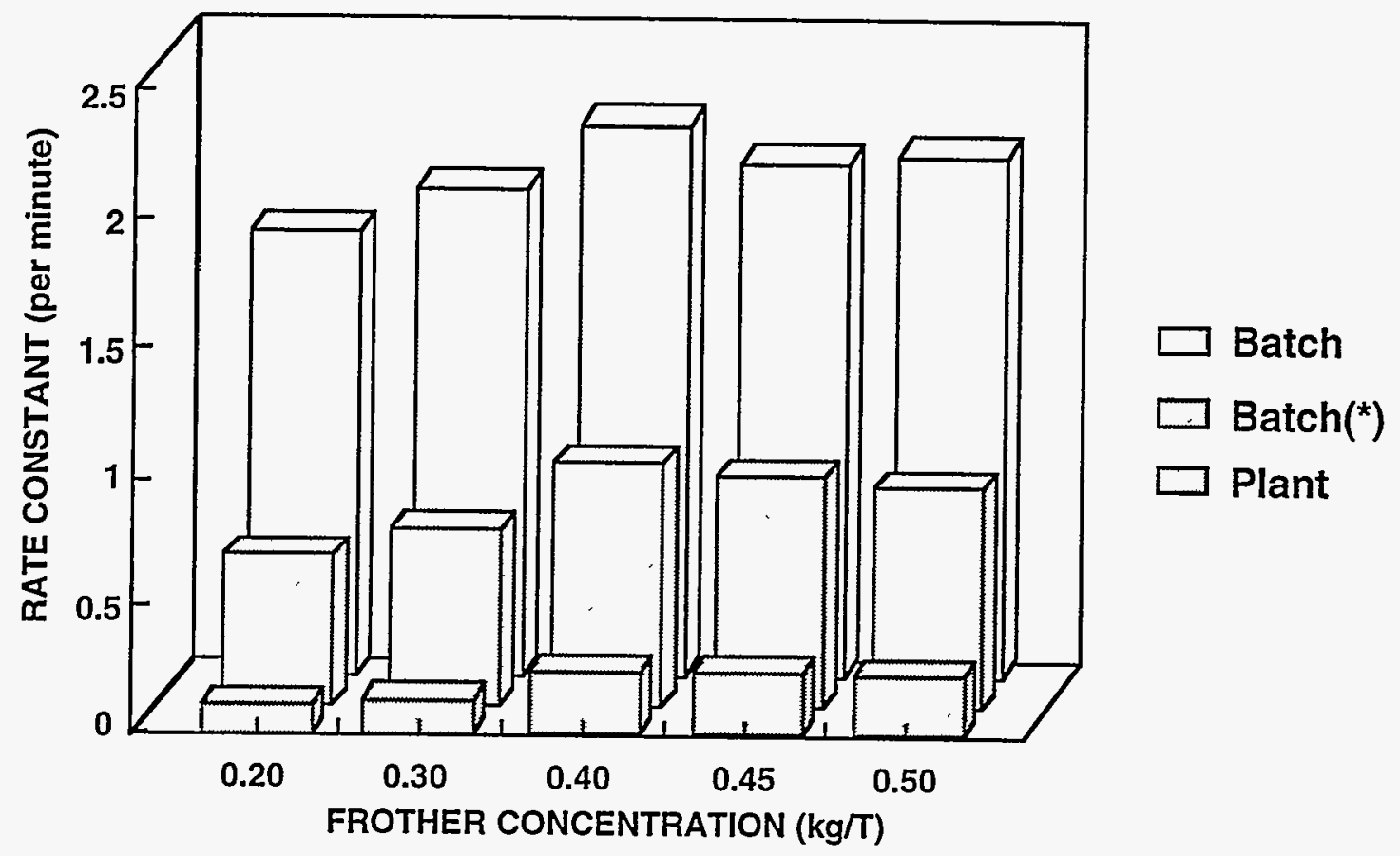

Figure 7-4. COMPARISON OF FLOTATION RATE CONSTANTS FOR THE BATCH, BATCH WITH NO PADDLING (BATCH*), AND PILOT PLANT TESTS AT DIFFERENT FROTHER CONCENTRATIONS 
paddling, is a function of the frother concentration. In the presence of an oily collector, such as dodecane, the froth factor was smaller as can be seen from the results in Table 7-3 and Figure 7-5. These result are not surprising since the collector is likely to increase froth stability.

From these studies one may conclude that the lower than expected recovery in the pilot plant flotation circuit were due to low mobility and less stability of the froth. It should be possible to improve the performance with the help of a frother which is likely to give a more mobile froth. The use of an appropriate frother will also improve the recovery of coarse particles in the pilot plant operation.

\subsection{PHASE III, TASK 2 EMISSIONS REDUCTION}

\subsection{Subtask 2.1 $\mathrm{SO}_{2}$ Reduction}

No work was conducted in Subtask 2.1 during this reporting period.

\subsection{Subtask $2.2 \quad \mathrm{NO}_{\mathrm{x}}$ Reduction}

\subsubsection{Research Objectives}

The objectives for this subtask are as follows:

- To identify and/or develop a $\mathrm{NO}_{\mathrm{x}}$ reduction catalyst that is compatible with the typical operating conditions and the economic constraints of industrial boilers, specifically:

1. flue gas temperatures of $550^{\circ} \mathrm{F}\left(288^{\circ} \mathrm{C}\right)$;

2. $\mathrm{O}_{2}$ concentrations of 3-5 vol.\%;

3. $\mathrm{H}_{2} \mathrm{O}$ concentration of $10-20$ vol. $\%$;

4. $\mathrm{SO}_{2}$ concentrations of $500-1,000 \mathrm{ppm}$;

5. NO concentrations of $100-500 \mathrm{ppm}$;

6. No regeneration of sorbent/catalyst required; and

7. Low maintenance and operating costs.

- To establish the limitations of the candidate $\mathrm{NO}_{\mathrm{x}}$ reduction catalyst so that its implementation in pilot and demonstration-scale tests will be straightforward, for example, determining the relationship between space velocity and $\mathrm{NO}_{x}$ conversion efficiency for scale-up purposes.

- To identify maximum allowable transients that the catalyst can be exposed to before losing effectiveness, such as swings in flue gas temperature and sulfur and unburned hydrocarbon concentrations.

\subsubsection{Current Status of the Bench-Scale Catalyst Tests}

A new series of Bench-scale tests of the NOxCat® LT 920 catalyst (supplied by Engelhard Corporation for this study) is commencing to supplement the tests that were completed in Fall 1996. This previous bench-scale work was summarized in a previous 


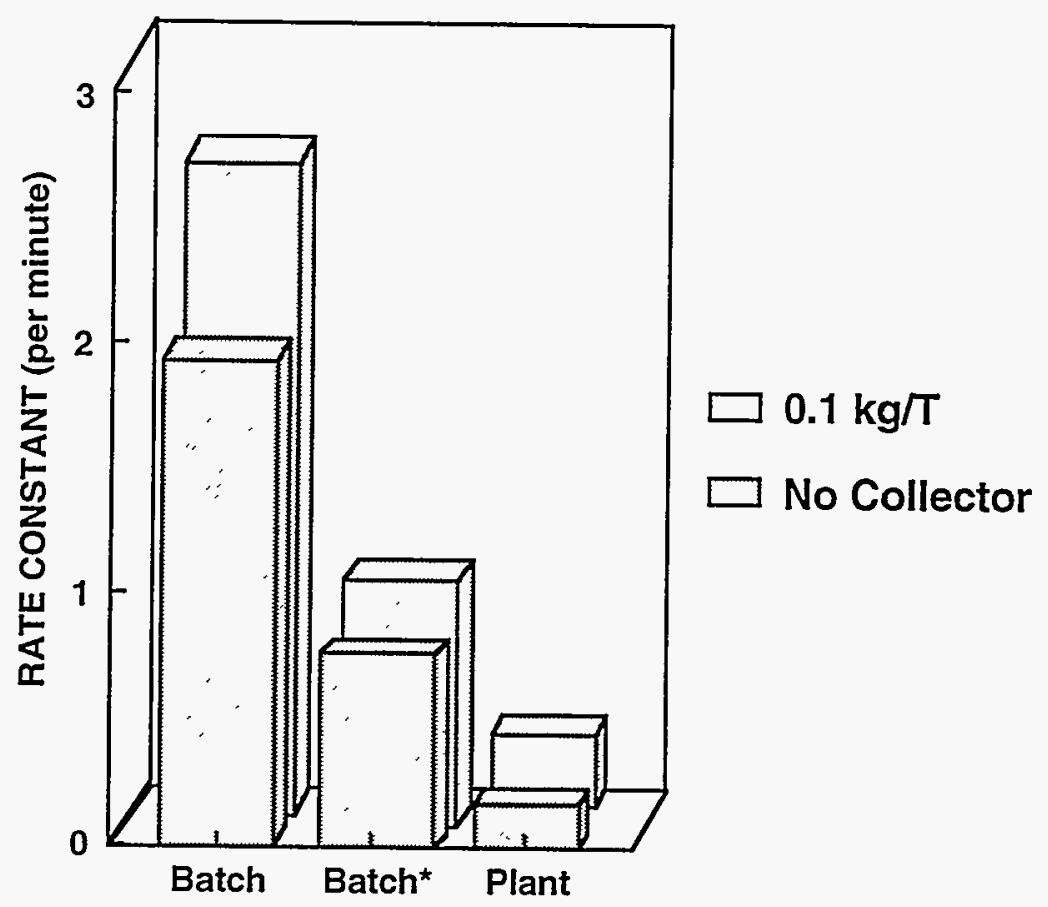
CONSTANT FOR THE BATCH, BATCH WITH NO PADDLING $\left(B A T C H^{*}\right)$, AND PILOT PLANT TESTS 
semiannual technical progress report (Miller et al., 1996b). These new tests were suggested by Engelhard to determine a critical parameter for demonstration-scale and future commercial application of this process. The objective of the new tests is to examine the influence on catalyst behavior of changes in precious metal loading on the catalyzed monoliths. Since the recommendation from the bench-scale tests is to operate this catalyst at low space velocity, the implementation of the catalyst will require large catalyst volumes. A larger catalyst volume means a larger capital expenditure for the catalyst because of both the cost of the precious metals and the support materials. If the precious metal loading can be decreased without an appreciable change in catalyst performance, a significant cost saving could be achieved.

\subsubsection{Current Status of Pilot-Scale Testing}

The bench-scale testing was extended to the pilot-scale through use of Penn State's down-fired combustor (DFC). Preliminary pilot-scale tests were completed in early 1997 an examined the operation of a larger sample of the NOxCat@ LT 920 catalyst while the DFC was fired on natural gas. These tests confirmed the observations of the bench-scale tests with a simplified ( $\mathrm{SO}_{2}$ free) flue gas. Subsequent pilot-scale tests, planned tentatively for November 1997, will examine the behavior of the catalyst during simultaneous $\mathrm{deSO}_{\mathrm{x}}$ deNO ${ }_{x}$ operation, wherein a dry sorbent and ammonia will be injected into the flue ductwork of the DFC. Catalyst samples will be mounted in one of the nine filter bags of the DFC baghouse, while blank monoliths will be mounted in the other 8 bags to provide equal pressure drop through each bag. The $\mathrm{NO}_{x}$ conversion and catalyst selectivity will be monitored across the catalyzed filter bag.

\subsection{Subtask 2.3 VOC and Trace Elements}

No work was conducted on Subtask 8.3 during this reporting period.

\subsection{PHASE III, TASK 3 ECONOMIC ANALYSIS}

Phase III, Task 3 has been completed except for Subtask 3.8, integration of analysis. No work was conducted on Subtask 3.8 during this reporting period.

\subsection{PHASE III, TASK 4 EVALUATION OF DEEPLY-CLEANED COAL AS BOILER FUELS}

Activities in Task 4 included receiving three deeply-cleaned coals from CyprusAmax. In addition, one parent coal was also received.

\subsection{Subtask 4.1 Modify MCWM Preparation Circuit}

Subtask 4.1 was previously completed.

\subsection{Subtask 4.2 Fuels Characterization}

During this reporting period, the remaining deeply-cleaned filter cake samples were received from Cyprus-Amax. A total of 205 nominal one ton supersacks have been 
delivered to Penn State where they are currently being stored. An itemized list of these samples is provided in Table 10-1. Only a limited amount of Indiana VII filter cake was shipped due to its reported high moisture content (> $50 \mathrm{wt} . \%)$.

A nominal $350 \mathrm{lb}$ composite sample for each of the filter cake samples was produced by sampling the individual supersacks. The composite sample is being used to characterize the chemical composition and the slurryability of the six filter cake shipments. Proximate and ultimate analyses, calorific value, and ash fusion temperatures and major/ minor elements are being determined for each composite sample. The slurryability of the filter cake has started. Slurryability is being determined using a two-pronged approach. Initially, the as-received filter cake is formulated without the use of viscosity or stability modifiers and without manipulating the particle size distribution to determine an as-received slurryability. The initial slurryability testing will be followed by a more extensive formulation. The second formulation step will involve the use of viscosity and stability modifiers (e.g., A-23M and Flocon $4800 \mathrm{C}$, respectively) to produce a stable, highly loaded MCWM. If needed, the particle size distribution of the filter cake will be modified to improve slurry rheology and static stability. The filter cakes are currently undergoing the initial formulation step.

\subsection{PHASE III, TASK 5 FINAL REPORT/SUBMUSSION OF DESIGN PACKAGE}

No work was conducted on this task.

\subsection{MISCELLANEOUS ACTIVITIES}

A project review meeting was held on June 11, 1997 at FETC (Pittsburgh). Representatives from DOE, the Corps of Engineers, and Penn State were in attendance.

\subsection{NEXT SEMIANNUAL ACTIVITIES}

During the next reporting period, the following will be done:

- Complete the characterization of the ceramic filter system (i.e., $\mathrm{PM}_{2.5}$ and $\mathrm{PM}_{10}$, and condensable particulate matter measurements) and compare its performance to the fabric filter baghouse;

- Test the sodium bicarbonate duct injection system;

- Conduct pilot-scale $\mathrm{NO}_{\mathrm{x}}$ catalyst tests;

- Interpret results from the Phase II VOC and trace elements studies;

- Prepare the final report for Phase II, Task 2, Coal Preparation/Utilization; (except for the atomization testing in Subtask 2.10);

- Prepare the final report for Phase II, Task 3, Economic Analysis;

- Complete $\mathrm{NO}_{\mathrm{x}}$ reduction study (Phase II, Task 1); 
Table 10-1. Summary of Cyprus-Amax Deeply Cleaned Filter Cakes

\begin{tabular}{|c|c|c|}
\hline Coal & Cleaning Method & $\#$ Bags \\
\hline Taggart & Column Flotation & 50 \\
\hline Taggart & Oil Agglomeration & 31 \\
\hline & & 50 \\
\hline Hiawatha & Column Flotation & 66 \\
\hline Hiawatha & Oil Agglomeration & 1 \\
\hline & & 7 \\
\hline Indiana VII & Column Flotation & \\
\hline Indiana VII & Oil Agglomeration & \\
\hline
\end{tabular}


- Complete preliminary evaluation of BioLime as a $\mathrm{SO}_{2} \mathrm{NO}_{x}$ reduction strategy (Phase II, Task 1);

- Complete Phase III, Task 1, Coal Preparation/Utilization;

- Complete Phase III, Task 5, Economic Analysis;

- Complete initial and expanded MCWM formulation (Phase III, Task 1) and;

- Begin pilot-scale MCWM production (Phase III, Task 1).

\subsection{REFERENCES}

Armington, P. 1969. "A Theory of Demand for Products Distinguished by Place of Production," IMF Staff Papers 16: 159-178.

Baffes, J. and U. Vasavada. 1989. "On the Choice of Functional Forms in Agricultural Production Analysis," Applied Economics 21: 1053-1061.

Bandara, J. S. 1991. "Computable General Equilibrium Models for Development Policy Analysis in LDCs," Journal of Economic Surveys 5: 1-69.

Bergman, L. 1982. "A System of Computable General Equilibrium Models for a Small Open Economy," Mathematical Modeling 3: 421-435.

Bohi, D. and M. Toman. 1993. "Energy Security: Externalities and Policies," Energy Policy 21: 1093-1109.

Caves, D. W. and L. R. Christensen. 1980. "Global Properties of Flexible Functional Forms," American Economic Review 70: 422-432.

Davidson, J. E., Hartock, D. K., Conley, A. D., Hein, R. L., and Schanche, G. W., USACERL, Overview of Slagging Coal Combustor Systems as Applied to Army Central Heat Plants, Technical Report, E-91-04, 1991.

Despotakis, K. A. 1986. "Economic Performance of Flexible Functional Forms," European Economic Review 30: 1107-1143.

Li, P. C. 1994. Environmental Policy, Coal and the Macroeconomy: The Impact of Air Quality Regulations on the Pennsylvania Economy, unpublished Ph.D. dissertation, Department of Mineral Economics, The Pennsylvania State University.

Li, P. C. 1995. Global Warming Policy and the Pennsylvania Economy: A Computable General Equilibrium Analysis," Economic Systems Research 7: 151-171.

Kilkenny, M. and S. Robinson. 1990. "Computable General Equilibrium Analysis of Agricultural Liberalization: Factor Mobility and Macro Closure," Journal of Policy Modeling 12: 527-556.

Kraybill, D. S. 1990. “A Computable General Equilibrium Analysis of Regional Impacts of Macro-shocks in the 1980," Ph.D. Dissertation, Department of Agricultural Economics, VPI, Blacksburg, VA.

Miller, B. G., Pisupati, S. V., Scaroni, A. W., Boehman, A., Hatcher, P., Knicker, H., Hogg, R., Chander, S., Cho, H., Ityokumbul, M. T., Klima, M. S., Luckie, P. T., 
Rose, A., Considine, T. J., Gordon, R. L. K., A.E., Lazo and McClain, K. The Development of Coal-Based Technologies for Department of Defense Facilities, Semiannual Technical Progress Report for the Period 09/28/1995 to 03/27/1996, U.S. Department of Energy Federal Energy Technology Center, DE-FC2292PC92162, May 31, 1996a.

Miller, B. G., Pisupati, S. V., Scaroni, A. W., Hogg, R., Chander, S., Cho, H., Ityokumbul, M. T., Klima, M. S., Luckie, P. T., Rose, A., Considine, T. J., Gordon, R. L. K., A.E., Lazo and McClain, K. The Development of Coal-Based Technologies for Department of Defense Facilities, Semiannual Technical Progress Report for the Period 03/28/1996 to 09/27/1996, U.S. Department of Energy Federal Energy Technology Center, DE-FC22-92PC92162, December 13, 1996 b.

Miller, B. G., Morrison, J. L., S. V. Pisupati, Poe, R. L., Sharifi, R., Shepard J. F., Walsh, P. M., Xie, J., Scaroni, A. W., Hogg, R., Chander, S., Cho, H., Ityokumbul, M. T., Klima, M. S., Luckie, P. T., Rose, A., Considine, T. J., Gordon, R. L. K., A.E., Lazo, McClain, K., Schaal, A. M., Painter, P. C., Beytsman, B., Morrison, D., Englehardt, D., and Sommer, T. M. . The Development of Coal-Based Technologies for Department of Defense Facilities Phase I Final Report, U.S. Department of Energy Federal Energy Technology Center, DEFC22-92PC92162, January 31, 1997.

Norrie, K. H. and M. B. Percy. 1983. "Freight Rate Reform and Regional Burden: A Regional Equilibrium Analysis of Western Freight Rate Proposals," Canadian Journal of Economics 16: 325-349.

Pennsylvania Department of Labor and Industry. 1994. "Industrial Boiler Data" (computer file), Harrisburg, PA.

Robinson, S., M. Kilkenny and K. Hanson. 1990. The USDA/ERS Computable General Equilibrium Model of the United States, USDA, Washington, DC.

Robinson, S., M. Kilkenny and K. Hanson. 1993. The USDA/ERS Computable General Equilibrium Model of the United States: Update (diskette), USDA, Washington, DC.

Schaal, A. M. 1995. A Market Penetration Model for an Industrial and Commercial Boiler Retrofit Technology, M.S. Thesis, Department of Mineral Economics, The Pennsylvania State University.

Schaal, A. M. 1997. "Cost and Market Penetration of Coal-Based Fuel Technologies" in The Development of Coal-Based Technologies for Department of Defense Facilities, Final Report. U.S. Department of Energy, Pittsburgh Energy Technology Center Cooperative Agreement No. DE-FC22-92PC92162.

Sen, A. K. 1963. "Neo-classical and Neo-Keynesian Theories of Distribution," Economic Record 39: 53-66.

Shoven, J. B. and J. Whalley. 1984. "Applied General-Equilibrium Models of Taxation and International Trade: An Introduction and Survey," Journal of Economic Literaturé 22: 1007-1051.

U.S. Energy Information Administration (EIA). 1995. State Energy Price and Expenditure Report 1993, Office of Energy Markets and End Use, U.S. Department of Energy, DOE/EIA-0376(92). 
Whalley, J. and I. Trela. 1986. "Regional Aspects of Confederation," Toronto: University of Toronto Press.

\subsection{ACKNOWLEDGMENTS}

Funding for the work was provided by the U.S. Department of Defense (via an interagency agreement with the U.S. Department of Energy) and the Commonwealth of Pennsylvania under Cooperative Agreement No. DE-FC22-92PC92162. The project is being managed by the U.S. Department of Energy, Federal Energy Technology Center (Pittsburgh). Anthony Mayne of FETC is the project manager.

The following Penn State staff were actively involved in the program: Michael Anna, David Bartley, Glenn Decker, Howard R. Glunt, Bradley Maben, and Ronald T. Wincek. 